WORLD BANK TECHNICAL PAPER NO. E 10

\title{
WTP510
}

Work in progreas
for publlo alscusesion

May 2001

\section{The TB and HIV/AIDS \\ Epidemics in the Russian Federation}

Anatoly linokur

Joana Godinho

Christopher Dye

Viro Nagelkerke 


\section{Recent World Bank Technical Papers}

No. 414 Salman and Boisson de Chazournes, International Watercourses: Enhancing Cooperation and Managing Conflict, Proceedings of a World Bank Seminar

No. 415 Feitelson and Haddad, Identification of Joint Management Structures for Shared Aquifers: A Cooperative Palestinian-Israeli Effort

No. 416 Miller and Reidinger, eds., Comprehensive River Basin Development: The Tennessee Valley Authority

No. 417 Rutkowski, Welfare and the Labor Market in Poland: Social Policy during Economic Transition

No. 418 Okidegbe and Associates, Agriculture Sector Programs: Sourcebook

No. 420 Francis and others, Hard Lessons: Primary Schools, Community, and Social Capital in Nigeria

No. 421 Gert Jan Bom, Robert Foster, Ebel Dijkstra, and Marja Tummers, Evaporative Air-Conditioning: Applications for Environmentally Friendly Cooling

No. 422 Peter Quaak, Harrie Knoef, and Huber Stassen, Energy from Biomass: A Review of Combustion and Gasification Technologies

No. 423 Energy Sector Unit, Europe and Central Asia Region, World Bank, Non-Payment in the Electricity Sector in Eastern Europe and the Former Soviet Union

No. 424 Jaffee, ed., Southern African Agribusiness: Gaining through Regional Collaboration

No. 425 Mohan, ed., Bibliography of Publications: Africa Region, 1993-98

No. 426 Rushbrook and Pugh, Solid Waste Landfills in Middle-and Lower-Income Countries: A Technical Guide to Planning, Design, and Operation

No. 427 Mariño and Kemper, Institutional Frameworks in Successful Water Markets: Brazil, Spain, and Colorado, USA

No. 428 C. Mark Blackden and Chitra Bhanu, Gender, Growth, and Poverty Reduction: Special Program of Assistance for Africa, 1998 Status Report on Poverty in Sub-Saharan Africa

No. 429 Gary McMahon, José Luis Evia, Alberto Pascó-Font, and José Miguel Sánchez, An Environmental Study of Artisanal, Small, and Medium Mining in Bolivia, Chile, and Peru

No. 430 Maria Dakolias, Court Performance around the World: A Comparative Perspective

No. 431 Severin Kodderitzsch, Reforms in Albanian Agriculture: Assessing a Sector in Transition

No. 432 Luiz Gabriel Azevedo, Musa Asad, and Larry D. Simpson, Management of Water Resources: Bulk Water Pricing in Brazil

No. 433 Malcolm Rowat and José Astigarraga, Latin American Insolvency Systems: A Comparative Assessment

No. 434 Csaba Csaki and John Nash, eds., Regional and International Trade Policy: Lessons for the EU Accession in the Rural Sector-World Bank/FAO Workshop, June 20-23, 1998

No. 435 Iain Begg, EU Investment Grants Review

No. 435 Roy Prosterman and Tim Hanstad, ed, Legal Impediments to Effective Rural Land Relations in Eastern Europe and Central Asia: A Comparative Perspective

No. 437 Csaba Csaki, Michel Dabatisse, and Oskar Honisch, Food and Agriculture in the Czech Republic: From a "Velvet" Transition to the Challenges of EU Accession

No. 438 George J. Borjas, Economic Research on the Determinants of Immigration: Lessons for the European Union

No. 439 Mustapha Nabli, Financial Integration, Vulnerabilities to Crisis, and EU Accession in Five Central European Countries

No. 440 Robert Bruce, Ioannis Kessides, and Lothar Kneifel, Overcoming Obstacles to Liberalization of the Telecom Sector in Estonia, Poland, the Czech Republic, Slovenia, and Hungary: An Overview of Key Policy Concerns and Potential Initiatives to Facilitate the Transition Process

No. 441 Bartlomiej Kaminski, Hungary: Foreign Trade Issues in the Context of Accession to the EU

No. 442 Bartlomiej Kaminski, The Role of Foreign Direct Investment and Trade Policy in Poland's Accession to the European Union

No. 443 Luc Lecuit, John Elder, Christian Hurtado, François Rantrua, Kamal Siblini, and Maurizia Tovo, DeMIStifying MIS: Guidelines for Management Information Systems in Social Funds

No. 444 Robert F. Townsend, Agricultural Incentives in Sub-Saharan Africa: Policy Challenges

No. 445 Ian Hill, Forest Management in Nepal: Economics of Ecology

No. 446 Gordon Hughes and Magda Lovei, Economic Reform and Environmental Performance in Transition Economies

No. 447 R. Maria Saleth and Ariel Dinar, Evaluating Water Institutions and Water Sector Performance

(List continues on the inside back cover) 
WORLD BANK TECHNICAL PAPER NO. 510

\section{The TB and HIV/AIDS Epidemics in the Russian Federation}

$\overline{\text { Anatoly Vinokur }}$

Joana Godinho

Christopher Dye

Nico Nagelkerke

The World Bank

Washington, D.C. 
Copyright $(2001$

The International Bank for Reconstruction

and Development/THE WORLD BANK

1818 H Street, N.W.

Washington, D.C. 20433, U.S.A.

All rights reserved

Manufactured in the United States of America

First printing May 2001

123404030201

Technical Papers are published to communicate the results of the Bank's work to the development community with the least possible delay. The typescript of this paper therefore has not been prepared in accordance with the procedures appropriate to formal printed texts, and the World Bank accepts no responsibility for errors. Some sources cited in this paper may be informal documents that are not readily available.

The findings, interpretations, and conclusions expressed in this paper are entirely those of the author(s) and should not be attributed in any manner to the World Bank, to its affiliated organizations, or to members of its Board of Executive Directors or the countries they represent. The World Bank does not guarantee the accuracy of the data included in this publication and accepts no responsibility for any consequence of their use. The boundaries, colors, denominations, and other information shown on any map in this volume do not imply on the part of the World Bank Group any judgment on the legal status of any territory or the endorsement or acceptance of such boundaries.

The material in this publication is copyrighted. The World Bank encourages dissemination of its work and will normally grant permission promptly.

Permission to photocopy items for internal or personal use, for the internal or personal use of specific clients, or for educational classroom use, is granted by the World Bank, provided that the appropriate fee is paid directly to Copyright Clearance Center, Inc., 222 Rosewood Drive, Danvers, MA 01923, U.S.A., telephone 978-750-8400, fax 978-750-4470. Please contact the Copyright Clearance Center before photocopying items.

For permission to reprint individual articles or chapters, please fax your request with complete information to the Republication Department, Copyright Clearance Center, fax 978-750-4470.

All other queries on rights and licenses should be addressed to the World Bank at the address above or faxed to 202-522-2422.

ISBN: 0-8213-4964-3

ISSN: 0253-7494

Anatoly Vinokur was a consultant with the Human Development Unit of the Europe and Central Asia Region of the World Bank. Joana Godinho is a Senior Health Specialist with the Human Development Unit of the Europe and Central Asia Region of the World Bank. Christopher Dye and Nico Nagelkerke were consultants with the Human Development Unit of the Europe and Central Asia Region of the World Bank

Library of Congress Cataloging-in-Publication Data

The TB and HIV / Aids epedemics in the Russian Federation / Anatoly Vinokur... [et al.].

p. cm.- (World Bank Technical Paper ; no. 510)

Includes bibliographical references.

ISBN 0-8213-4964-3

1. Tuberculosis-Russia (Federation) 2 AIDS (Disease)-Russia (Federation) I.

Vinokur, Anatoly, 1973-II. Series.

RC316.R9 T3 2001

$616.9^{\prime} 95^{\prime} 00947-$ dc21 


\section{Table of Contents}

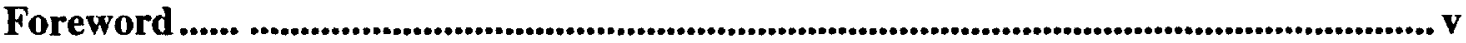

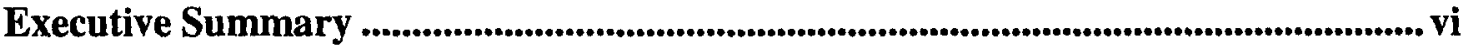

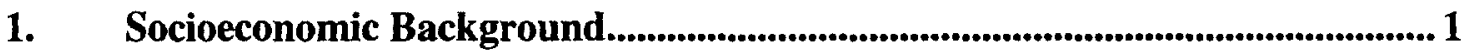

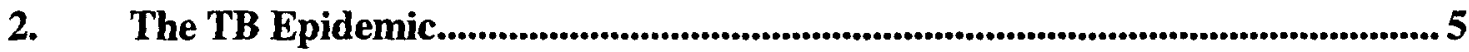

TB Incidence and Prevalence ....................................................................... 7

TB Incidence and Prevalence in Russian Prisons ................................... 10

TB Control System .............................................................................. 13

TB Control in Russian Prisons .................................................................... 19

The Russian Pharmaceutical Sector ................................................................. 20

Performance of the National TB Control Program ............................. 22

Performance of WHO TB Control Strategy (DOTS) ............................ 25

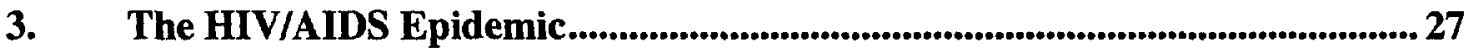

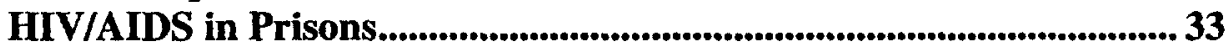

The Role of STI's and Drug use in the HIV/AIDS Epidemic................ 34

HIV/AIDS Management and Control ...................................................... 37

4. Potential Impact of TB Control, with Implications for HIV/AIDS................ 41

A Dynamic Compartmental Model for Tuberculosis ............................ 42

Results .............................................................................................. 44

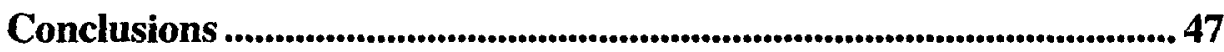

Annex 1 Technical Terms ..............................................................................................51

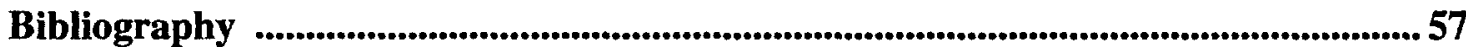

Boxes

Boxes, Figures, and Tables

1.

WHO TB Control Strategy (DOTS) ................................................... 24

2. Current State of the HIV.AIDS Epidemic (MOH)..........................29

Figures

1.

2.

"The Russian Cross", birth and death rates per 1000, 1980-1999........ 1

TB Mortality Rates (per 100,000), 1980-1999......................................... 5

3. TB Notification Rates (new cases, all forms including relapses), per 100,000 in WHO Europe and Russia (1991-1998) ..................................... 7

4. TB Incidence and Prevalence per 100,000 1970-1998) .......................... 8

5. TB Incidence and Annual Number of the Convicted to Imprisonment ( $r=0.91)$

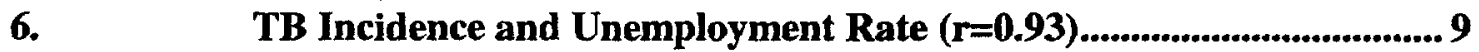

7. Cumulative Numbers of HIVIAIDS Cases by Year ............................. 27

8. HIV Prevalence in Selected Countries (1999)........................................... 28

9. Percent Distribution of HIV Infection by Major Risk Factor

(1991-1999) .................................................................................................................. 31 
Distribution of New HIV Infection by Age and Sex (1998)................... 33

Tables

Life Expectancy in the Russian Federation ................................................3 3

2.

Relative Risk (RR) of TB Mortality in Selected Areas (1997)................. 6

3.

TB Mortality in Russian Regions............................................................... 10

4.

5.

New ss+TB Cases in the Russian Federation and EUR ........................... 10

Number of Persons in the Prison System ................................................ 11

6.

Number of Persons Newly Admitted to the Prison System .................... 11

7.

Number of Persons Released from the Prison System............................. 11

TB in the Prison System (including persons in pre-trail facilities)..... 12

8.

TB Notification Rate in Pre-Trial Facilities (per 100,000 persons) .... 12

10.

11.

Incidence of Respiratory TB among Prison Personnel............................. 12

TB Control Infrastructure................................................................................. 18

12.

Expenditures on Health and Drugs ................................................................ 21

13.

TB Control Coverage (1998) .............................................................................. 23

14.

Case Detection (1998).........................................................................................23

15.

Case Notification (1998)..................................................................................... 23

16.

17.

Treatment Outcomes on Non-DOTS TB Control Strategy Areas in the

Russian Federation and WHO European Region ......................................24

Progress in DOTS Implementation ...........................................................25

18. Change in Case Detection Rates .................................................................... 25

19. Treatment Outcomes of the Who TB Control Strategy (DOTS) in the

Russian Federation and the WHO European Region........................... 26

20.

Number of Individuals with TB in DOTs Areas .......................................26

21.

HIV.AIDS Incidence and Prevalence ................................................................. 28

22.

UNAIDS Estimates of HIV Infection

in the Russian Federation (1999)

23.

HIV/AIDS High Burden Regions (March 2000) ..................................... 30

24.

HIV Infection among Foreign Citizens and Russian Citizens ............. 32

25.

Number of HIV Cases in the Prison System

26.

Syphilis and Gonorrhea Incidence per 100,000 in the Prison System 34

27.

Percentage of Crimes Associated with Drugs ............................................ 34

28.

Syphilis Incidence by Age and Sex ...........................................................35

29.

Drug Use Growth Rates.......................................................................................37

30. Percent Distribution of HIV Tests ....................................................................39

31. Percentage of Patients Assumed to be Cured under Different

Interventions ................................................................................................................ 46

32. Summary of the Potential Impact of Five Interventions on TB

Epidemiology in the Russian Federation . 


\section{Foreword}

The Russia Federation has been confronting a major epidemiological crisis, which will have considerable human and economic costs if it is not swiftly addressed. Between 1999 and 2000, the country experienced the world's biggest increase in new cases of HIV/AIDS infection. The epidemic of tuberculosis that has spread throughout the former Soviet Union over the last decade and has claimed thousands of lives. The TB epidemic is at risk of becoming uncontrollable if the country experiences a moderate epidemic of HIV/AIDS - even if an appropriate TB program is implemented in the near future.

Urgent action is needed to control both the TB and the HIV/AIDS epidemics. Efforts have been initiated to assist the government of the Russia Federation to update its TB program and orienting the HIV/AIDS and Sexually Transmitted Infections (STIs) programs to work with the highest risk groups. These programs are in their infancy.

This report represents the analysis and recommendations of a group of experts from the World Health Organization and the World Bank, and focuses on the current epidemiological situation in the Russian Federation and the existing institutional arrangements available to tackle both epidemics. It encompasses projections for the TB epidemic, the interaction with the HIV/AIDS epidemic, and the impact of a spiraling duel epidemic.

The paper is meant to contribute to increasing the understanding of the development of the TB, HIV/AIDS and STIs epidemics in the Russia Federation, and to facilitating policy options for initiating prompt actions to preserve and improve the health of the Russian population.

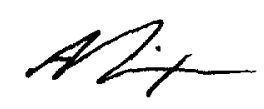

Annette Dixon Sector Director Human Development Unit Europe and Central Asia region 


\section{Executive Summary}

Epidemics of preventable diseases such as tuberculosis (TB), HIV/AIDS and sexuallytransmitted infections (STIs) are growing rapidly in the Russian Federation. According to national data, incidence of these diseases has increased from over two times (TB) to almost sixty times (STIs); tens of thousands of individuals have HIV/AIDS, while many hundreds of thousands have TB and STIs. These data likely underestimate the extent of the problem, given the growing inefficiency of the reporting system. To large extent the public health sector continues to use outdated, costly and ineffective strategies for the control, diagnosis and treatment of these diseases. Of special concern is the epidemiological situation in Russian prisons, which house approximately 1.2 million prisoners: rates of TB and HIV/AIDS are tens of times higher among prisoners than in the general population.

The socioeconomic and human losses due to TB, HIV/AIDS, and STIs are enormous: approximately 30,000 people die and another 30,000 become long term disabled annually due to TB only. The prevailing majority of the victims are people of economically and reproductively active age. The emergence of difficult-to-treat, drug resistant forms of these infections threaten to increase losses even more; in addition, drug-resistant infections are hundreds of times more costly to treat than regular infections.

Economic difficulties, coupled with stress, depression and unhealthy behaviors (such as smoking, alcohol and drug use, and poor diet), have increased the need for health care. Young and middleage Russians (especially males) have been affected most severely. However, the national health care system, lacking emphasis on disease prevention and undermined by rapid decentralization and insufficient funding, has failed to maintain the health of the population. As a result, the population's health status has deteriorated sharply.

\section{TB epidemic}

The deterioration in TB control began in 1991 due to worsening socioeconomic conditions, migration from other ex-Soviet republics with higher TB burden, and civil conflicts and wars. A shrinking health budget resulted in an erratic supply of diagnostics and anti-TB drugs, which in turn resulted in inadequate treatment and drug resistance. TB case notification and mortality more than doubled between 1991 and 1997. Case notification reached 82/100,000 in 1997; however, up to 20 percent of existing cases may not be notified. The TB mortality rate is the highest in Europe - 20/100,000 in 1999, with 40 percent of these deaths occurring among young adults. At the same time, the survey-based rates of multi-drug resistant (MDR) TB in The Russian Federation are the highest in the world, ranging from 9 to 22 percent of all TB cases among the general population and from 36 to 57 percent among the prison population. Today in the Russian Federation, patients with MDR TB are virtually incurable, due to a lack of secondline drugs, effective laboratory support, and trained staff.

Despite the existence of an extensive and costly system of TB treatment, TB patients in the Russian Federation are currently not reliably diagnosed, effectively treated, systematically monitored, or reported using standard international definitions. Current diagnostic activities are 
limited by the lack of inclusion of primary health care facilities and over-reliance on X-ray screening and diagnosis. Treatment is limited by shortages of drugs and use of non-standard regimens. The pilot DOTS projects that have been carried out with assistance from international and bilateral organizations have not, by and large, achieved dramatically impressive results.

\section{HIV/AIDS in the Russian Federation}

After many years of low incidence, in 1996 the outbreak of HIV infection among intravenous drug users (IDU) opened a new page in the history of the HIV/AIDS epidemic in the Russian Federation. By March 1st, 2000, the number of prevalent HIV infection cases exceeded 38,427. In 1998 and 1999, up to 90 percent of newly recorded infections were contracted through intravenous drug use. Unfortunately, testing is not concentrated among high-risk individuals; therefore, HIV incidence may be significantly higher than reported. In fact, the number of HIVinfected Russian citizens estimated by UNAIDS in 1999 was between 100,000 and 160,000. Treatment is inadequate, given insufficient health services relative to need and the high cost and low availability of drug therapies used in Western nations.

Soaring numbers of STI incidence in the Russian Federation from 1992 to 1998 indicate that sexual transmission of HIV will increase in the coming years. The reported syphilis rate for the Russian Federation in 1998 was 234.8 cases per 100,000 population, but experts believe that the true incidence may be from 30 to 50 percent higher.

\section{Organization of the Report}

This paper is presented in four sections. The first section briefly describes socioeconomic conditions in the Russian Federation and touches on how they are driving infectious disease epidemics. The second section discusses the impact on the population of the epidemic, incidence and prevalence in the general and prison populations, diagnosis and treatment processes, and current TB management and control structures. The third section profiles the HIV/ADS epidemic and its impact, and the role of STIs in fostering the disease. Finally, the fourth section offers a description of a mathematical model of improvements in health status possible under various TB control strategies, with implications for HIV/AIDS as well. 



\section{Socioeconomic Background}

For more than 70 years, the Russian Federation was the dominant member of the former Soviet Union as well as the entire socialist bloc. It also used to be one of the world's two superpowers, and the stronghold of the communist ideology in the world's political arena.

In the early 1990s The Russian Federation undertook a transition to a market economy and an open society. This transition has been accompanied by an unfair redistribution of national property and revenues, drastic price liberalization, a huge and uncontrolled economic slump, galloping inflation, and a considerable drop in the real incomes of the population (UNDP 1999, 2000). These phenomena have led to rapidly increasing unemployment and poverty, leading to soaring crime rates, homelessness, prostitution, and deterioration in survival (Klugman 1997, 1998).

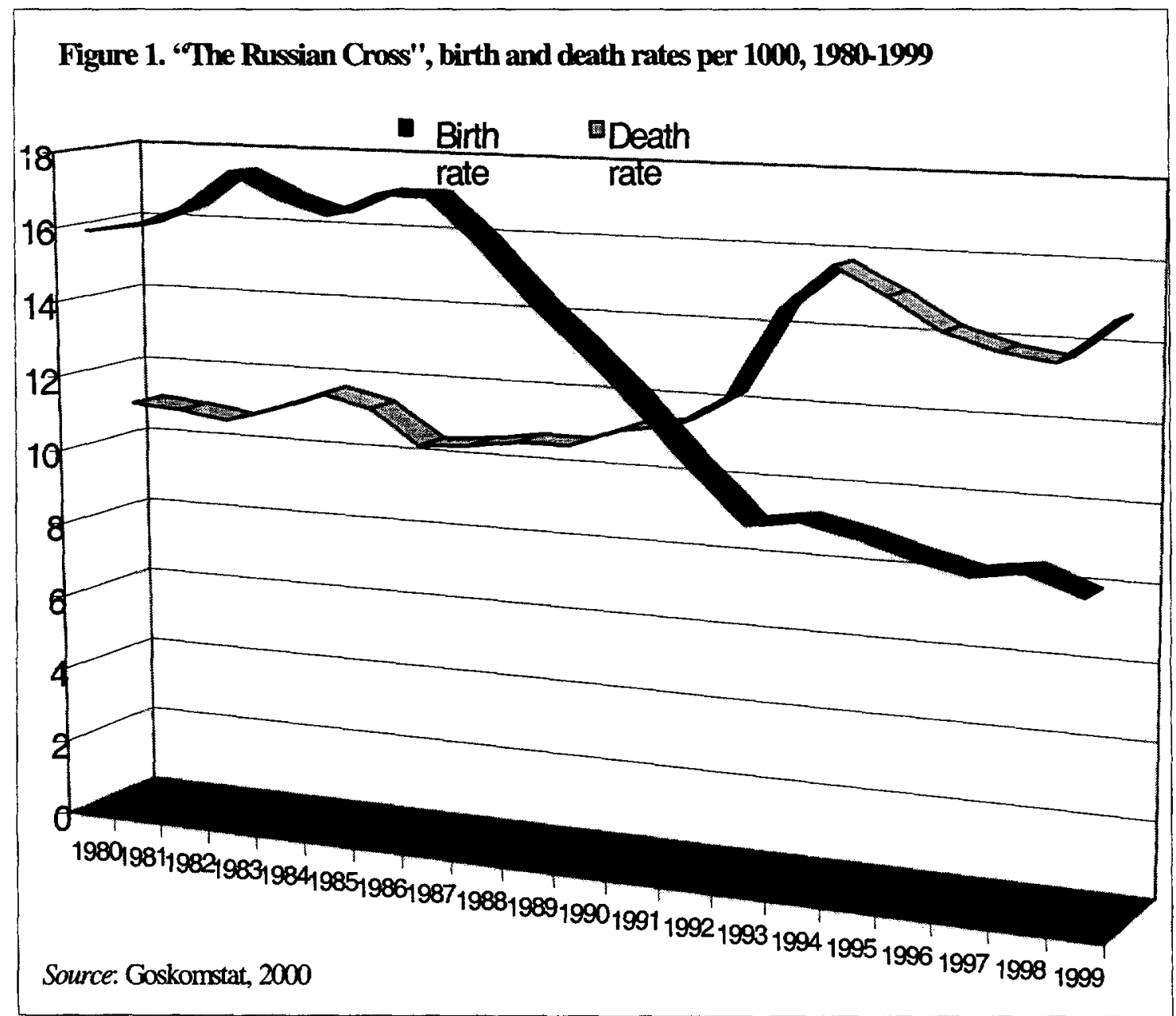


The Russian Federation is the world's largest country, at almost twice the size of the US and one-sixth of the world's land surface. The Russian Federation borders 14 foreign states. It is a federation of 89 oblast (regions), encompassing a vast Eurasian expanse of field, forest, desert, and tundra, and spanning eleven time zones. With a total population of 146 million, it is also the world's sixth most populous country, and represents great ethnic and cultural diversity. Living standards vary widely. The Russian Federation includes industrial regions with established infrastructure, production centers set in vast sparsely populated regions, and agricultural areas in poorly developed rural settings. About $77 \%$ of the Russian population lives in urban areas (Goskomstat 2000).

Despite the promise and optimism with which the dissolution of the USSR was greeted in 1991, the economic transition, upon which the Russian Federation embarked in 1992, has been difficult (Rutkowski 1999). As the old political regime crumbled, inflation surged and output fell precipitously, leading to the collapse of internal and external trade, and a rapid rise in the fiscal deficit. Between 1990 and 1998, the cumulative decline in GDP was about $42.3 \%$. Furthermore, the growth in inequality of income distribution was twofold, far exceeding that indicator among other transition economies (Milanovic 1998).

Slight economic improvements achieved in 1997 were swept away by the financial crisis, which broke out on August 17, 1998 and continued throughout early 1999. Real GDP contracted further by $4.6 \%$, and industrial output decreased by $5.2 \%$. By the end of 1998 inflation reached $84.5 \%$. The ruble exchange rate skyrocketed fourfold (to 20.65 rubles per U.S. dollar by year-end, compared to 5.96 at the beginning of the year). Real disposable income dropped by one third $(28 \%)$ in the fourth quarter of 1998 relative to the same period of 1997 , substantially increasing the number of people living below subsistence level. The poverty headcount (number of people with incomes below subsistence level) was estimated at $50 \%$ of the population, and the unemployment rate -at $15 \%$-- was the highest since the beginning of the transition (Illarionov 2000).

However, industrial production in the first six months of 1999 grew by $3 \%$ over the same period of the previous year. This growth was driven mainly by the real depreciation of the ruble, which stimulated both import substitution and an increase in non-oil exports. At the same time, an almost two-fold increase in oil prices and a huge $(40 \%-50 \%)$ contraction in imports have prompted the accumulation of a large trade surplus, which has been sufficient to ensure timely payments on Russian-era debt while also keeping foreign exchange reserves above critical levels (RECEP 2000).

Fears that surfaced soon after the 1998 crisis of a large-scale reversal of market reforms and the heavy printing of money did not materialize. The election of Vladimir Putin as the new Russian President in March 2000 seems to have put an end to the period of significant government instability, when within 18 months, five prime ministers succeeded each other, the Duma was reelected, and President Yeltsin resigned in December of 1999. 
Nonetheless, the Russian Federation has very limited resources to effectively address the huge and growing burden of problems it faces. A key challenge facing the Russian Government is to demonstrate and sustain clear commitment to reforms, both at the national and regional levels. Such commitment is vital for the long and difficult path ahead.

Evidence exists of a broad-based and substantial deterioration in survival in the Russian Federation (Figure 1) (McNabb 1995, Cherniack et al 1996, Leon et al 1998, Notzon 1998, Eberstadt 1999). In the last ten years, Russia's population fell by 3.7 million, or 2.5\%. However, an adjustment for net in-migration (immigration minus emigration) during the same period (additional 3.4 million) reveals that the natural decrease (deaths minus births) was 7.1 million, or almost $5 \%$ of the total population. With the major source of migrants (Russian speakers from the Caucasus and Central Asia) largely exhausted and the world's lowest fertility rate, the population decline will intensify (Oxford Analytica 2000).

Reported slight improvements in birth and death rates observed between 1995 and 1997 were lost in 1999, and therefore it is not clear whether the positive trend in life expectancy will continue. (Table 1). The reported decrease in the incidence of some diseases (such as gonorrhea and syphilis) may only indicate the growing ineffectiveness of the national surveillance system, rather than a real improvement in health.

Table 1. Life Expectancy in the Russian Federation

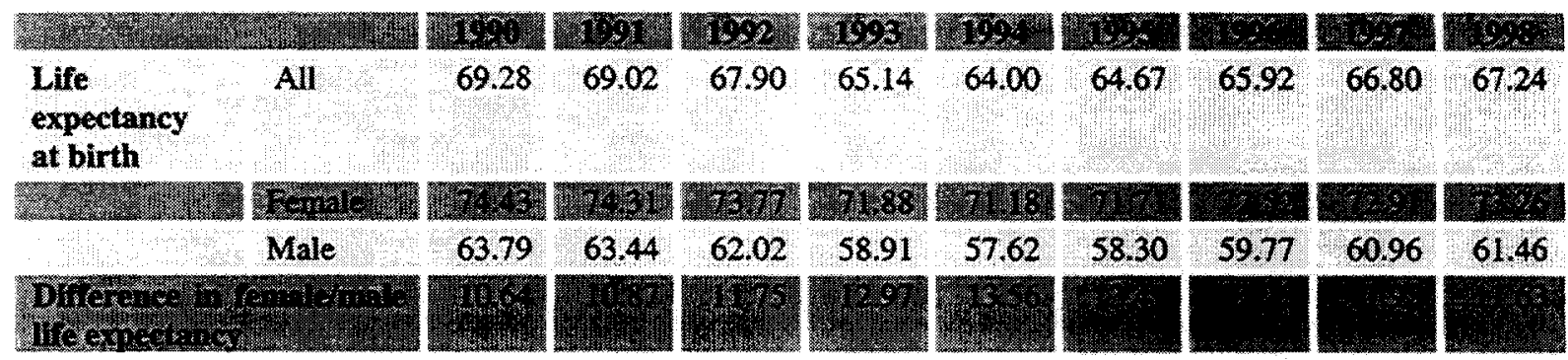

Source: WHO, 2000 and the authors' calculations

A natural loss of population observed in the Russian Federation since the mid 1990s is unprecedented in the peacetime experience of industrialized countries. Anecdotal reports indicate a considerable decrease in the number of pupils entering primary schools - an unsurprising trend, given the sharp drop in the birth rate in 1992 and the following years. In fact, according to some forecasts (Feshbach 1999), Russia's population may plummet from 145 million today to 80 million by 2050 . These adverse trends will have broad and long-lasting implications for the country's future. 



\section{The TB Epidemic}

The TB epidemic is taking a high toll on the Russian population and the country's economy. About 30,000 people, mostly men of productive age, die of TB each year (Goskomstat 2000). Over the 1990s mortality due to TB in the Russian Federation has more than doubled (Figure 2).

Figure 2. TB mortality rates (per 100,000), 1980-1999

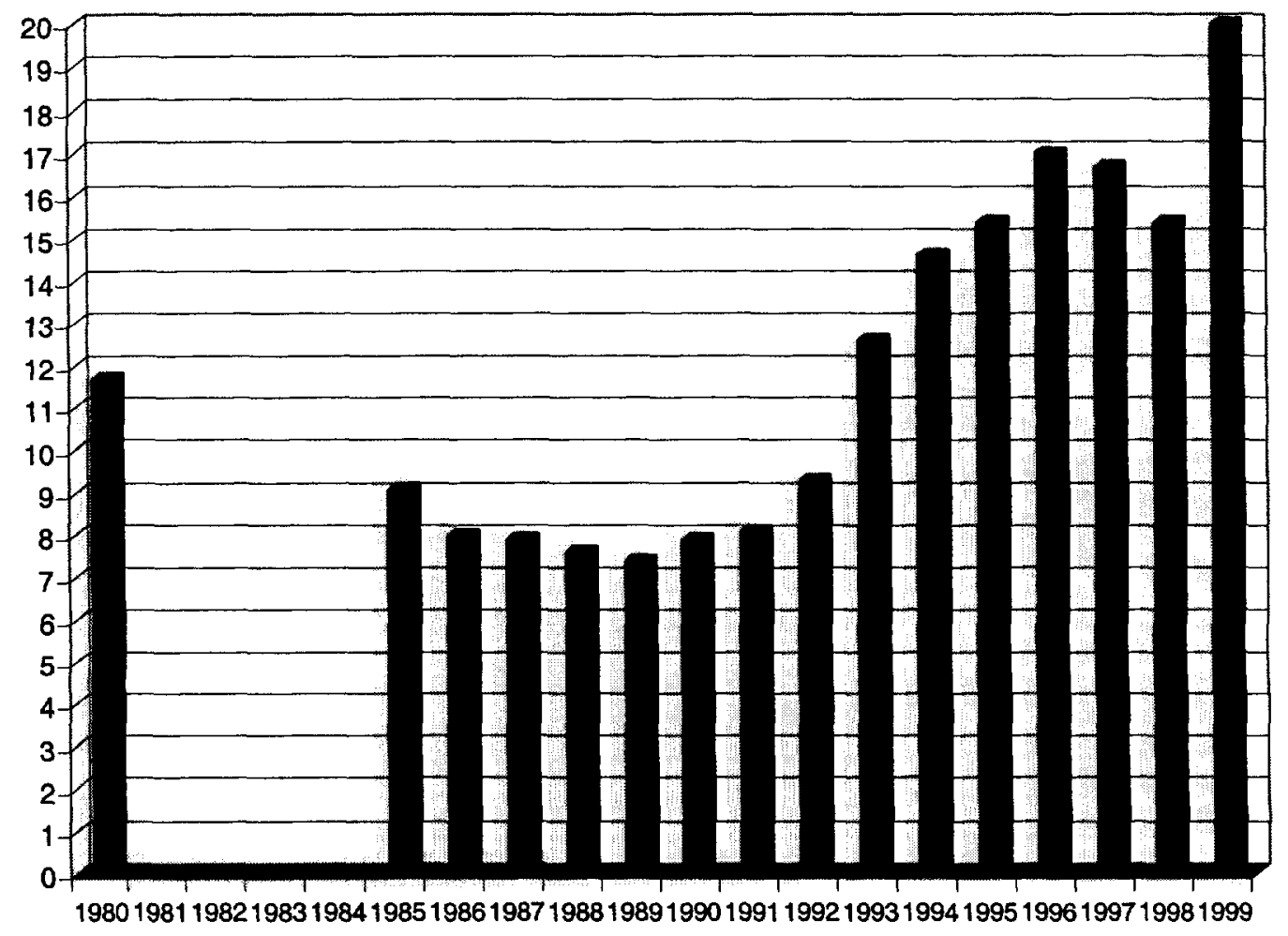

Source: Goskomstat 2000

TB is the greatest cause of death from infectious diseases in the Russian Federation the mortality from TB, including the delayed consequences of TB, accounts for more than 80 percent of all deaths due to infectious diseases. The share of TB alone in the mortality from all infectious diseases increased from 67.3 percent in 1991 to over 81 percent in 1997-98 (Goskomstat 2000).

In 1998 about $17 \%$ of TB deaths occurred within a year of diagnosis. Sputum conversion was observed in $73.2 \%$ and cavity closure occurred in $63.4 \%$ of newly diagnosed patients. According to the criteria established in the Russian Federation in 1998 the clinical cure was observed in $17.5 \%$ of patients with respiratory TB and in $15.5 \%$ with extra- 
respiratory TB (Shilova 1999). The poor treatment effectiveness contributed to the growth in the prevalence of TB by $6 \%$ between 1997 and 1998, to 341,700 cases.

The risk of dying from TB in the Russian Federation is the highest throughout the entire Europe and Central Asia region (WHO 1999). In 1997 the risk of dying from TB in The Russian Federation was, respectively, 7 and 28 times higher than in the European Union countries and the USA (Table 2).

Table 2. Relative risk (RR) of TB mortality in selected areas (1997)

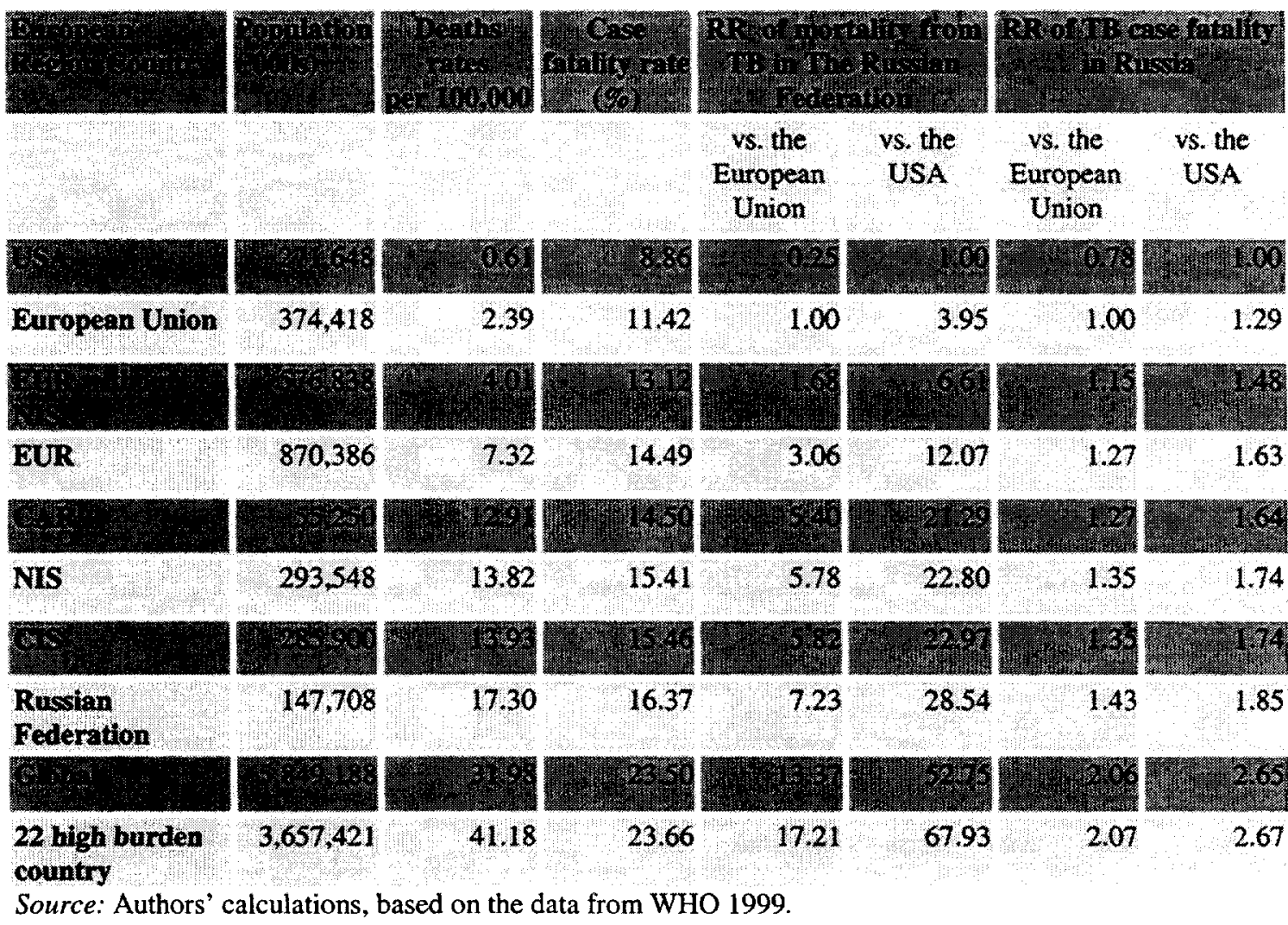

Poor treatment also contributes to the growth in the number of the disabled due to TB. With about 30,000 patients becoming long term disabled due to TB each year $(20 / 100,000)$, the total number reached 91,576 people in 1998. Between 1990 and 1997 , the annual number of the long term disabled due to TB has more than quadrupled, at an average annual growth rate of 28.6 percent. . The fact that the average annual growth rate of the number of the long-term disabled due to TB in the Russian Federation greatly exceeds (almost threefold) that of newly detected cases of the disease (11.7 percent) may suggest growing underdiagnosis/underreporting of $\mathrm{TB}$ and/or an increase in the number of severe cases of $\mathrm{TB}$, probably due to drug resistance. 


\section{TB Incidence and Prevalence}

While the Russian population comprises about 17 percent of the total WHO European Region population, Russia's contribution to annual TB incidence in the region has become disproportionately large. In 1998, the absolute number of new TB cases (all forms) in the Russian Federation accounted for about 35 percent of the total number of all new TB cases notified in the WHO European Region. During the pre-transition period (1980 to 1992) the Russian share averaged 23 percent. In 1997, the TB notification rate per 100,000 in the Russian Federation became more than twice as high as in the whole WHO European Region for the first time (82.3/100,000 vs. 39.9/100,000 (Figure 3).

\section{Figure 3. TB notification rates (new cases, all forms including relapses), per 100,000 in WHO Europe and Russia (1991 - 1998)}

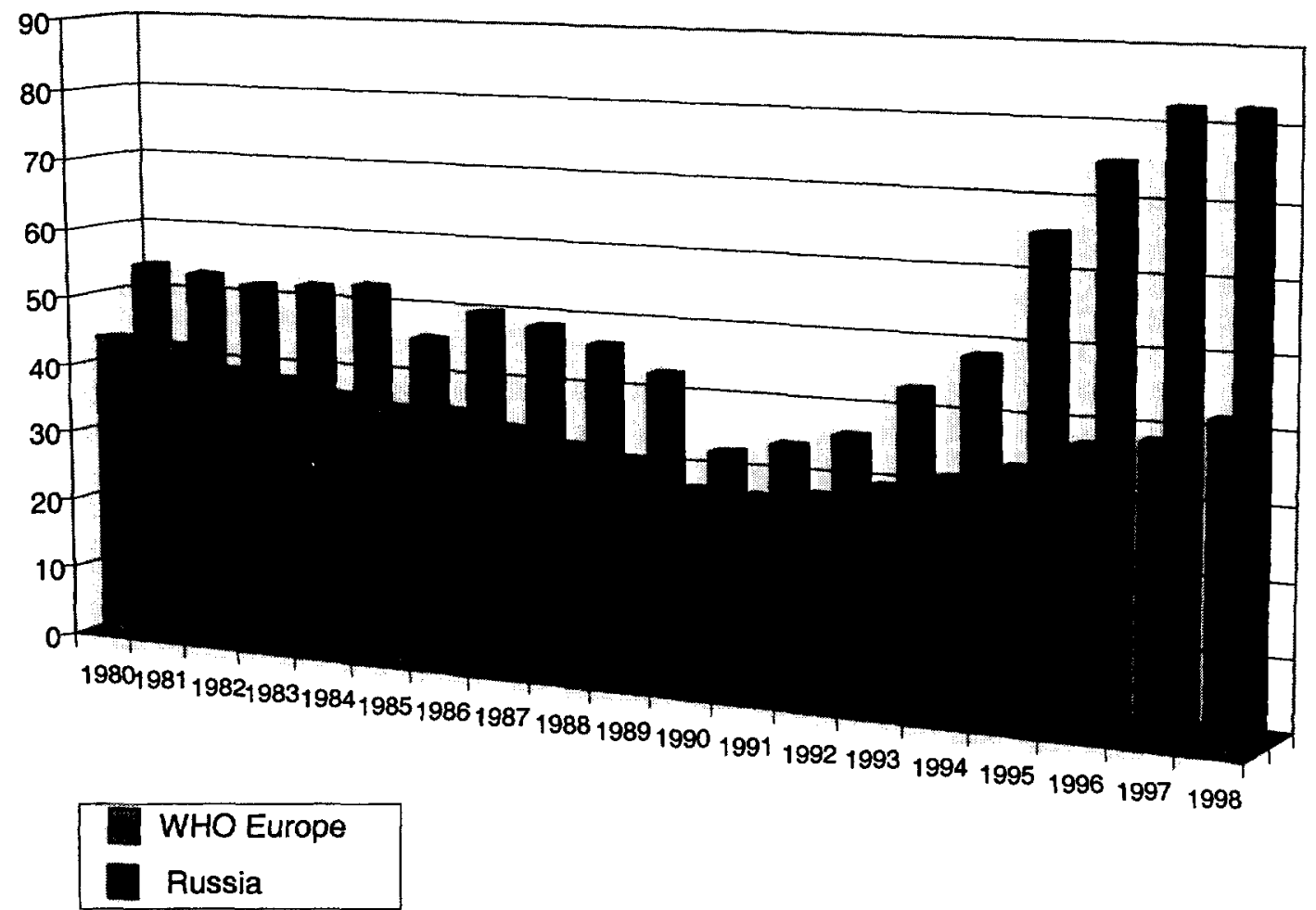

Source: WHO 2000

Furthermore, WHO specialists estimate that TB incidence in the Russian Federation in 1998 was considerably higher than the TB notification rate reported by the Ministry of Health (106 vs. 82.4 cases per 100,000 population) (WHO 2000). Their data suggest that annually about one forth of all new TB cases in the Russian Federation are neither diagnosed nor reported. 
Historically, the Russian Federation has been characterized by high rates of notified TB cases (Farmer, Becerra, Kim 1999). According to WHO data, even during the "best" years of Soviet times (1980-1991), the TB notification rate in the Russian Federation was on average almost one third (27.6 percent) higher than in the whole WHO European Region (Figure 3).

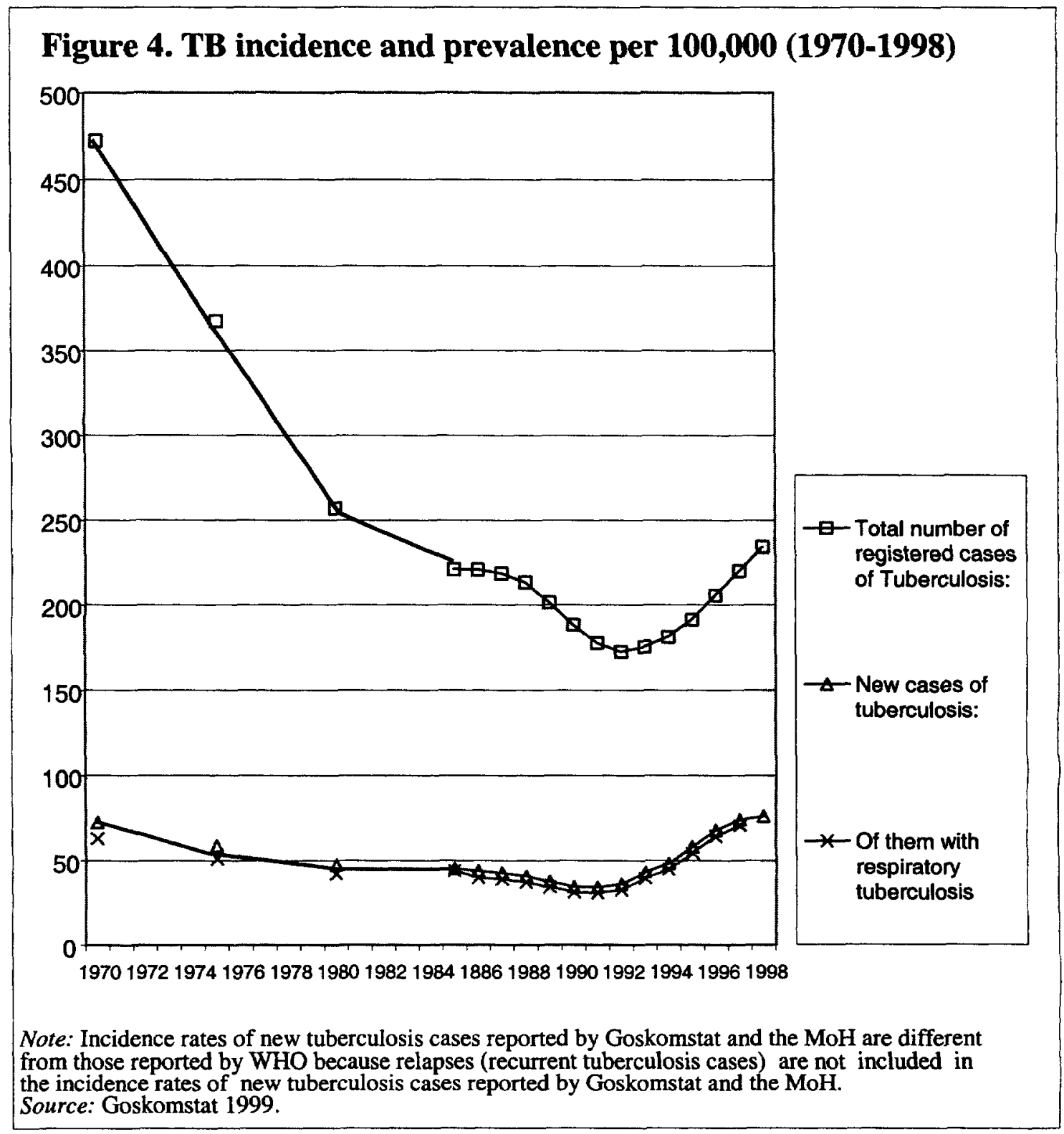

However, over more than two decades of the so-called 'developed socialist' period, there was a steady decrease in both newly notified and all registered TB cases in the Russian Federation. The data from the Russian MOH (Figure 4) show an impressive decrease by almost two thirds (58.5 percent) in the absolute number of all registered TB cases; the 
number of cases fell from 616,600 in 1970 to 255,900 in 1992 , a decline of an average of 3.6 percent annually. The decrease in TB prevalence looks even more significant $(63.5$ percent) when calculated based on rates per 100,000 population, from 472.2 in 1970 to 172.5 in 1992.

This positive trend was reversed in the early 1990's. From 1991 to 1998 the annual number of newly notified TB cases more than doubled, from 50,400 to 110,900 (Goskomstat 2000). As a result, in just six years (from 1992 to 1998), the absolute number of prevalent TB cases drastically increased by 33.5 percent, from 255,900 to 341,700 . At an average annual growth rate of almost 5 percent, growth in TB cases exceeded the annual average decrease rate of 3.6 percent that occurred from 1970 to 1992. In 1997, the notification rate of new TB cases per 100,000 exceeded the 1970 level, completely negating the positive achievements of the Soviet TB service over the previous 27 years.

Demographic distribution of TB cases. The available data show that TB is disproportionately prevalent among males, and among individuals of productive age, i.e. age 25-64 years (Goskomstat 2000, Shilova 1999). The data also suggest that TB is disproportionately prevalent among alcohol addicts, the poor, the homeless (Helvie 1998). During the transition period, there has been a very strong direct association ( $\mathrm{r}$ $>0.9$ ) between TB incidence in the Russian Federation and such social factors as unemployment and crime (i.e., the annual number incarcerated) (Figure 5 and 6).
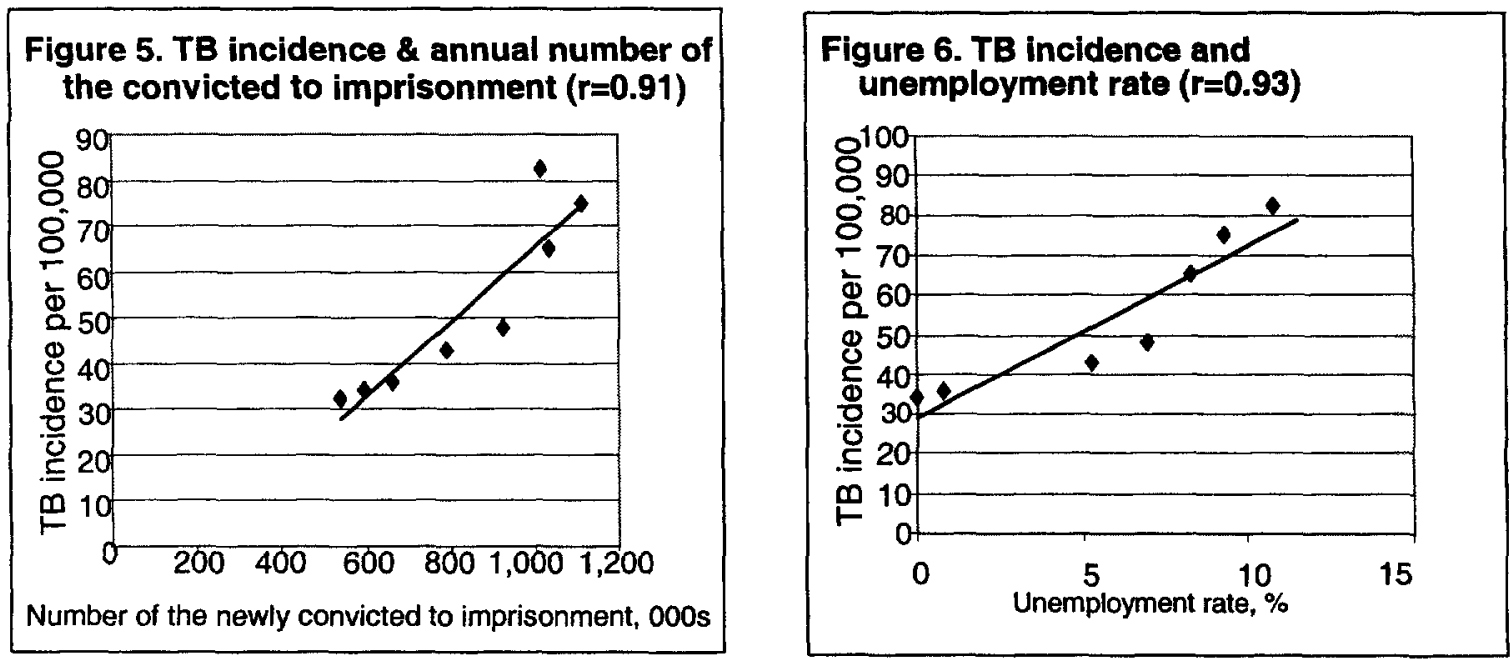

Source: The authors' calculations, based on the data from Goskomstat 1999.

Geographical distribution of TB cases. TB is very unevenly distributed throughout the country. In 1998, the number of newly reported TB cases per 100,000 varied from 42.1 in the City of Moscow to 284.8 in Tuva Republic (South-Eastern Siberia). 
Table 3. TB mortality in Russian regions

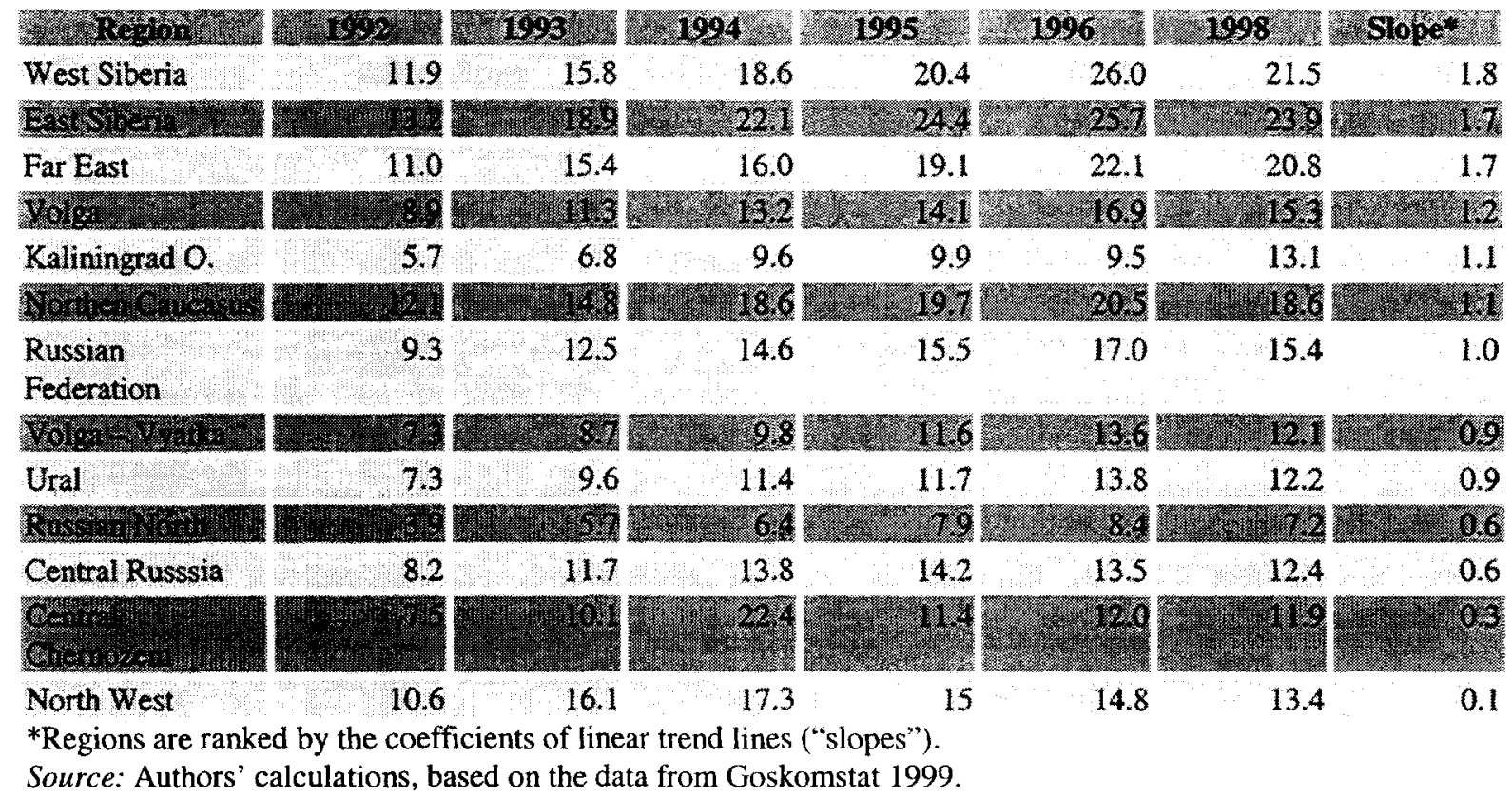

TB by case status: The rate of new smear sputum positive (ss+) TB - a more infectious and more severe form of the disease - has grown by almost one third from 1994 to 1996 (Table 4). By 1997, the risk of developing ss+ TB in The Russian Federationwas 2.2 times higher than in the WHO European Region, as a result of improving ss + TB rates in the European region as whole.

Table 4. New ss+ TB cases in The Russian Federationand EUR

\begin{tabular}{|c|c|c|c|c|c|c|c|c|c|c|}
\hline & & S & $3 x+2$ & 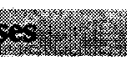 & 120 & & and & 10 & 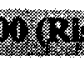 & 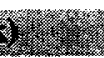 \\
\hline Years & 1994 & 1995 & 1996 & 1997 & 1998 & 1994 & 1995 & 1996 & 1997 & 1998 \\
\hline S. & 60 & 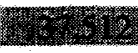 & (1958: & 20104 & (12,219 & 20.5 & 253 & 286 & 28.5 & 286 \\
\hline EUR & 83,568 & 104,633 & 119,080 & 113,587 & 111,371 & 9.7 & 12.1 & 137 & 13.1 & 12.8 \\
\hline & & & & & & & m & & 22 & 2 \\
\hline
\end{tabular}

* Authors' calculations, based on the data from the WHO Report.

Source: WHO 2000.

\section{TB Incidence and Prevalence in Russian Prisons}

The disease is dozens of times more prevalent in prisons than in the general population Russian prisons are home to almost one third of all TB cases in the country. The risk of dying from TB in prisons is almost 30 times higher than in the general population. Between 1993 and 1998, the number of TB cases among the prison population tripled. Each year cumulatively more than 500,000 persons were at risk of contracting TB while spending time in the pre-trial facilities. 
In 1999 , there were $98,567 \mathrm{~TB}$ cases in the prison system. Among them were 405 teenagers (355 boys and 50 girls); 13,744 in pre-trial facilities. 45,618 prisoners with active TB were treated in 55 specialized TB prisons; 35,238 were treated in 119 prison hospitals; 17,000 were isolated in general prisons; and 3,000 were not isolated. 2,807 inmates died of TB in 1999. 31,406 former prisoners with active respiratory TB were released from the prison system.

Table 5. Number of persons in the prison system

\begin{tabular}{|c|c|c|c|c|c|c|c|c|}
\hline Pre-ti & 550,357 & 610,535 & 677,989 & 722,834 & 763,168 & 731,081 & 739,701 & 765,9 \\
\hline 2 & & & & & & & & \\
\hline 1 & 750, & $849 ? 2$ & 8,982 & 018,022 & $1,051,199$ & $1,009,863$ & $1,014,272$ & 1,038 \\
\hline
\end{tabular}

Source: the Russian Ministry of Justice 2000

The Russian Federation has the highest incarceration rate in the world. According to the Russian Ministry of Justice, in 1999 there were more than 1 million inmates (suspects, defendants, and convicts) in Russian prisons. As of December $31^{\text {st }}, 1999$, the prison population included 273,008 suspects and defendants in pre-trial detention facilities, and about 765,980 convicts in the correctional facilities. Tables 5 through 7 show the trends on the flow of inmates in and out of the prison system.

Table 6. Number of persons newly admitted to the Prison system

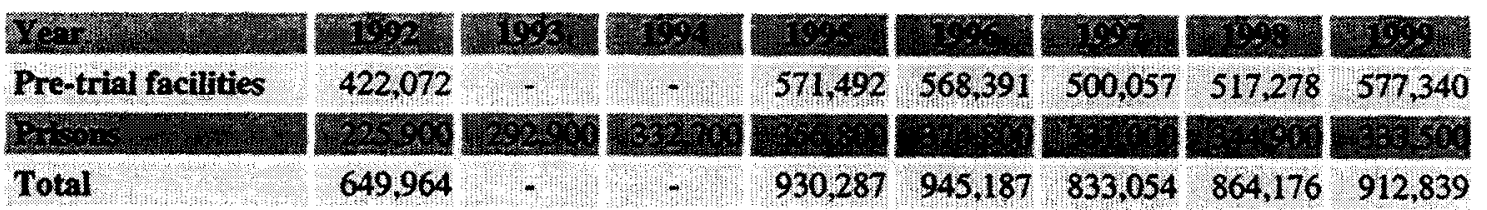

Source: the Russian Ministry of Justice 2000.

Table 7. Number of persons released from the Prison system

\begin{tabular}{|c|c|c|c|c|c|c|c|c|}
\hline Pre-trial tacilities & 44,832 & - & - & 62,437 & 59.604 & 59.662 & 50,354 & 125,602 \\
\hline 208 & 20867 & 2) & & & 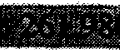 & 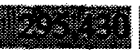 & & 8252 \\
\hline Total & 249,895 & - & & 309.60 & 323,58 & 357.089 & 338.899 & 450.8 \\
\hline
\end{tabular}

Source: the Russian Ministry of Justice 2000

From 1993 to 1997 , while the TB incidence rate in the penitentiary system quadrupled, the TB mortality rate increased nearly fivefold (Table 8). This suggests tremendous deterioration of TB control within the prison system. Since 1998, nearly one in each ten prisoners has had active respiratory TB. 
Table 8. TB in the prison system (including persons in pre-trial facilities)

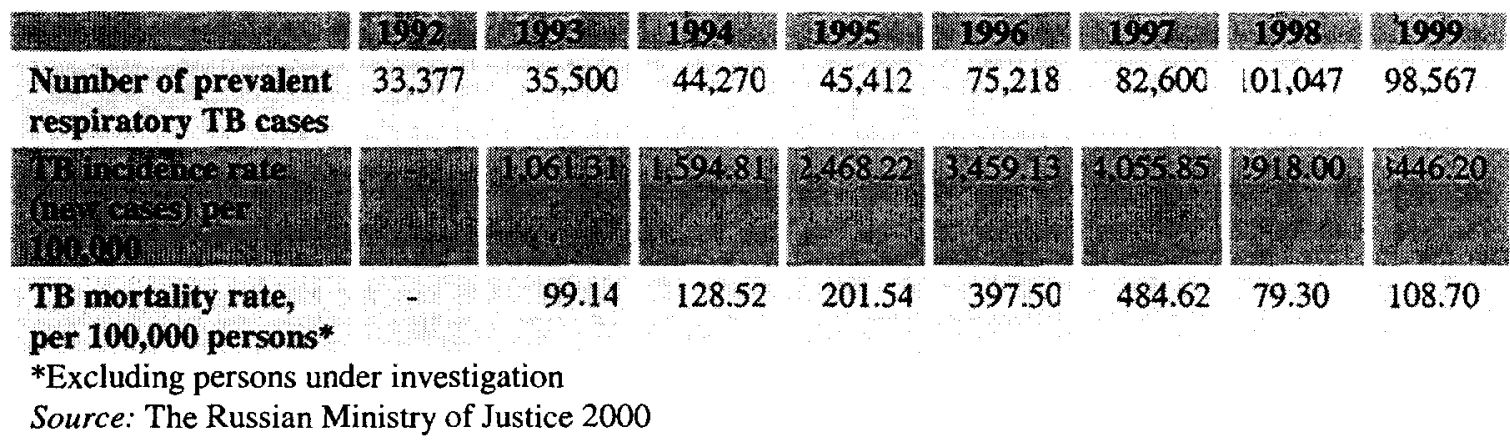

Over the same period (1993-1997), the detection rate in the pre-detention facilities increased 3.5 times (Table 9). Given that the level of overcrowding in the pre-trial facilities is twice as high as in the general sprison facilities (144 percent vs. 87 percent, respectively), as well as the significant turnover of inmates in the pre-trial facilities $(577,340$ persons in 1999), the pre-trial facilities present particularly favorable conditions for spreading TB.

Table 9. TB notification rate in pre-trial facilities (per 100,000 persons)

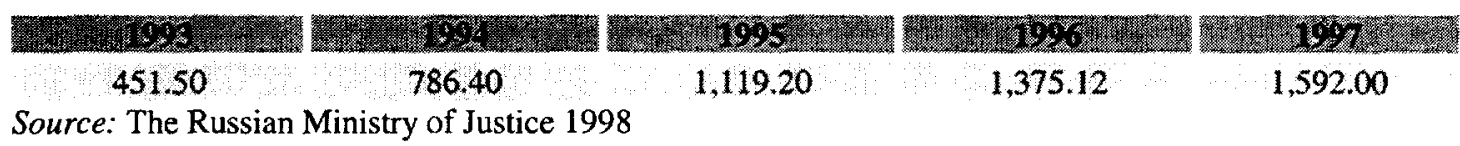

According to the crude estimates of the Russian Ministry of Justice, in 1997 TB incidence among personnel of the penitentiary system and the staff of the Ministry of the Interior of the Russian Federation was 11.5 and 73.9 per 100,000 , respectively, compared to 73.4 cases among the general population. This data is difficult to interpret since the significant distinctions in age, sex, and other parameters between the personnel and the general population are not taken into account. However, the data clearly show that the personnel of the penitentiary system, in dealing with prisoners on everyday basis, is increasingly affected by TB (Table 10). While there is no evidence of a significant increase in the number of personnel, the number of personnel with respiratory $\mathrm{TB}$ has increased almost twofold over three years.

Table 10. Incidence of respiratory TB among prison personnel (number of persons)

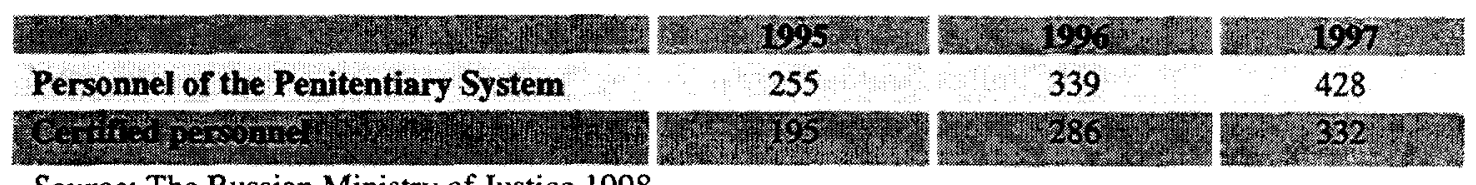




\section{TB Control System}

In the general move to a more democratic society, as well as to increase efficient resource utilization, the Russian Government undertook significant decentralization of the public health care system between 1991 and 1993. As a result of decentralization, the responsibility for health care was passed to the regional public health authorities. Since 1993, all TB control facilities, like all other public health facilities in the country, have been functioning under general management of regional and local (raion, city) Departments of Health. However, in performing specific duties, each TB control service represents a completely separate vertical structure.

Management and structure. The Public Health Sector, under the umbrella of the Ministry of Health (MOH), has always been the sole provider of TB control services. Largely because of decentralization, the role of the MOH has changed since 1991, but it remains the top Russian governmental agency for formulation and coordination of operational policies in the area of public health, including TB. However, in the early 1990s TB was not viewed as a high priority by the MOH; its TB unit was, in fact, reduced to a single person, and no national TB program manager existed. The steadily declining TB trend observed over several decades was considered to be adequate justification for this limited focus.

At the regional level, all TB services are provided by specialty facilities called TB dispensaries (TBDs). Each of the 89 Russian regions has one or more TBDs. In large and populous regions, where more than one TBD is established, one of them is appointed by a regional Department of Health to provide specific methodological and logistical management to all other regional TB facilities and coordinate all TB control activities in the region. Each TBD serves a population of strictly defined catchment areas delineated by Departments of Health. TBDs are also responsible for continually training TB medical personnel. According to a MOH decree (1995), TBDs may include (and usually comprise) the following functional units:

- outpatient department (for adults, children and adolescents)

- inpatient hospital (including surgery department)

- day hospital

- sanatorium

- clinical and bacteriological laboratories

- specialty offices, including X-ray, functional diagnostics, physiotherapy, rehabilitation for former TB patients with post-TB changes and non-specific lung diseases, and therapy for alcoholism and drug abuse

- labor facilities for patients

- differential diagnosis and health centers for pediatric TB patients (only available at regional TBDs)

- fibroendoscopy (only available at regional TBDs)

- epidemiology and surveillance department (only available at regional TBDs) 
In addition, a network of $\mathrm{TB}$ Research Institutes provides specific technical and methodological assistance to regional TB services. There are five TB Research Institutes, located in Moscow, St. Petersburg, Ekaterinburg, Novosibirsk, and Yakutsk. The leading role in the network belongs to the institute in Moscow (the Russian Institute of Phthisiopulmonogy or the RIP). All Russian regions are specifically assigned to one of the five institutes. The institutes may include referral clinical and research facilities, as well as departments for bacteriology, surveillance, epidemiology, TB services organization, computerized TB monitoring, and TB policy development.

The involvement of primary health care (PHC) in TB control is limited. PHC facilities are responsible for mass screening for TB among populations living in their catchment areas by conducting chest X-ray tests for adults and teens (older than 14 years), purified protein derivative (PPD) skin testing for children and teens aged 10-14, and referral of cases of suspected TB to TBDs. Until recently, PHC facilities did not have the capacity to perform smear sputum microscopy, let alone culture testing. When cases are detected at PHC facilities they are registered in integrated TB offices and are referred to TBDs for further examination and/or treatment. In rare cases, if a patient's condition is severe, he or she may be given TB treatment at PCH facilities for a few days before transportation to a TBD becomes possible. TB offices are also responsible for coordination of a patient's follow-up after the treatment at TBD is completed.

System financing. Since 1993, there have been two sources for funding TB services in Russia: state budgets and Mandatory Health Insurance Funds (MHIF).

MHIFs provide funding for TB services delivered by TB offices integrated into PHC facilities. Since most TB services are not provided at the PHC level, the share of MHIFs in overall financing of TB control in the Russian Federation is insignificant.

Together with HIV/AIDS, STIs, psychiatric illnesses and certain other diseases, TB was included by $\mathrm{MOH}$ in a group of so-called 'socially significant diseases'. As such, the financing of the system of specialized TB facilities (TBDs and TB sanatoria) is the responsibility of the state. State health system finance is formed by budgetary resources of governments at all levels. Allocations for TB are made from regional and district budgets at no particular rate. Authorities make their allocation decisions based on availability of resources and priority setting processes.

Little data is available on TB funding across the regions. However the fact that budgetary revenues fell precipitously during the 1990s is well documented (Klugman 1997, 1998, Rutkowski 1999). Even in the regions where public expenditures on health, including TB, as percentage of revenues did not change, the real amount of funding is now less than half of the pre-transition level (UNDP 1999, UNDP 2000). Even so, there is abundant evidence that in practice the funding actually received by the health facilities was on average $40-60 \%$ of the allocated amounts. In addition, barter transactions have been prevalent (UNDP 1999, Rutkowski 1999). This development is linked to the low political commitment to public health among regional and district authorities and in many cases the failure to recognize health, including TB control, as a 
priority in budgetary allocations. The Federal Budget, responsible for providing equalization of resource distribution among the regions, seems have failed to do so due to similar reasons. There is evidence of significant variation among regions in per capita expenditures on health, including provision of drugs.

TB surveillance. The TB surveillance system includes mandatory notification of new cases and relapses, notification of deaths from TB, treatment outcome monitoring, and collection of other information. Regional TBDs collect TB information in the regions using standardized $\mathrm{MOH}$-approved forms (including, for example, Form 33 for the resident civil population and Form 8 for all population including institutionalized groups and prisoners). However, TB notification is complex. Modern computers are rarely available at regional TBDs and are almost completely unavailable at the district level. Furthermore, physicians are burdened with a lot of paperwork. Information must be reported in triplicate: to the regional Department of Health, to the assigned Research Institute, and to the $\mathrm{MOH}$. In the latter case, regional officers are required to come to Moscow to submit the reports and the forms in person.

Not all the regions report their data to the $\mathrm{MOH}$ correctly (Shilova 1999). The quality of the reports and forms is subject to much criticism. Although statistics from prisons began to be reported to $\mathrm{MOH}$ in 1995, still not all prisons report, and even those that do may not always report correctly. Case definitions and treatment outcome criteria used in the Russian Federation differ from those recommended by WHO and are, therefore, difficult to analyze and compare. Although detailed historical data of satisfactory quality is available at $\mathrm{MOH}$, access to the data is difficult. This is due to the Soviet legacy of secrecy and to general technical problems. The software for the MOH's database is not user-friendly, requires significant technical proficiency, and is hardly compatible with conventional office applications. Finally, no regular countrywide surveillance of drug-resistant TB has been established in the Russian Federation to date.

TB detection and diagnosis. The TB detection practices inherited from the Soviet Union are primarily based on a mass TB screening of the population conducted at PHC facilities (MOH 1996). Emphasis is not on detection of infectious TB cases; rather, the goal has been to detect 'all TB cases' early in the disease. In this regard, regular X-ray examinations of the chest (called fluorography) and PPD testing have been thought appropriate and are extensively utilized. The activities are traditionally focused on occupational groups, such as all involved in education, child care, health services, food processing and catering, sales, communal services, seamen, etc., for which X-ray screening for TB is mandatory once or even twice a year (MOH 1973). The remaining adults and adolescents over 14 years old are subject to regular (at least once every two years) X-ray examination of the chest at PHC facilities (MOH 1996). According to the established screening guidelines, children and adolescents younger than 14 years old are subject to mandatory annual PPD testing at PHC facilities too. A special sophisticated methodology was developed to evaluate results of PPD testing in BCG-vaccinated ${ }^{\prime}$ children (MOH 1995). The mandatory screening is enforced by sanitary control

\footnotetext{
${ }^{1}$ Bacille Calmette-Guérin.
} 
legislation allowing state sanitary authorities to prevent unscreened individuals from coming to work, or even shutting down businesses until their staff is screened for TB.

A diagnosis of the disease detected either actively (as a part of the screening activities) or passively (when X-ray signs consistent with TB are found by chance during investigation with regard to disease other than lung diseases) is complemented by bacteriologic tests (sputum smear microscopy and culture) performed at TBDs. Since the case detection was not focused on identification of infectious cases, sputum smear examination was not a primary tool for diagnosis and monitoring of TB. Over-reliance on X-ray examination was reported to lead to misdiagnosis of TB in children and adults who were free of TB (Shilova 1999). This further led to unnecessary treatment with toxic TB drugs and use of hospital facilities.

Additionally, a number of factors that emerged with the political and socioeconomic changes in the Russian Federation in the late 1980's and 1990s have made the Soviet TB detection system increasingly ineffective. Democratic changes in society have made people more reluctant to undergo mandatory testing procedures. People also became more reluctant to visit TBDs, where they were referred for bacteriology tests, as TBDs are associated with social stigma and are inconveniently located (specialized TB facilities are usually set in secluded locations to prevent TB patients from leaving them and communicating the disease to TB-free individuals in the neighborhoods). Deteriorating quality of health services has caused loss in people's confidence, and health authorities could not conduct mass TB screening at the previously high level. However, the most important factor was that, as the economic situation worsened, the number of socially disadvantaged and hard-to-reach groups (including the unemployed, homeless, former prisoners, poor and those with reduced access to health care) grew. The mass screening based on a catchment area principle and largely targeting certain occupational groups became apparently unable to reach out those who were at the highest risk for contracting TB. Therefore, the overall effectiveness of TB detection system in the Russian Federation has been gradually deteriorating over the last decade.

TB treatment. Until 1998 no standardized TB treatment regimens were available for nationwide implementation in the Russian Federation. The so-called 'individualized approach' in administering chemotherapy for TB patients was favored by the medical community. In addition, adjunct therapy and surgery have been extensively applied. Little value was given to a sputum microscopy method The definition of cure applied in the Russian system, apart from the sputum conversion, included also clinical X-ray improvement ('cavity closure'), and culture conversion.

In the Soviet times, the system was able to contain the spread of the disease, as most of the TB cases were isolated for long periods in specialized hospital facilities (TBDs and TB sanatoria). The worsening of the financial situation during the 1990 s resulted in shortages of TB drugs and, consequently, declining cure rates. The average cure rate was about 70 percent, but in some regions it was as low as $40-50$ percent. The reasons for the decline listed by Russian specialists were: lack of basic anti-TB drugs; 
utilization of low quality drugs; prescription of inadequate treatment regimens; selfadministration of drugs; and poor patient compliance with the treatment.

On February 2, 1998, the MOH issued a decree (Decree Number 33) prescribing certain standard protocols for TB treatment in the Russian Federation. This was a significant step in revising TB control in the Russian Federation and bridging with internationally accepted practices. The decree specifies several 'basic treatment regimens' for various clinical cases of respiratory TB to be selected by a qualified TB doctor.

However, there is still little consistency with the WHO recommended guidelines. The terminology and major definitions used in the decree are not consistent with those used by WHO: respiratory TB and relapse in the Russian Federation are defined differently from the WHO definitions of pulmonary TB and TB relapses. In addition, the four Russian patient categories are hardly comparable with the four TB treatment categories developed by WHO. Not only is comparison between the new Russian and WHO TB treatment guidelines very complicated, but there seems to be little internal coherence between the patient categories and the suggested regimens. To grasp this link would require very high proficiency of TB treatment providers. This may limit inclusion of PHC facilities in the provision of TB treatment and increase the risk of treatment failure.

The way patient categories are defined suggests that smear microscopy is not viewed as a primary diagnostic and monitoring method. Thus, the concept of having TB control programs emphasize the interruption of TB transmission by first detecting and curing infectious cases (smear+ pulmonary TB) does not seem to have been accepted by the decree development team and the MOH. Although the decree has introduced valuable changes, such as a phased approach in TB case management and treatment in outpatient settings in the follow-up phase, the extensive use of sanatoria, day-time hospital facilities, and reliance on X-ray examination seem to remain.

TB system resources. As noted above, until 1998, no changes in how TB infrastructure was managed or financed were effected. Therefore, all trends in the allocation of resources for TB before 1992 reflect the political will of the central Government and the MOH towards TB control. The available data (Gokcomstat 2000) show that the Government reduced the number of TB physicians by slightly less then ten percent and cut TB beds by almost one third from 1970 to 1991. This reduction in resources corresponds to the twofold decrease in TB incidence and prevalence observed over the same period.

Reduction in TB beds slowly continued until 1994, and by the same year the number of TB physicians fell by another $15 \%$. As a result of the growing TB epidemic, the number of TB physicians and TB beds per 1000 new TB cases decreased more than twofold since 1990, and was at the lowest level ever in thirty years. Moreover, until 1994 the number of TB beds and TB physicians have been reduced at a greater pace than other kinds of beds and physicians, as evidenced by the data. These trends confirm that the political commitment to the allocation of resources for TB control in the first half of the 
1990s was insufficient (Table 11). TB was not recognized as an emerging epidemic in time to stem its growth.

Table 11. TB control infrastructure

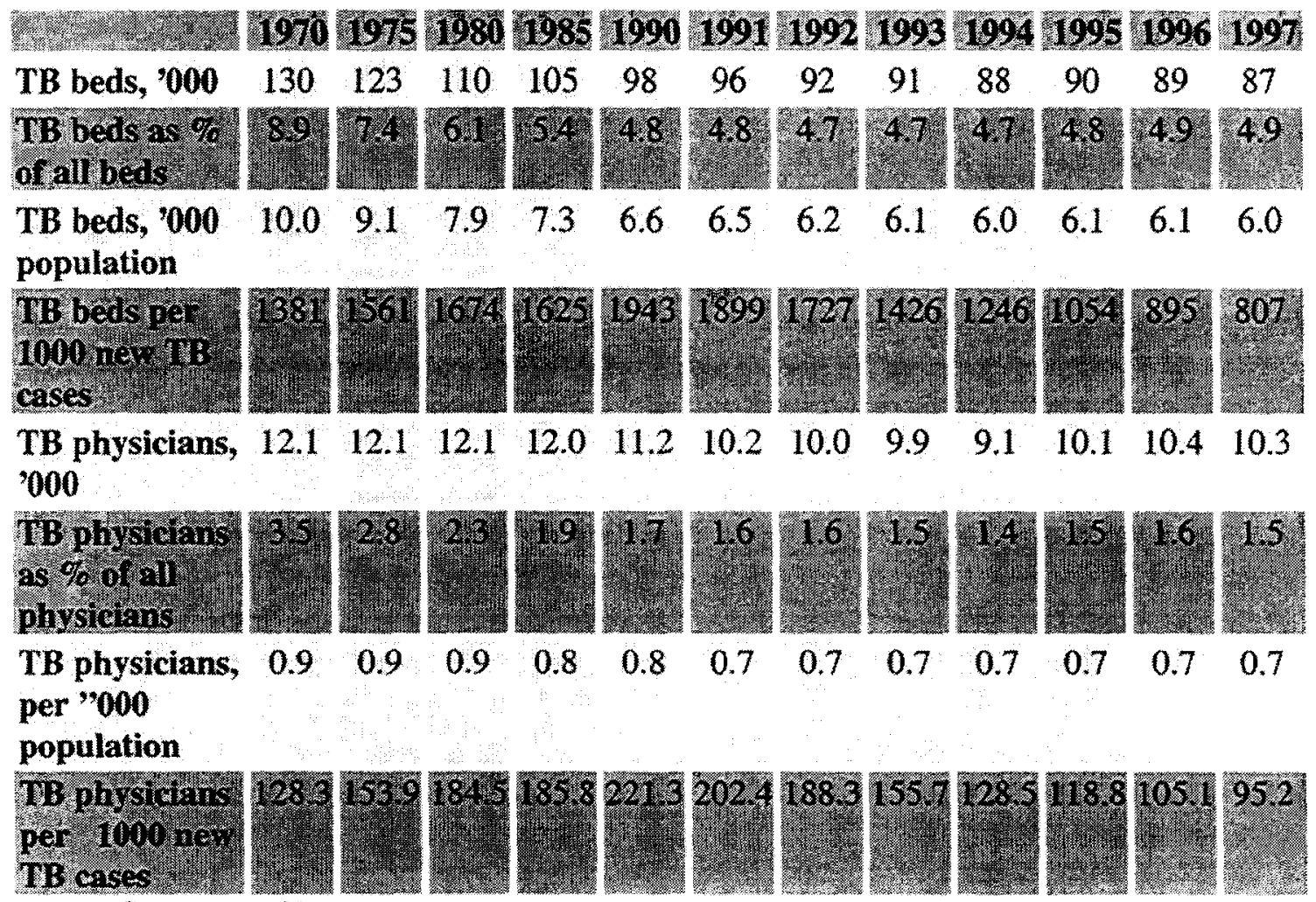

Source: Goskomstat 1999.

Despite the significant reduction of resources in the 1980s and epidemic growth in 1990s, the infrastructure of the Russian TB control system remains extensive. In 1998 there were a total of 502 TBDs in the Russian Federation one for every 300,000 people. In 1998, 9,281 TB physicians (6/1000 population) and 33,000 nurses worked in those 502 TBDs and over 100 TB sanatoriums. The combined bed capacity of TBDs and sanatoria was 114,727 ( 83,051 and 31,676 beds, respectively). There were $500 \mathrm{~TB}$ surgeons and 6,000 thoracic surgery beds in TBDs. In addition to treatment facilities, 650 bacteriological laboratories (including 300 laboratories which perform cultures) and 4,978 X-ray machines were also in operation.

System resource utilization. In 1998, surgery treatment for $\mathrm{TB}$ was used as a treatment method for 11,398 TB patients (of those, 9,292 had respiratory TB). In total, about 80 million people were screened for TB with chest X-ray tests, but only $7,747,300$ microscopy and 6,555,300 culture tests were performed. Although $56.1 \%$ of all the adults and teenagers was X-rayed for TB, this level is considered low when compared with the level of $75.4 \%$ during the Soviet period (Shilova 1999). 


\section{TB Control in Russian Prisons}

Structure of prison health services. The State Department of Prisons, 'GULN,' (recently placed under the Ministry of Justice) and its regional bodies, , are in charge of 996 correctional institutions across the country. Prison systems in regions are managed by Regional Departments of Prisons ('UINs'). Health service in the Russian prison system (RPS) is separate from the public health care system. It is an integral part of the RPS and follows its logistics. Since Soviet times, decentralization of the RPS has been less significant than that of the civil services.

Each correctional institution maintains a medical unit staffed by several physicians (4-5 per 1000 inmates) and auxiliary medical personnel. Large institutions have hospitals, usually with integrated TB divisions. Specialized prisons for prisoners with TB ('TB colonies') and TB divisions in prison hospitals have a sufficient number of physicians and auxiliary medical personnel (usually 50-60 per 1000 patients) and some diagnostic facilities (Kononets 2000).

In 1999 the RPS included 55 TB prisons, 119 hospitals and 189 medical divisions. The medical staff of these institutions includes administrators, general physicians, specialists (physiatrists, radiologists, bacteriologists, etc.), and includes both uniformed medical officers and contract civilian staff.

Management of prison health services. Prison medical facilities are managed by the prison's chief medical officers, report to both the prison's director and a chief medical officer of the regional UIN. A UIN's chief medical officer reports to the head of a regional UIN and to the GUIN's Health Department in Moscow. There is no mechanism to mandate the reporting of prison medical services data to the regional Departments of Health.

Funding for TB treatment. Prison medical services are funded out of regional UIN budgets. However, regional budgetary allocations for medical services require GUIN approval in Moscow. Procurement and distribution of TB drugs between the regions is usually centralized. However, centralized allocations are insufficient and are supplemented by locally procured drugs.

In 1999, only $20-30 \%$ of TB drug and diagnostic supply needs were covered (not including foreign aid). Approximately $30 \%$ of the food budget was also covered, but was supplemented by in-house agricultural production. In 2000 , the available supply of first line TB drugs is only $30 \%$ of the estimated need (Kononets 2000 ).

TB services. TB detection in prisons is basically identical to that in the civil health care facilities: formally, all inmates are to be screened for active TB with chest X-ray tests within three days from the date of entry in a pre-trial facility, and annually thereafter. Bacteriology services are very poor, and are only available in specialized TB facilities. A system of 33 TB hospitals and 55 TB referral centers - 'TB penal colonies' - was established to treat TB among prisoners. A diagnosis of TB does not always 
prompt initiation of treatment. Only convicted prisoners are transferred to TB prisons. As it may take months before a case comes before a judge, some detainees with TB in pre-trial facilities may languish for months before treatment is initiated. Out-of-stock drugs, drug resistance, lack of supplies, unimaginable overcrowding and short food rations are commonly cited as contributing to rising TB mortality in prisons (Kononets 2000).

Continuation of treatment after release. Each year the Russian penal system releases about 300,000 prisoners, possibly 10 percent of whom have active TB. Formally, exprisoners are supposed to return to their place of residence. Upon return home, the prisoners with TB should report to local TB facilities to continue the treatment or get registered for the follow up. However, according to the MOJ, only $60-70 \%$ of the released prisoners do, in fact, present for such services. There are two main reasons for this. First, the referral system from the MOJ to the MOH is faulty. Second, most ex-prisoners are unemployed and cannot afford user fees introduced in some regions to finance part of the treatment costs.

\section{The Russian Pharmaceutical Sector}

In the past, no private sector existed in the Russian Federation and the pharmaceutical industry was entirely owned and governed by the Federal Government. Accordingly, there was a strict and ultimately centralized drug procurement system (Bachman 1998). Both the range and the quantities of drugs to be produced domestically and imported from abroad (almost entirely from the socialist block countries of Eastern Europe) for all 89 regions of the Russian Federation were defined by the Government, while little or no consideration was given to consumer demand. Prices were set by the appropriate government agencies and kept at a relatively low level through regular subsidies.

Since 1991 major changes have taken place both in the governance and ownership of the Russian pharmaceutical manufacturers. The range and quantities of products produced have also changed significantly. Most pharmaceutical manufacturers have been privatized and private distributors and retail outlets have been allowed to enter the market (The Economist 1998, 1999). As of January 1, 1994, all price controls on pharmaceuticals have been removed. Because prices at the retail level are now subject to market forces, they have become much higher than in the past. Further, lacking capital for investment (in 1996 government investment in the industry amounted to just $5.03 \%$ of its 1992 level (Bachman 1998), Russian manufacturers have failed to compete with Western competitors on many parameters, including range and quality of drugs. More expensive, aggressively advertised Western imports captured 70\% of the Russian pharmaceutical market in 1996. However, while availability of drugs has improved, their affordability has become a major concern.

The Government dismantled its centralized procedures for purchasing pharmaceuticals, devolving power to regional and local authorities. As a result of the escalating economic crisis, regional governments lacked resources to make sufficient allocations for health and drugs, and could not get funding commitments from the national level. 
They have developed their own procurement practices - mostly handing over responsibility to hospitals, physicians and even patients (The Economist 1999).

Deteriorating health status increased demand for pharmaceuticals, and in 1997 medicine consumption in The Russian Federation surpassed pre-transition level by $70 \%$ (Bachman 1998). The percentage of drugs sold without prescription in the Russian Federation has more than doubled from 1993 to 1996 and reached over 40\%, far higher then in other east European markets. In 1998, the Government was paying for only onefifth of drugs consumed in the Russian Federation out of Federal and regional budgets and insurance funds. The rest was paid by patients out-of-pocket (Table 12). Studies have shown that drug costs have become the largest share of personal expenditures on health. The financial crisis of 1998 left as much as $50 \%$ of Russians bellow subsistence level, and, therefore, undermined their access to necessary drugs.

Presently, the Ministry of Economics (MOE) is in charge of regulating the pharmaceutical manufacturers, of which around 30 are state entities and around 40 are joint stock companies (most of these are independent producers) (UNICEF 1999). The financial crisis of 1998 actually helped Russian pharmaceutical producers by making prices on imported drugs prohibitively high. It is estimated that the Russian pharmaceutical industry now has $50 \%$ of the market share. This share is likely to increase, as many stimuli favor the Russian pharmaceutical industry, i.e. high taxation on imported products while domestic production is subject to tax breaks and exemption from profit taxes. The Government also considers the domestic pharmaceutical production important in solving budgetary and drug affordability problems through low pricing. But the quality of Russian drugs remains an issue.

Table 12. Expenditures on health and drugs

\begin{tabular}{|c|c|c|c|c|c|c|c|c|}
\hline \multicolumn{9}{|c|}{ 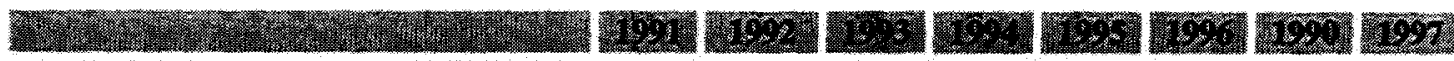 } \\
\hline Total Health expenditures ( $\%$ GDP) & 2.6 & 2.5 & 3.2 & 5.2 & 4.5 & 5.8 & 2.3 & 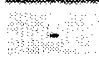 \\
\hline 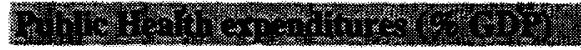 & & 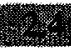 & & 4 & 4 & & 9 & 6 \\
\hline Private Health expenditures ( $\%$ GDP) & 0.2 & 0.1 & 0.2 & 0.7 & 12 & 1.6 & 0.0 & - \\
\hline 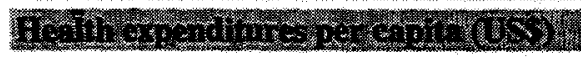 & & & & 2 & & & 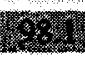 & 826 \\
\hline $\begin{array}{l}\text { Public expenditures on drugs per } \\
\text { capita (US\$) }\end{array}$ & 0.5 & 0.4 & 3.3 & 13.7 & 8.6 & - & 10.2 & - \\
\hline 1819. & & & & & & & & \\
\hline
\end{tabular}

Source: The World Bank, ECSHD 2000.

Sources of TB drug financing. Generally, around $90 \%$ of public funds for pharmaceutical products derive from regional health care budgets and insurance funds, while less than $10 \%$ of funds derive from the federal budget. The situation is worse for TB drugs, as no TB drug funding is available from insurance funds. Up until 1999, there was no federal budget for procurement of TB drugs either. In 1999 some federal funds for the purchase of TB drugs have been made available, mainly for the treatment of TB patients in prisons. 
TB drug procurement. Federal legislation specifies procurement procedures for all pharmaceutical products (including TB drugs) purchased with government funds. However, in practice, since the majority of drug procurement today is done at the regional level, and the role of Federal-level funding for drug procurement is very small, regions do not strictly follow the federal instructions. There is significant variation in procurement practices and prices in different regions. With the relatively small size of many territories, over-decentralization has also led to the loss of the possibility for maximizing economies of scale in drug procurement.

TB drug availability. All first-line tuberculosis drugs are produced in The Russian Federation but several of the second-line drugs are imported. In all, the MOH estimates that 15 domestic manufacturers have marketing authorizations for relevant TB drugs. Fixed dose combination (FDC) TB drugs are presently not produced in Russia; however, a number of products are registered and joint venture production of these drugs is possible (UNICEF 1999).

There are several manufacturers of first-line TB drugs in the Russian Federation. The major Russian producers of TB drugs are: Akrikhin (most of the single TB drug tablet formulations); Kraspharma JSC (streptomycin and kanamycin); Moscow Pharmaceutical Factory (parenteral formulations); and Brinzalov, former Ferein JSC (several single TB drug tablet formulations). In addition, Biopreparat Center; Medbiotechprom; Russian Cardiological; Moshimpharmpreparaty SE; and Sintez JSC (Kurgan) are producing TB drugs (Bachman 1998).

TB drug quality. The production standard of the Russian pharmaceutical industry has generally not been in compliance with Good Manufacturing Practice (GMP). Only in 1996 were GMP principles officially recognized, and a Russian GMP standard was issued (UNICEF 1999). The Russian GMP is scheduled for full implementation by 2005. However, all new production facilities will have to comply with the Russian GMP in order to be licensed.

Access to and affordability of TB drugs. Formally, necessary inpatient pharmaceuticals, to the extent they are available, are to be provided to patients free of charge. Since TB treatment has been largely provided in hospital settings, this should also apply to TB drugs. However, because of insufficient financing from government budgets and inefficient pharmaceutical management at medical facilities, hospitals were often lacking even the most essential drugs. As a result, in reality, patients have been denied the drug benefits to which they are entitled by law, and have had to purchase drugs out-of-pocket. In the case of TB patients, among whom there are many poor, unemployed and ex-prisoners, access to TB drugs is particularly affected.

\section{Performance of the National TB Control Program}

Officially, all Russian citizens are believed to have universal access to health care, and, consequently, are covered by regional TB control programs. The majority of the population is covered by such programs, which, as described earlier, are based on regular X-ray screening of the entire population of adults and teens (once in a 1-2 year 
period), annual tuberculin skin testing for children at primary health care facilities, as well as diagnosis, treatment, and follow up provided at specialized TB facilities.

Table 13. TB control coverage (1998)

\begin{tabular}{|c|c|c|c|c|}
\hline & & $\begin{array}{l}\text { Population covered } \\
\text { with DOTS }\end{array}$ & $\begin{array}{l}\text { Population covered } \\
\text { with non -DOTS }\end{array}$ & $\begin{array}{c}\text { No coverage/No } \\
\text { report }\end{array}$ \\
\hline 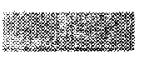 & 120 & 110 & II & No: \\
\hline Russia & $147,433,600$ & $7,371,680$ & $138,587,584$ & 0 \\
\hline DUR & 870,163084 & 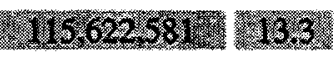 & 655,825.915. & $58715,68.67$ \\
\hline $\begin{array}{l}\text { Global } \\
\text { Source: } \mathrm{W}\end{array}$ & $\begin{array}{l}5,898,346,509 \\
\text { HO } 2000 .\end{array}$ & $2,510,378,390$ & $3,279,313,797$ & $108,654,322$ \\
\hline
\end{tabular}

In contrast, coverage by DOTS, the WHO TB control strategy (Box 1), remains very low (5 percent) compared with globally and in the WHO European region (Table 13) (WHO 2000). In 1998, the infectious (ss+) case detection rate in the Russian Federation was lower than the WHO target of 70 percent. However, it was insignificantly better than in WHO Europe (60.3 and 56.5 percent, respectively), and considerably better than globally (60.3 and 40.0 percent, respectively) (Table 14). In addition, in 1998 the notification rate of new ss+ cases in the Russian Federation(in both DOTS and nonDOTS areas) remained significantly lower than the WHO target of 55-70 percent (Table 15).

Table 14. Case detection (1998)
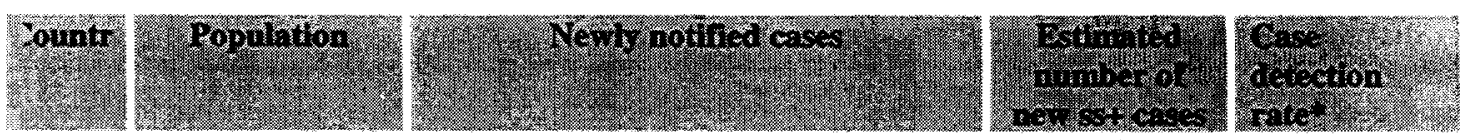

All types sst.

$\%$

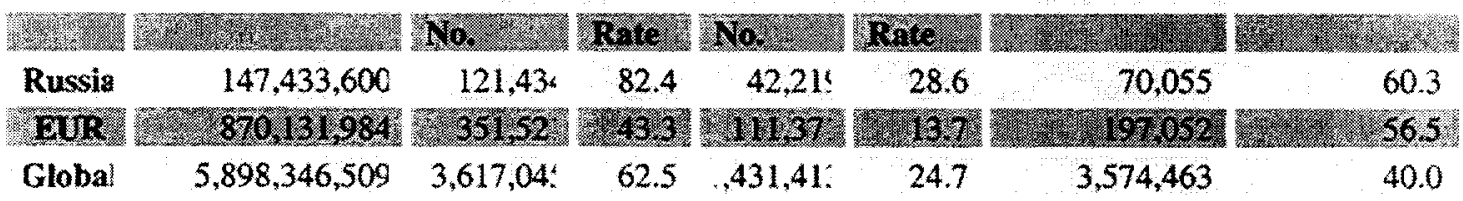

* case detection rate is the proportion of the number of newly notified ss+ TB cases to the estimated number of new ss+ cases.

Source: Who 2000

Table 15. Case notification (1998)

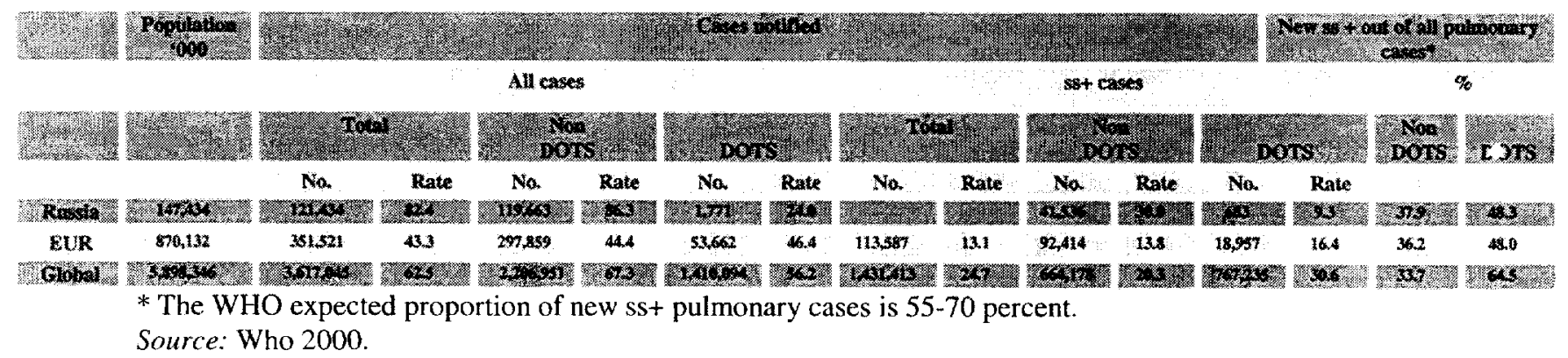




\section{Box 1. WHO TB Control Strategy (DOTS)}

Microscopy . Case detection among symptomatic patients self-reporting to health services, utilizing sputum smear microscopy. In countries which can afford sputum culture, culture could be utilized for diagnosis, but direct sputum smear microscopy should still be performed for all suspected cases.

SSC/DOT. Administration of standardized short-course chemotherapy to at least all confirmed sputum smear-positive cases under proper case management conditions (Directly Observed Therapy - DOT - during at least the intensive phase of treatment). In industrialized countries achieving high treatment success rates, Directly Observed Therapy may be reserved for a subset of patients, as long as cohort analysis of treatment results is provided to document the outcome of all cases.

Drug Supply. Establishment of a system of regular drug supply of all essential anti-TB drugs to ensure no interruption in their availability.

Recording and Reporting. Establishment and maintenance of a standardized recording and reporting system, allowing assessment of treatment results.

Source: WHO 1999.

Overall, the success of TB treatment in the Russian Federation did not differ significantly from the WHO Europe indicator (56.7 and 57.0 percent, respectively). However, a comparison of the treatment outcomes revealed considerably greater proportion of those who defaulted and failed in the Russian Federation than in the WHO European region (17.4 and 13.1 versus 9.8 and 11.7, respectively) (Table 16).

\section{Table 16. Treatment outcomes of non-DOTS TB Control Strategy areas in the Russian Federation and WHO European Region}

\begin{tabular}{|c|c|c|c|c|c|c|}
\hline \multirow[b]{2}{*}{ Cacestans: } & \multicolumn{2}{|c|}{$\begin{array}{c}\text { New sst } \\
\text { (Short course) }\end{array}$} & \multicolumn{2}{|c|}{$\begin{array}{c}\text { New sst } \\
\text { (Short course) }\end{array}$} & \multicolumn{2}{|c|}{$\begin{array}{c}\text { New sst } \\
\text { (Short course) }\end{array}$} \\
\hline & Bunco: & 2310 & Gaxin & Thon & Iusciar & Bures \\
\hline No. of registered for treatment & $\because$ & 28,702 & 42,251 & 88,093 & 41,434 & 7,329 \\
\hline 96 not evaluated & 87 & 1140. & & 64 & (3) & 85 \\
\hline$\%$ cured & - & 59.5 & 56.7 & 54.9 & - & 62.5 \\
\hline romphro & & Wh & & 21 & & 10.1 \\
\hline$\%$ defaulted & - & 3.8 & 17.4 & 9.8 & - & 5.3 \\
\hline 86 aned & & 20 & 131. & 117 & 秘 & 62 \\
\hline$\%$ dead & - & 5.8 & 9.3 & 11.3 & - & 3.9 \\
\hline Whansterted & S. & 22 & 183.5. & 36) & (1) & 15 \\
\hline $\begin{array}{l}\% \text { Treatment success }=\% \\
\text { cured }+\% \text { completed treatment } \\
* \text { No treatment results were provid } \\
* * \text { Including only those WHO/EU }\end{array}$ & 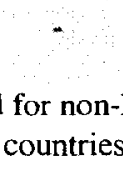 & 66.8 & 56.7 & 57.0 & - & 72.7 \\
\hline
\end{tabular}




\section{Performance of WHO TB Control Strategy (DOTS)}

The Russian Federation made little progress nationwide between 1995 and 1998 on the implementation of DOTS. Although population coverage with DOTS increased twofold between 1997 and 1998, it remains low (5 percent), as does smear positive case detection ( 1 percent) (Tables 17 and 18), because DOTS is restricted to just a few oblasts (Map 1).

\section{Table 17. Progress in DOTS implementation}

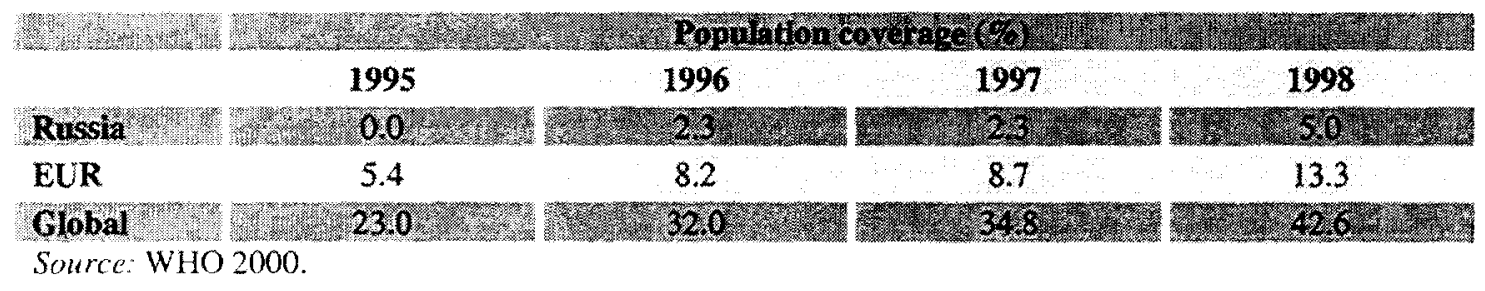

Table 18. Change in Case Detection Rates

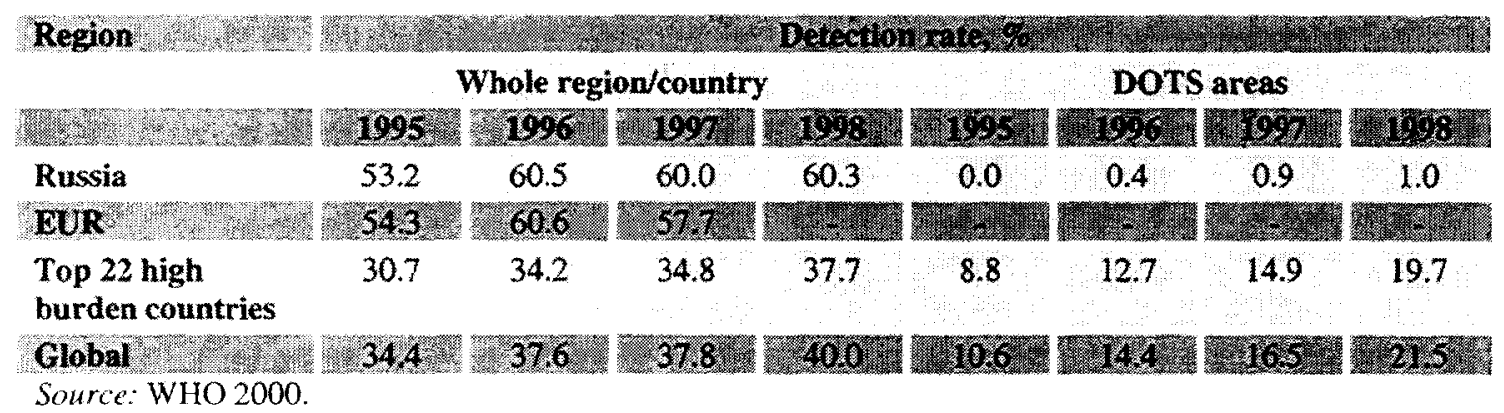

Treatment success was low in the 1997 cohort: 67.5 percent versus 82 percent in 22 high burden countries and 78 percent globally (Table 11 ). This success rate is 17.5 percent less than the WHO target of 85 percent (14.5 percent less than in 22 high burden countries and 10.5 percent less than globally). As in the 1995 and 1996 cohorts, low treatment success was due to high death ( 9.7 percent), failure ( 7.9 percent) and default $(8.2$ percent) rates. The same was true for patients on re-treatment regimens (WHO 2000). 
Table 19. Treatment outcomes of the WHO TB control strategy (DOTS) in the Russian Federation and the WHO European Region

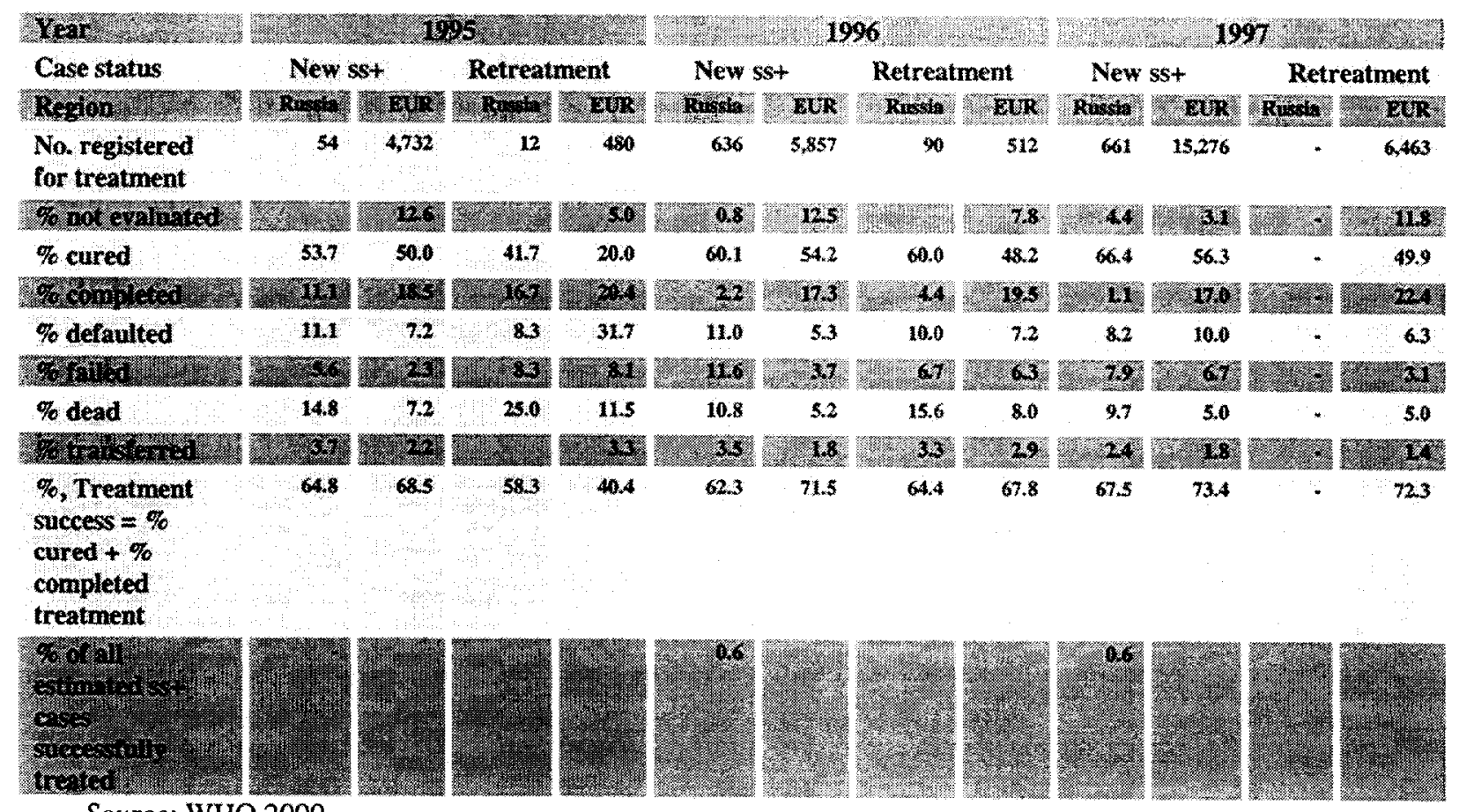

Source: WHO 2000.

Table 20. Number of Individuals with TB in DOTS areas

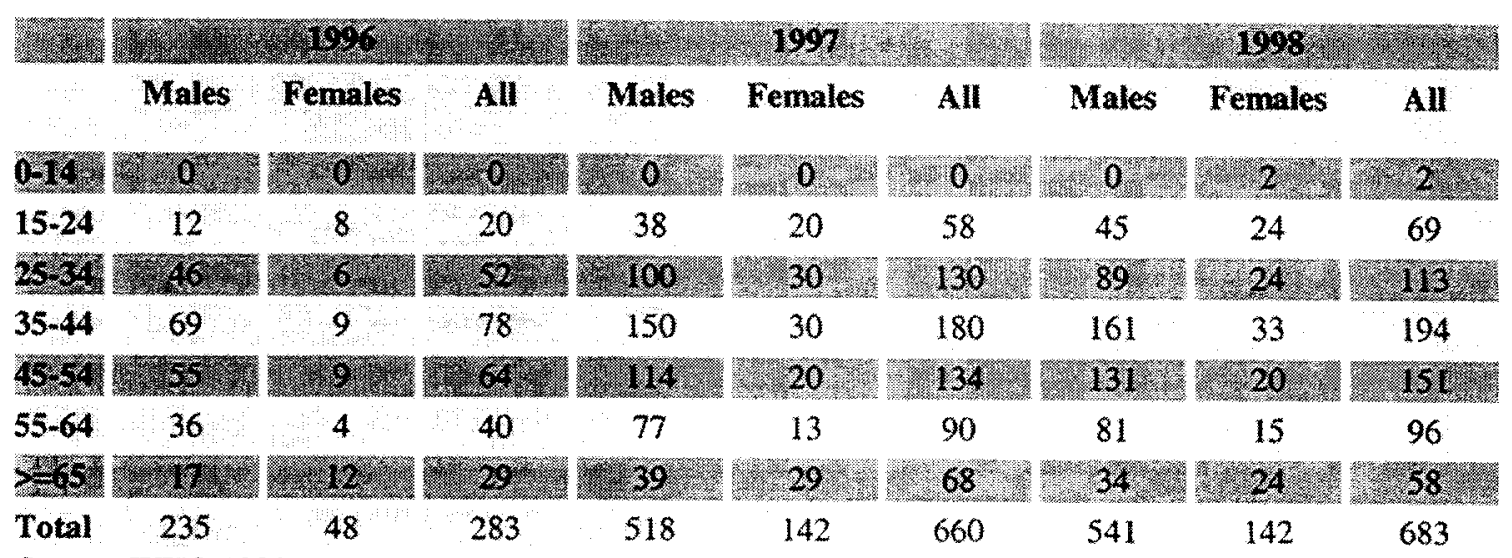

Source: WHO 1999.

A change in TB incidence rate, and, hence, in the notification rate, may be hard to measure because it is expected to fall slowly, at no more than 10 percent per year. However, good TB control programs can eliminate much illness (i.e., reduce prevalence) and many deaths (WHO 2000). This is demonstrated by the high cure rates and low death rates reported by many successful DOTS programs (such as those in Peru and China). This suggests that the prevalence of TB has also been markedly reduced, and that many drug-resistant cases have been prevented.

Analysis of TB surveillance data in the Russian Federation revealed insignificant treatment outcomes of the WHO TB Control Strategy (DOTS) from 1995-1997. Further 


\section{The HIV/AIIDS Epidemic}

The HIV/AIDS epidemic skyrocketed in the Russian Federation in 1999. During 1999, 18,118 new cases were reported (4.6 times the number reported in 1998), exhibiting the steepest growth of HIV infection in the world. For the first four and a half months of 2000 , the number of newly reported HIV/AIDS cases was 11,932; if this trend continues, over 61,000 new cases will be reported by the end of the year (Figure 7, Box 2).

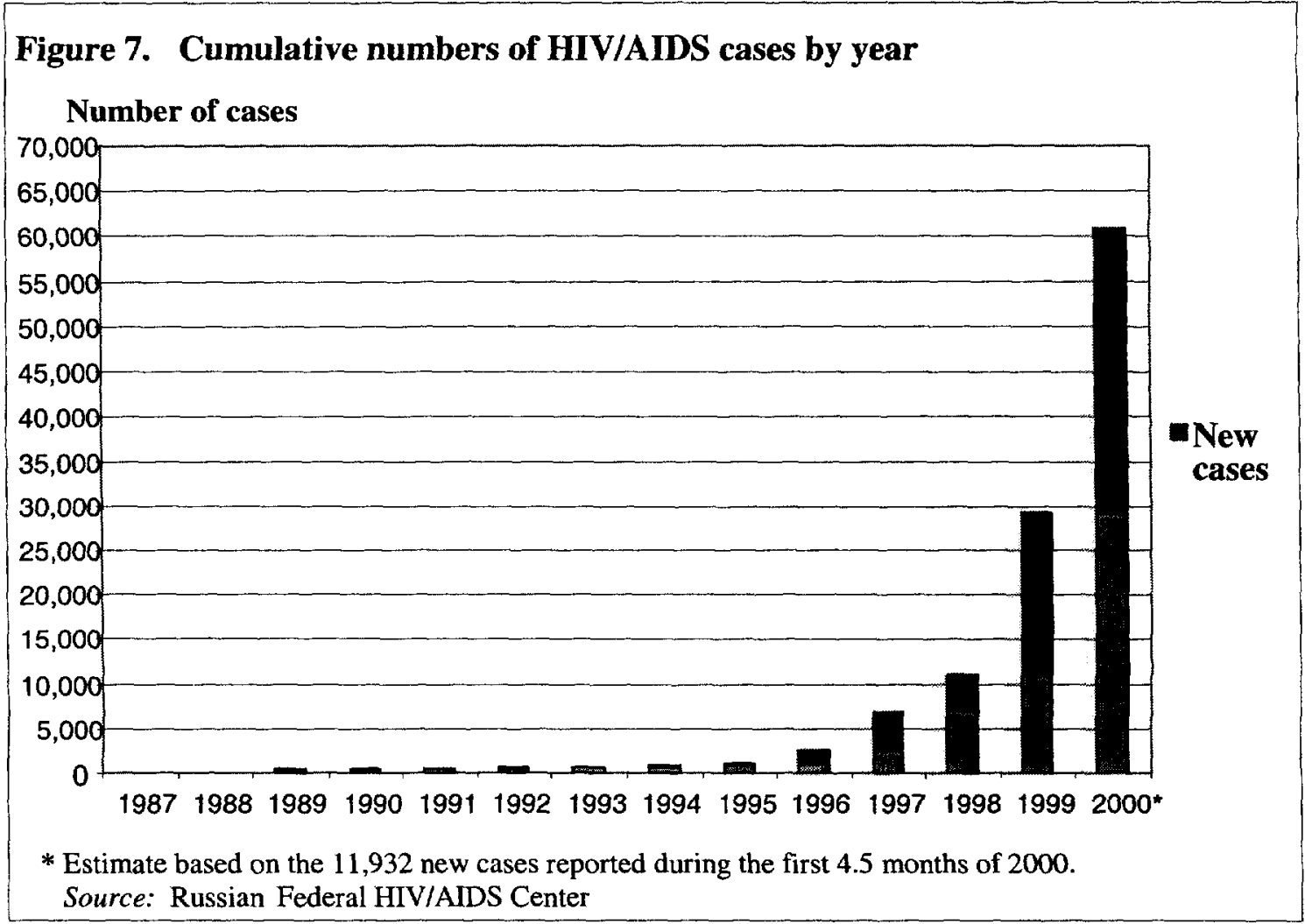

On May 2000, the Ministry of Health reported that the number of citizens with HIV totaled 41,122. In 1997, based on many parameters (including the rates of STIs), UNAIDS estimated that the true number of HIV infected people living in the Russian Federation was about 41,000 (UNAIDS/WHO 1998), compared to official estimates of about 7,000. However, since 1998 improvement in the effectiveness of HIV testing in The Russian Federation occurred as a result of better targeting of the most at-risk groups, namely intravenous drug users (IDUs) and their contacts. The latest UNAIDS estimates indicate that HIV infection rates in the Russian Federation may be threefold of the officially reported rates (UNAIDS 2000).

The prevalence of HIV in the Russian Federation is still low by international comparison (Figure 8), but the number of infections is escalating exponentially. The epidemic is expanding rapidly, given approximately 11,000 cases by $1998,26,000$ by 1999 , and 
36,000 by April 2000. Therefore, as experience of other countries suggests (Ainsworth, Over 1997), if HIV becomes much more prevalent in the Russian Federation, the current increase in TB and in drug resistance could become explosively worse.

From 1998 through 2000, at least 90 percent of newly registered HIV infection cases have been attributed to intravenous drug use (UNAIDS 1999). Reports indicate that the percentage of new cases attributed to heterosexual contacts is increasing, suggesting that the epidemic is leaking into the general population. The average age of individuals infected with HIV in the Russian Federation is $18-25$ years old (Pokrovsky et al 2000). In 1999, nine cases of HIV infection were registered in individuals between 11 and 14 years old. Since 1987, 288 people have been officially registered as having died of AIDS. However, over half of all deaths among HIV-positive individuals occur before developing AIDS as a result of suicide, drug overdose, and other reasons not directly related to AIDS.

Figure 8. HIV prevalence in selected countries (1999)

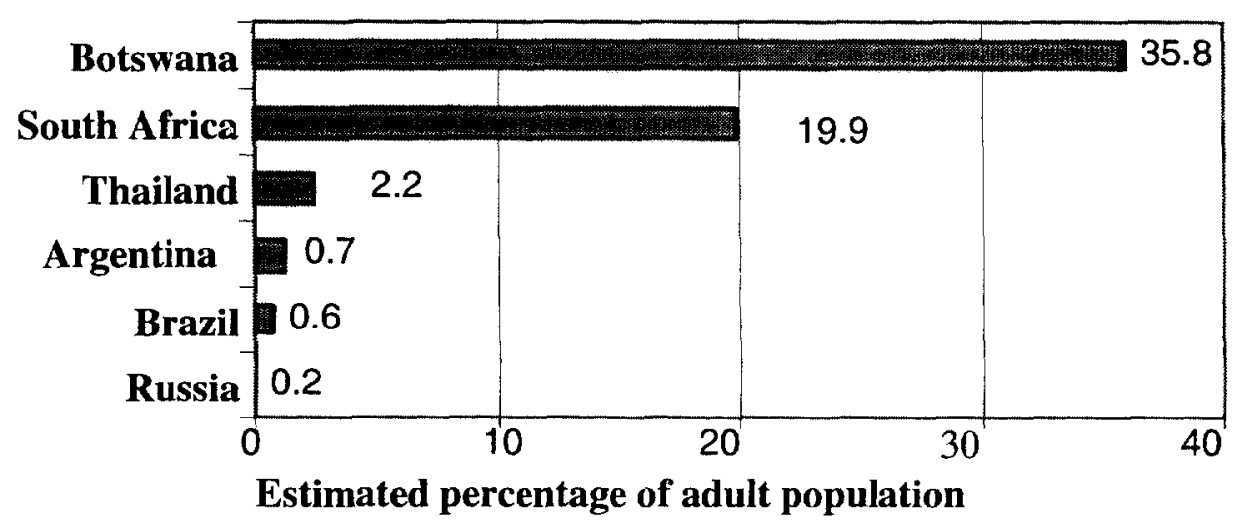

Source: UNAIDS 2000

The first HIV/AIDS case in the Russian Federation was diagnosed in 1986 in Moscow (UNAIDS 1999). That case involved a Russian returning from abroad who later infected 15 others through homosexual contact. During the eight subsequent years the epidemic progressed very slowly - approximately 1,072 HIV/AIDS patients had been registered by the end of 1995 (table 21).

Table 21. HIV/AIDS incidence and prevalence

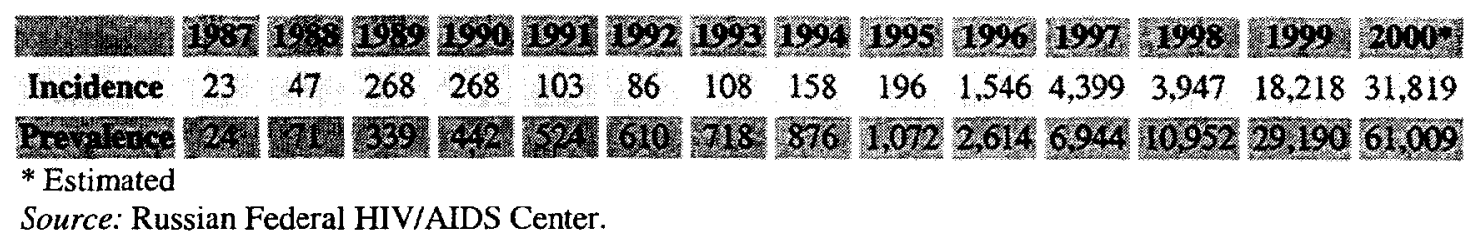


Since 1996 the situation has changed dramatically. The number of new HIV infection cases in 1996 increased eight times compared to 1995, and accounted for 1,546 cases. That number was more than the total of HIV/AIDS cases detected over the prior nine-year period. In 1997, the number of people newly infected with HIV increased four-fold . During 1998, the growth in HIV incidence seemed to slow, remaining virtually the same as in 1997. However, the epidemic growth accelerated again in 1999. The 18,218 new cases of HIV infection reported in 1999 and the 11,932 new cases reported during only four and a half months of the current year suggest a catastrophic escalation of the HIV infection incidence in the Russian Federation (Tables 21, 22).

\section{Box 2. Current state of the HIV/AIDS epidemic (MOH)}

\section{HIV/AIDS prevalent cases: $\mathbf{4 1 , 1 2 2}$}

- Adults : 40,243 (98\% of all HIV + )

- Children: $879(2 \%$ of all HIV + )

- Infants born to HIV+ mothers (vertical transmission): 193 (33\% of all HIV+ infants)**

\section{AIDS prevalent cases : 408 (2.26\% of all HIV + cases)}

- Adults: 281 (69\% of all AIDS cases)

- Children: 127 (31\% of all AIDS cases)

Cumulative number of HIV and AIDS deaths : 577

- Deaths of adults HIV+ or with AIDS: 475 (82\% of all HIV and AIDS deaths)

- Deaths of children HIV+ or with AIDS: 102 (18\% of all HIV and AIDS deaths)

\section{Cumulative number of AIDS deaths: 288}

- Deaths of adults: 201 (70\% of all HIV and AIDS deaths)

- Deaths of children with AIDS: 87 (30\% - of all HIV and AIDS deaths)

**As of October 1, 1999.

Source: The Russian Ministry of Health 2000.

Regional distribution. HIV infection is now present in all oblasts of the Russian Federation. However, the distribution of HIV/AIDS cases throughout the country varies significantly (Maps 1-3): from two cases in Chukotka to 12,932 cases in Moscow City and Oblast combined (first quarter 2000). Over 90 percent of all HTV infection cases are registered in 20 territories with a total population of 70,608 thousand people (50 percent of the Russian population. Over 80 percent of all HIV infection cases are in ten regions, and over 50 percent of cases are just in the first three (Table 23). 
Table 22. UNAIDS Estimates of HIV infection in The Russian Federation (1999)

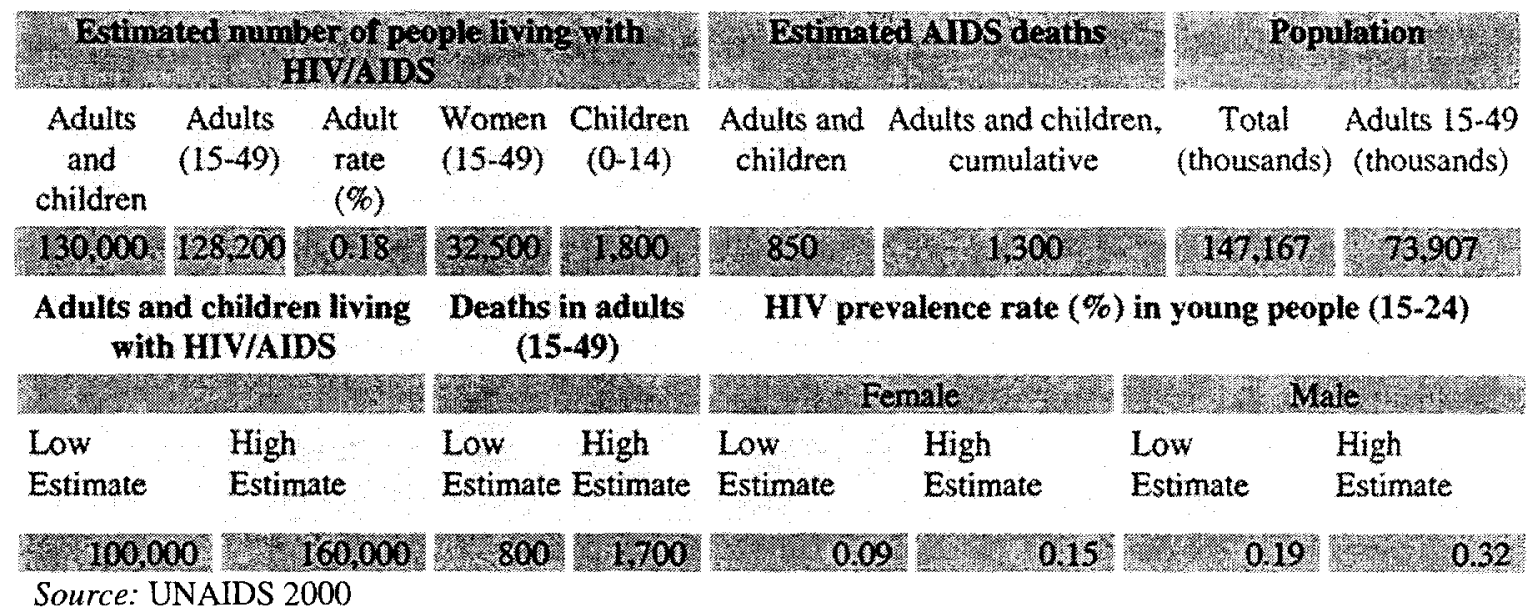

Table 23. HIV/AIDS High burden regions (March 2000)

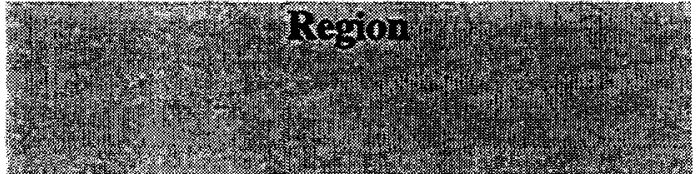

Russia

Moscow and Moscowoblast

Irkutsk Oblast

1. Kaningrad Oblast

Tyumen Oblast

- Including Thanty - Mansisly okng

Krasnodar

Rostov Oblast:

Tver Oblast

Samatov Oblast

St. Petersburg and Leningrad Oblast

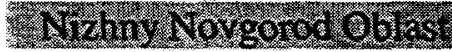

Chelyabinsk Oblast

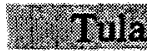

Ryazan Oblast

Perm oblast :

Sverdlovsk

Tatarstan Republic

Kaluga Oblast

Prinorslgy Krat (Mladiostol)

Kemerovo

The 20 mW/ IDS high wra en, regions

Source: Russian Federal HIV/AIDS Center 2000
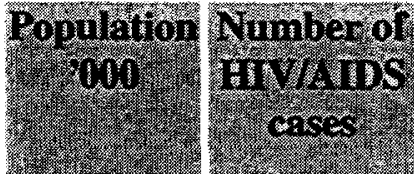

147,105

$$
38,427
$$
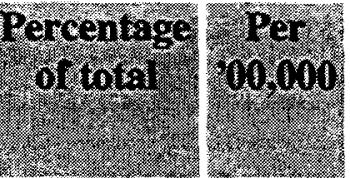

\section{5,193}

2,774

12,932

4,496

100.0

26.1

943

2,742

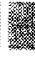

3,211

2,591

712008

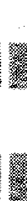

1358

1128

$\begin{array}{ll}6.7 & 80.7\end{array}$

5,075

2,406

$6.3 \quad 47.4$

4.404 1,711

4.530 .98

1,633

1,633

$4.2 \quad 100.0$

$2,724 \times 1.111$

$2.9=40.8$

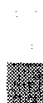

6,431

938

$2.4 \quad 14.6$

3.697 1 719

1990.4

$3,681 \quad 710$

$\begin{array}{ll}1.8 & 19.3\end{array}$

1.786

507

1.3128 .4

1,307

492

$1.3 \quad 37.6$

2,986

4,656

488

13.163

1.2034

424

1.19 .1

419

1.161111

(t)

1,094

289

$0.8 \quad 26.4$

2,216

27

$0.7 \% 12.2$

3,023

252

0.7

8.3

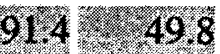

70,608

35,131

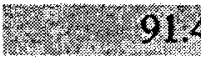


From the beginning of HIV/AIDS surveillance in the Russian Federation, the Moscow region (the City and Oblast) has carried the highest burden of HIV/AIDS in the country: 12,932 prevalent HIV/AIDS cases (85.1 per 100,000), as of March 2000. This region has only 10 percent of the population but over one third of all HIV/AIDS cases; in 1999, 70 percent of all the new cases were registered here.

However, the prevalence of HIV infection per 100,000 population is the highest in Kaliningrad (291 per 100,000), as well such urbanized centers as Irkutsk and Tver (162 and 100 per 100,000, respectively). Earlier this year, an outbreak of HIV infection was reported among intravenous drug users (IDUs) in the city of Toliyatti (Samara Oblast): about 900 young people became infected in this city, which has a population of 700,000 .

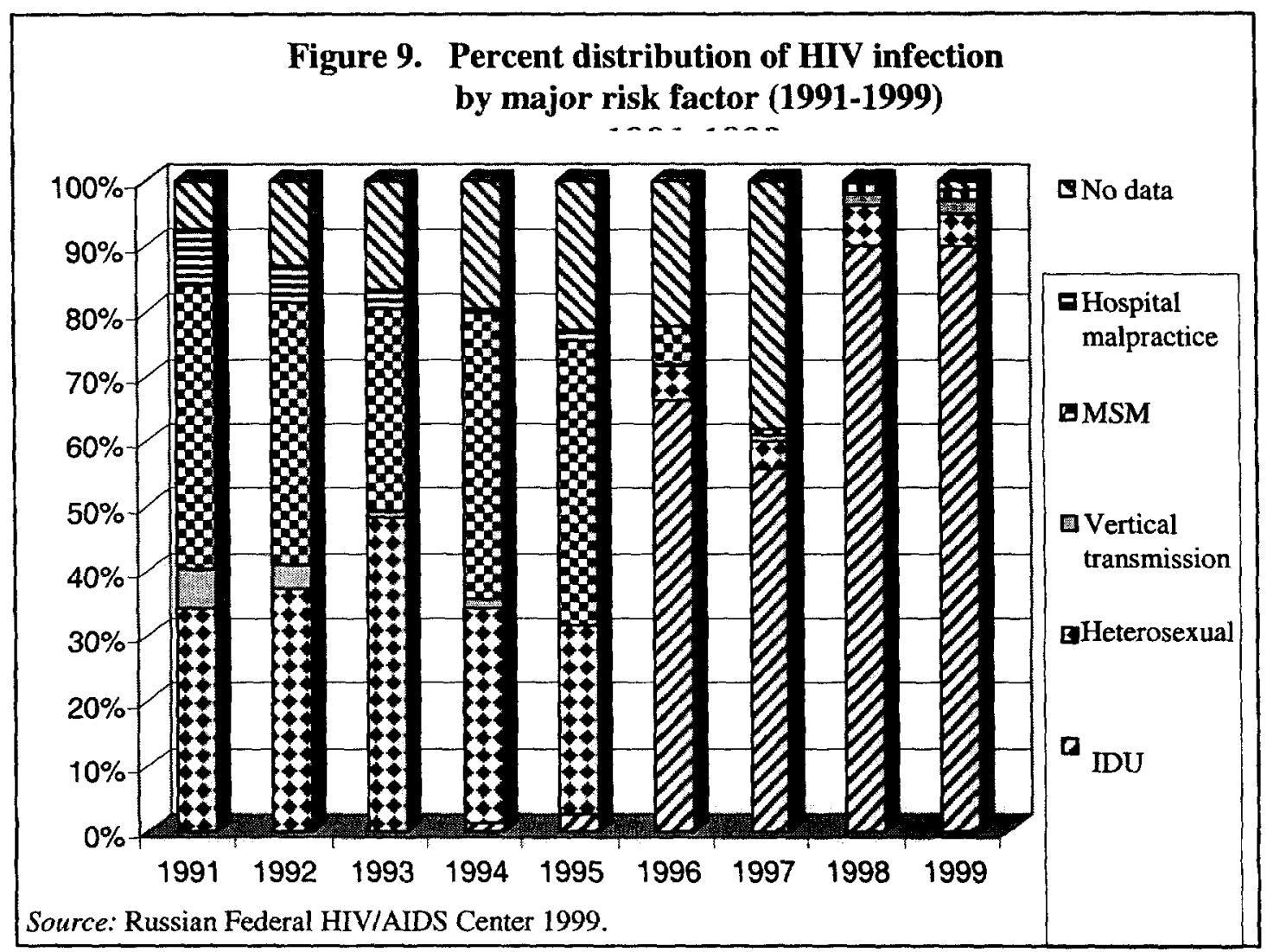

Modes of transmission. Early in the epidemic, the majority of cases involved either homosexual or heterosexual transmission (Pokrovsky et al 2000). One exception occurred in 1989 and 1990, when 246 children became infected through improperly sterilized needles in hospitals. Since then, blood transfusions have not been a major mode of HIV transmission, causing about one case per year. From 1991 to 1995 , the annual proportion of new HIV positive cases attributed to homosexual and heterosexual contacts averaged 80 percent. The frequently reported risk factor was having unprotected sex with foreigners, mostly male students from African countries (Rakhmanova et al. 1999). 
A new trend emerged in 1996 when the IDUs became widely involved in the epidemic (Kalfin, Nozhkina 2000 to appear). The annual proportion of new HIV cases attributed to the exposure category labeled as MSM (men who have sex with men) declined sharply from 43.9 percent in 1994 to 5.7 percent in 1996, and further to 1.7 percent in 1998. At the same time, the proportion of cases attributed to intravenous drug use drastically increased during the same period, from virtually 0 percent in 1993 to 66.1 percent in 1996. Since 1996, IDUs have been disproportionately prevalent among new HIV cases. On June 1, 1999, IDUs accounted for 6,444 cases: almost 47 percent of all registered HIV infected individuals and 90 percent of the cases with confirmed modes of transmission. In fact, the epidemiological data clearly indicate that the current HIV epidemic in the Russian Federation is driven by infections occurring in the population of IDUs (Figure 9). However, this year the Russian Federal AIDS Center reported that the percentage of people who became infected through sexual contacts has been increasing again (Pokrovsky et al 2000).

HIV infection by citizenship status. The number of HIV infected individuals per 100,000 of those tested remains much higher among foreigners as compared to Russian citizens. Over the period from 1992 to 1998 the number of HIV positive individuals per 100,000 tested increased among both Russian citizens and foreigners (Pokrovsky et al 2000). However, beginning in 1993, the relative risk of HIV infection among foreigners versus Russian citizens has significantly decreased ${ }^{*}$ (Table 24).

Table 24. HIV infection among foreign citizens and Russian citizens

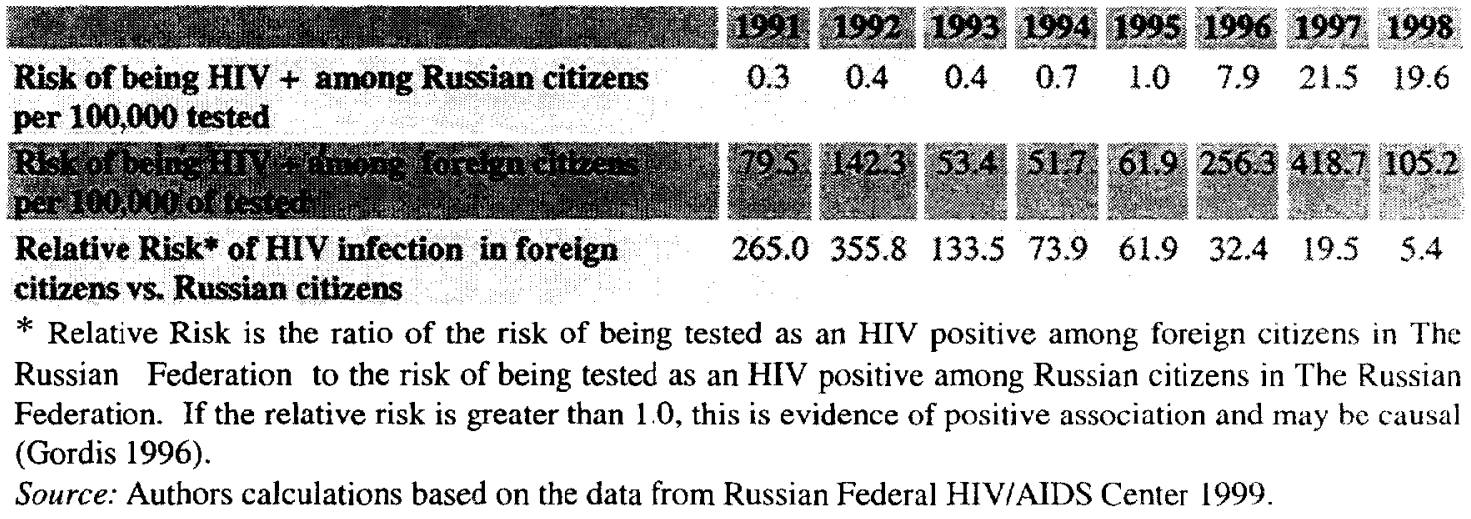

Age and sex distribution. HIV is predominantly present in young people: over 90 percent of all new HIV positive cases in 1998 were individuals 15-39 years old (Figure 10). The distribution of AIDS cases is characterized by a two-phased pattern: 31 percent of all new cases in 1998 were registered in infants $0-5$ years old, while the second highest wave (55 percent) was observed in 20-49 year olds. Overall in 1998, an infant/adult ratio for HIV infection and AIDS was $1: 32$ and 1:3, respectively. These data suggest that infants infected with HIV are likely to develop AIDS in the absence of proper treatment much sooner than adults. Both HIV infection and AIDS are more prevalent in males. The male/female ratio in 1998 was almost the same for HIV infection and AIDS: 3:1. 
Figure 10. Distribution of new HIV infection by age and sex (1998).

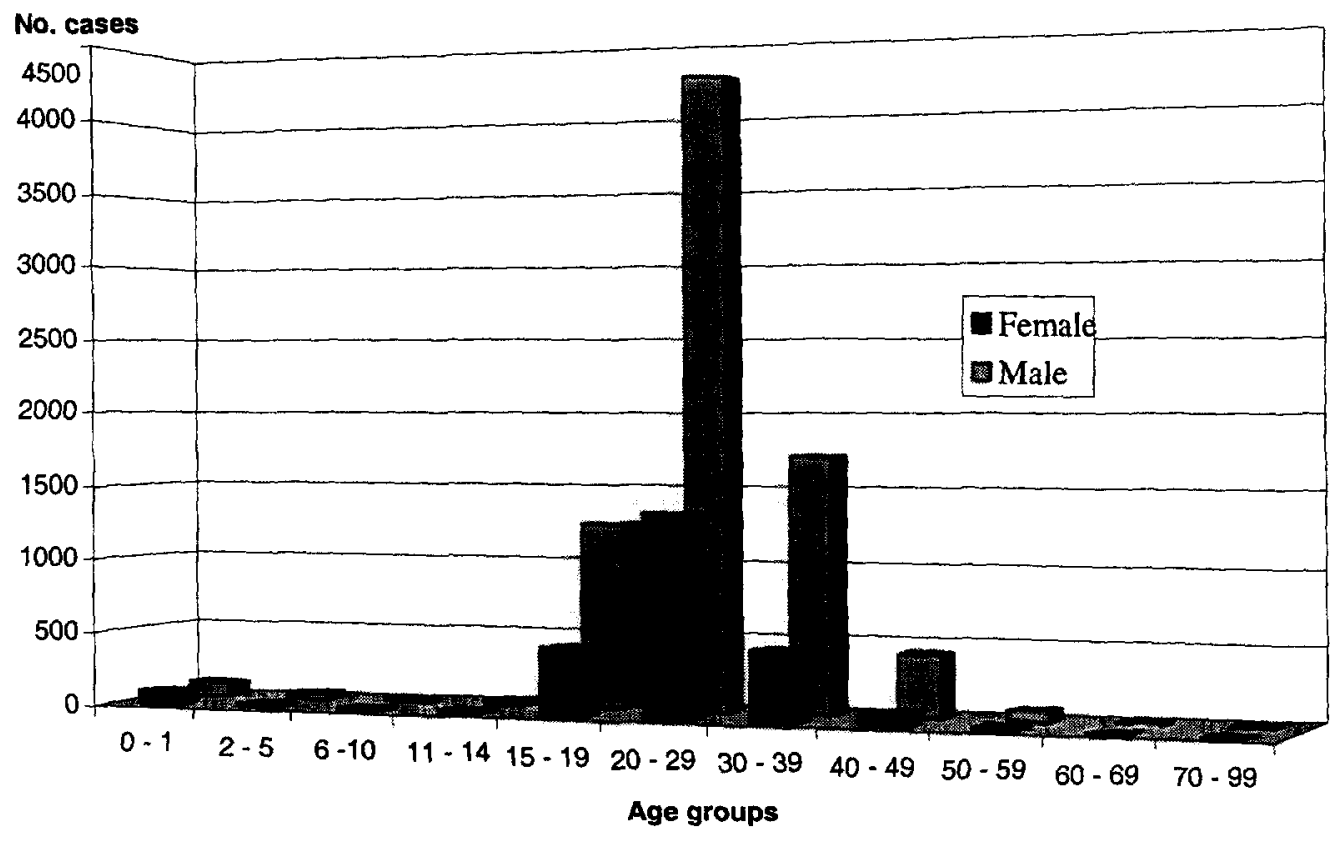

Source: Russian Federal HIV/AIDS Center 1999.

\section{HIV/AIDS in Prisons}

HIV/AIDS in prisons is an increasingly growing problem. According to the data from the Russian Ministry of Justice, the cumulative number of HV infected in the penitentiary system has increased exponentially over five years, from 7 in 1994 to 3,500 in 1999 (Table 25).

Table 25. Number of HIV cases in the Prison System

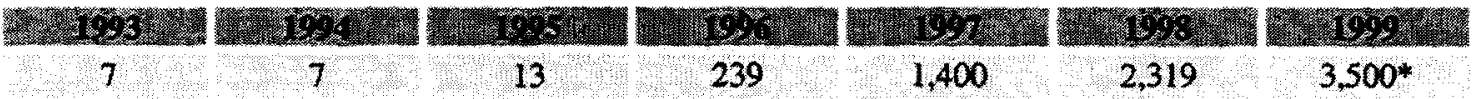

*by August 1999.

Source: Russian Ministry of Justice 1999.

According to the reported data, HIV infection is 26 times more prevalent among prisoners than in the general population. However, officials from the Ministry of Justice (Kononets 2000), report that all HIV infected prisoners had contracted HIV infection before imprisonment and that no one has been infected within the system over the reported period.

The Ministry of Justice reports that the incidence of syphilis is more than 10 times lower in prisons than in the general population (25.68 vs. 234.8 per 100,000) (Table 26). Even if this is true, the rate is still high and comparable with the incidence of syphilis among the 
general population in Western countries such as the USA (20.2 cases per 100,000 in 1996) (USDHHS 2000). Moreover, it suggests that transmission of HIV infection is highly possible in Russian prisons regardless of constrains imposed by the strict regimen and tough living conditions. The gonorrhea incidence in prisons is clearly underreported and suggests that data for other diseases (including HIV/AIDS and syphilis) may be inaccurate.

Table 26. Syphilis and gonorrhea incidence per 100,000 in the prison system

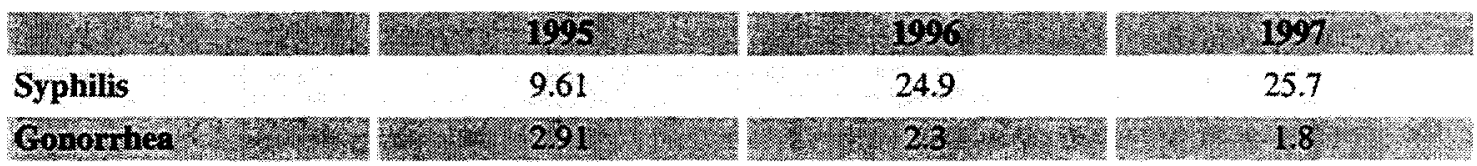

Source: Russian Ministry of Justice 1999.

The current patterns of HIV/AIDS epidemic in the Russian Federation (the exponential incidence increase, the predominance of transmission via intravenous drug use), and increasing proportion of crimes committed by drug users (Tables 27), may lead to a substantial inflow of HIV infected criminals into the penitentiary system in the nearest future .

Table 27. Percentage of crimes associated with drugs

\begin{tabular}{|c|c|c|c|c|c|c|c|}
\hline $19 \%$ & 1891 & 1992 & 1993 & 1994 & 1905 & 1996 & 1997 \\
\hline 0.9 & 0.9 & 1.1 & 19 & 2.8 & 2.9 & 3.7 & 7.8 \\
\hline \multicolumn{8}{|c|}{ ercentage of olenders convicted forctinesossocin ded with drugs } \\
\hline & 1991 & 1992 & 1993 & 1994 & 1995 & 1996 & 1997 \\
\hline 183 & 15 & 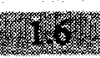 & 5 & 31 & 13.7. & 4.1. & 6.4 \\
\hline
\end{tabular}

Source: Authors calculations based on the data from Goskomstat 1998.

\section{The Role of STIs and Drug Use in the HIV/AIDS Epidemic}

Sexually transmitted diseases. Rates of sexually transmitted infections (STIs) are often used as proxy measures for estimating the true rate of HIV infection in a country and are also often associated with HIV transmission (WHO 1998). In the Russian Federation, the rates of syphilis and gonorrhea have reached epidemic proportions. Since 1990, the incidence of syphilis has increased from 5.4 per 100,000 population to 279.2 per 100,000 in 1996 - an increase of over 5,000 percent (Figure 11). Similar to HIV infection, syphilis rates differ significantly among regions: syphilis rates are especially high in Eastern Siberia (390.2; including Tuva Republic: 1,562.3), the Far East (347.3), and Western Siberia (337.3). However, only 70 percent of syphilis cases are estimated to be officially reported in the Russian Federation (WHO 1998). The real total number of syphilis cases would therefore have exceeded 580,000 in 1997. 


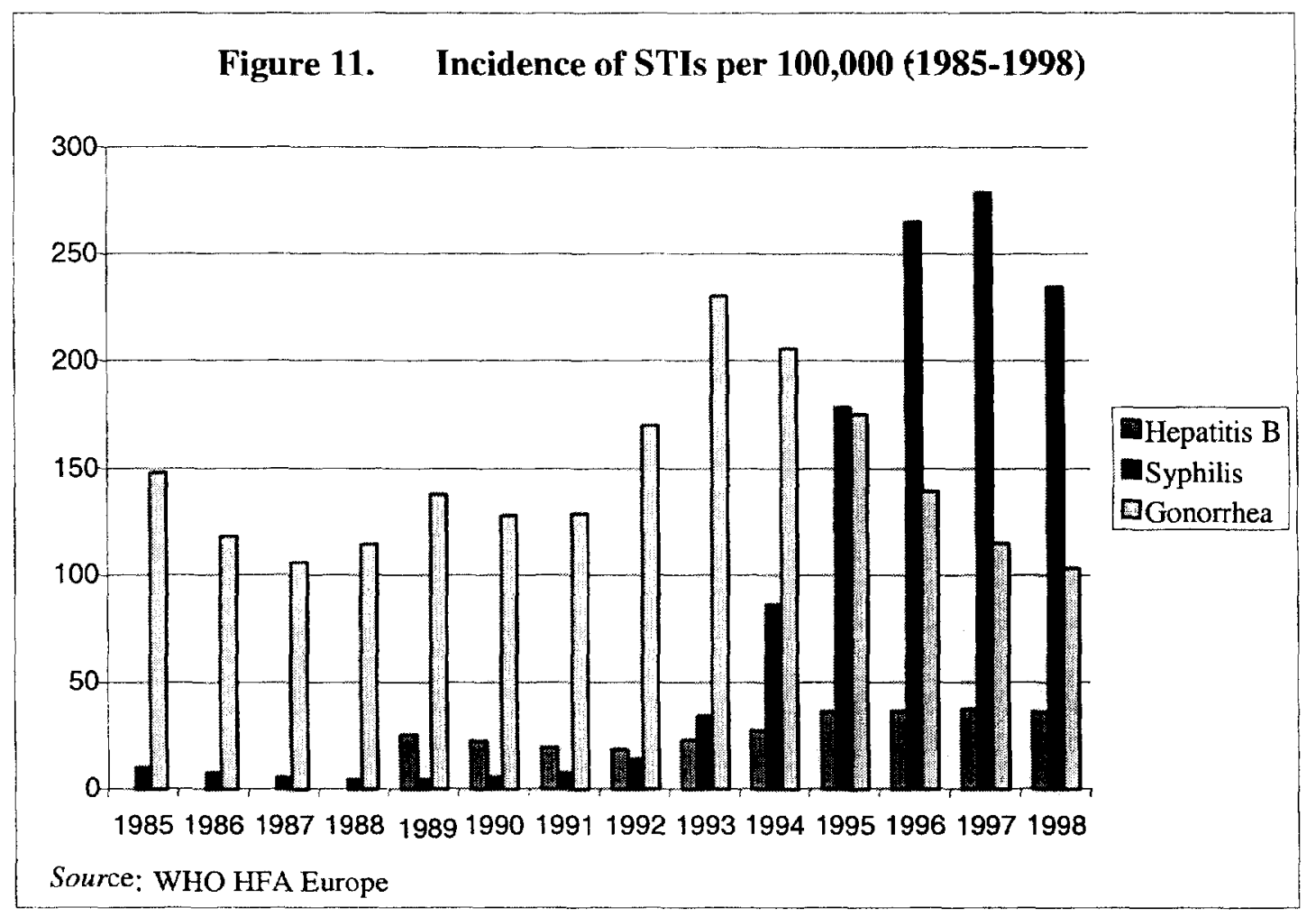

Of special concern is the growing incidence of STIs in younger population groups. The number of syphilis cases among 15-17-year-old girls increased 120-fold between 1985 and 1997. Congenital syphilis is clearly rising as well (Table 28). WHO considers syphilis case reports to be the most reliable indicator of STIs trends in the region (WHO 1998). However, the observed stabilization of the reported syphilis and gonorrhea incidence in the Russian Federation during recent years is unlikely to reflect the true development of the epidemic (Figure 12).

Table 28. Syphilis incidence by age and sex

\begin{tabular}{|c|c|c|c|c|c|c|c|c|c|c|}
\hline Males & 27.3 & 110.0 & 5.9 & 7.9 & 14.3 & 36.3 & 92.7 & 189.1 & 277.6 & 288.3 \\
\hline Femat & 194 & 87 & (g) & 01: & 1246 & 46 & 80.5 & $10 \%$ & 50.8 & 68 \\
\hline Boys, 0-14 years & 0.6 & 0.20 & 0.1 & 0.1 & 0.3 & 0.6 & 1.4 & 3.0 & 6.2 & 8.9 \\
\hline Givls 014 rers & 006 & 6.3 & 0.1 & 02 & 0.4 & 1.12 & 84 & 68 & his & Fit \\
\hline Boys, 15-17 years & 7.8 & 3.1 & 2.7 & 4.6 & 9.0 & 25.2 & 65.3 & 128.3 & 186.1 & 181.4 \\
\hline Girs 15.174): & 132 & 821 & B) & 141 & 315 & 89.4 & 217 & S & & \\
\hline
\end{tabular}
Source: Russian Ministry of Health 1999. 


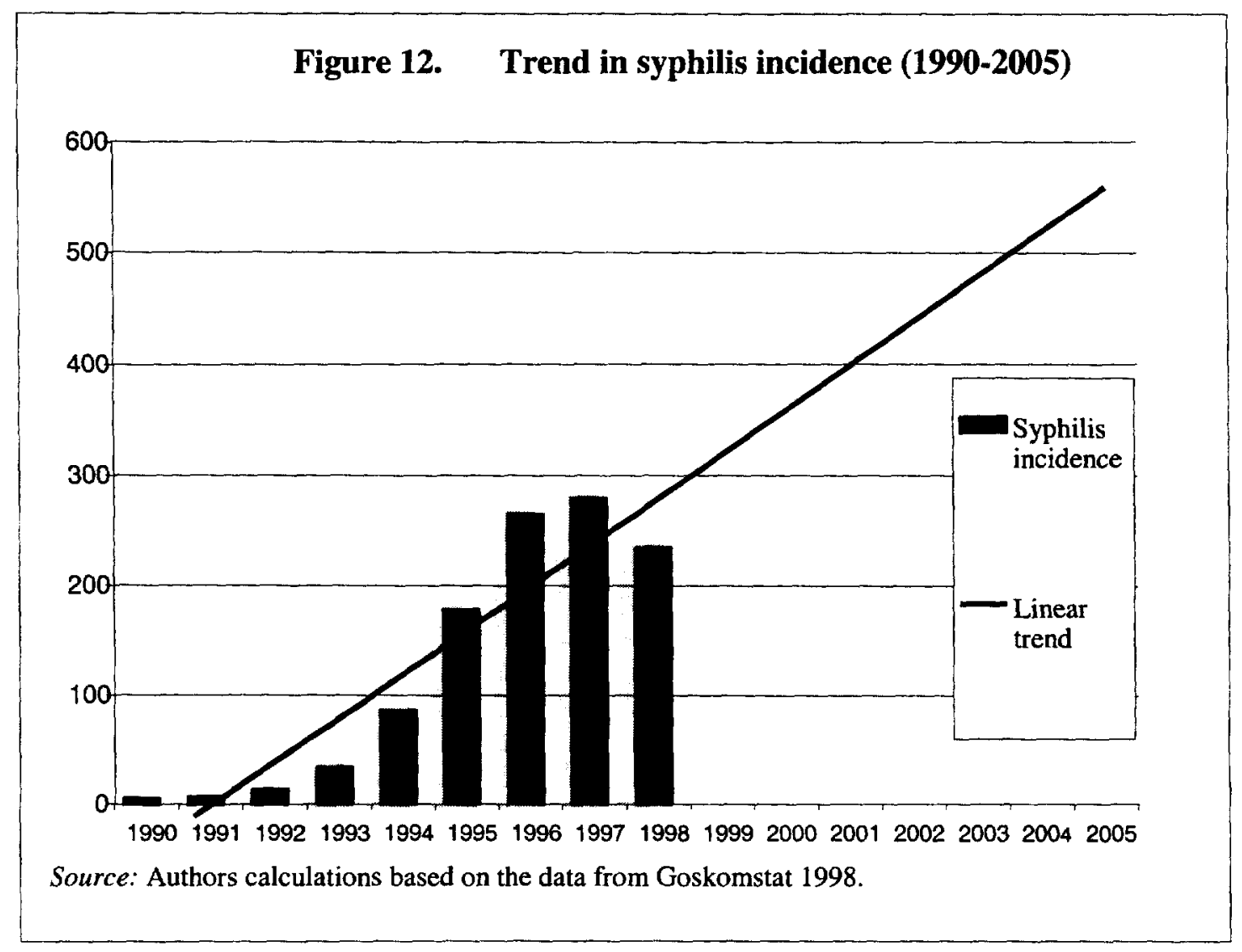

Drug use. Given the recent shift from the homosexual and heterosexual modes of HIV transmission to the transmission of the infection via IDU, the role of IDU has become of paramount significance for the HIV/AIDS epidemic in the Russian Federation (Figure 13).

According to official data (Goskomstat 2000), during the 1970s and 1980s the incidence of drug use in the Russian Federation was more or less stable. The period of democratization during the late 1980s ('perestroika') was marked with a greater than twofold increase in both incidence and prevalence of drug use. The official data also show that the epidemiological situation remained somewhat under control during the early 1990s.

However, beginning in 1993, drug use incidence once again began to grow. From 1993 to 1997, the incidence of drug use increased seven times, at an average annual growth rate of 48.3 percent. Over the same period, the prevalence of drug use more then tripled, at the average annual growth rate of 27.8 percent. That increase is even more significant when compared to the pre-transition period - an increase in incidence of almost fifteen-fold, and an increase in prevalence of almost eight-fold (Table 29). Moreover, during 1996 and 1997, the increase in prevalence overrode the increase in incidence, which allows the conclusion that the control of the drug epidemic was absolutely ineffective as was the care provided to drug users. The number of officially registered drug users is likely to represent only a small portion of the true number of drug users. 


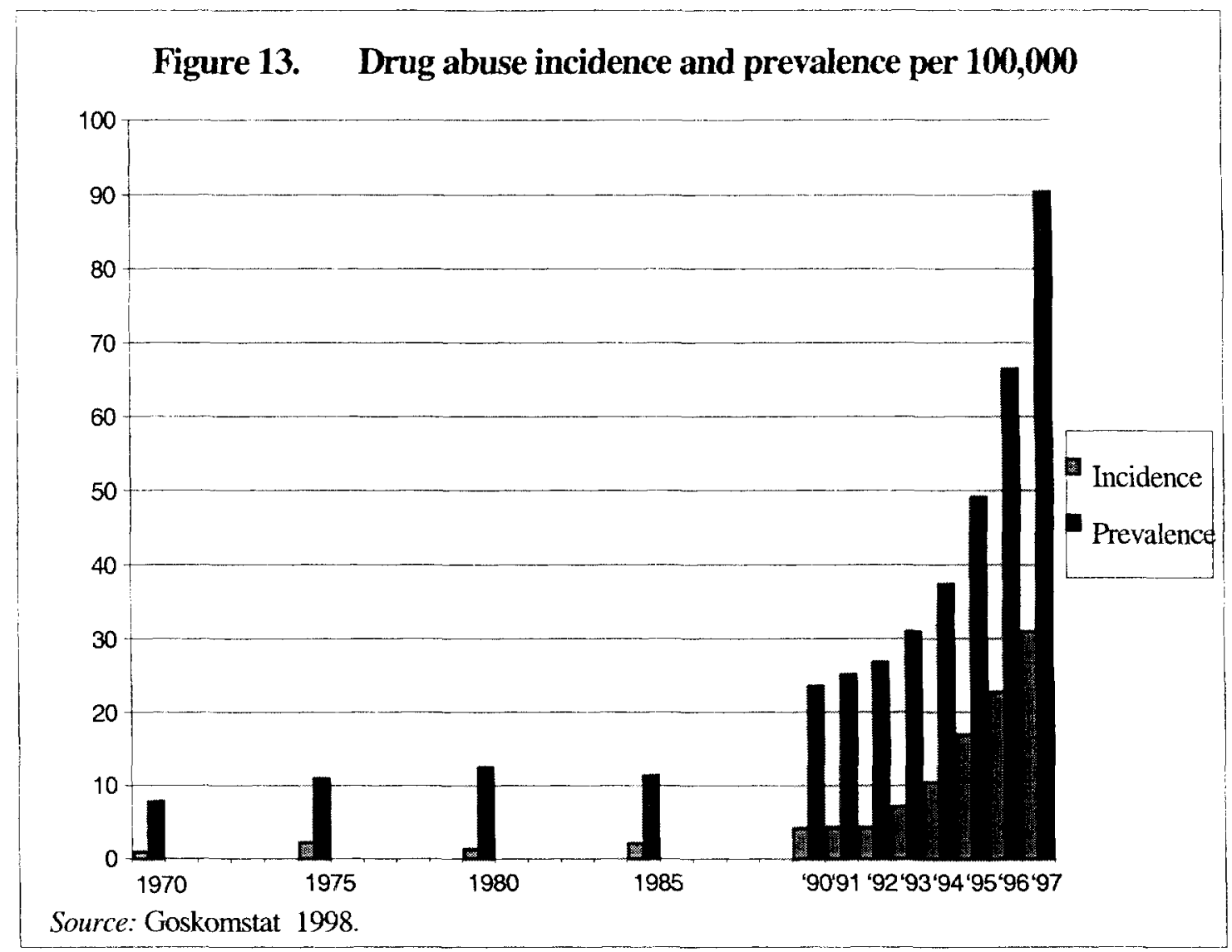

Table 29. Drug use growth rates

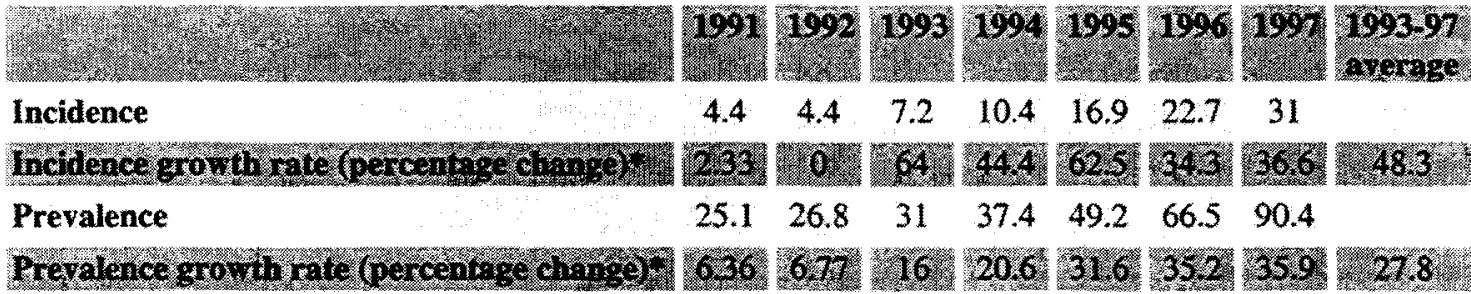

*Authors calculations.

Source: Goskomstat 1998.

\section{HIV/AIDS Management and Control}

In 1993, the Russian Federation developed a national Anti-AIDS Federal Program that was renewed in 1996, with continuation through 2000. The AIDS Program has functioned under the auspices of the Ministry of Health through an extensive vertical system of federal, territorial and regional AIDS centers.

At the national level the system is represented by two federal agencies: the Russian Federal Scientific and Methodological Center for AIDS Prevention, in Moscow, and the Russian Federal Clinical Center on AIDS Prevention, in St. Petersburg. 
The Russian Scientific and Methodological Center for AIDS Prevention handles epidemiological surveillance, diagnostics, clinical treatment, and scientific research issues. This center monitors the epidemic by collecting data from 86 regional and 6 territorial AIDS centers about HIV/AIDS cases, transmission routes, as well as patients' knowledge and attitudes towards the risk factors associated with HIV transmission. Center specialists process the collected data, and distribute information and respective recommendations to the AIDS centers and other concerned bodies.

The Russian Federal Clinical AIDS Center was established to provide treatment to the HIV/AIDS patients from across the Russian Federation. The Center largely functions as a research and clinical center for HIV infected pregnant women and children).

The regional AIDS centers bear responsibility for HIV surveillance, epidemiological investigation of HIV cases, and ensuring the safety of medical interventions, donated blood, medical immune-biological products, biological fluids, organs and tissues. They offer training to health care workers, and initiate and participate in HIV prevention work. Patients are referred to an AIDS center only after testing HIV positive. If the positive result is confirmed, the AIDS center follows up with the patient. The system also includes over 1000 screening laboratories, and over 500 offices for anonymous testing.

HIV/AIDS policies. In 1995, the Russian Federation enacted the Federal HIV/AIDS Law outlining guidelines for coping with and preventing HIV/AIDS. The Federal HIV Law authorizes mandatory HIV testing for blood, organ, and tissue donors and for medical/laboratory personnel working with HIV prevention and care, for foreigners intending to stay in the country for longer than three months, as well as people "suspected of drug use". In addition, testing is obligatory for certain categories of workers as a condition of employment. However, some of the categories are not defined or limited in the law; and judgment is left to the ministries to determine who should be tested.

Concerns about appropriate application of the testing law and human rights abuses have been expressed (TvT Associates 1999). According to the International Council of AIDS Service Organizations (ICASO), many categories of people have been required to undergo testing: salespersons, drivers of public transportation, police officers, patients (when entering a hospital or public health care institution), children and youth, as part of medical checkups required by summer camps, students when enrolling in colleges, senior citizens when entering institutions for the elderly, and pregnant women, including women applying for an abortion. Lack of information about the law on the part of testing personnel and the person to be tested, as well as lack of choice about whether to be tested and knowledge that refusal may result in the inability to access desired services, has created tense situations.

The policy in the Russian Federation is to separate HIV-infected prisoners into living quarters apart from the general prison population. Communal living within one large room that houses many inmates is the standard arrangement in Russian prisons. Prisoners, by law, are to be extended adequate treatment related to HIV infection.

HIV/AIDS testing. Each year between 1991 and 1999, about 20 million people were tested for HIV (Pokrovsky et al 2000). During this period, 90\% of those tested fell into 
categories such as 'clinical indications,' blood donors and recipients, pregnant women and 'miscellaneous/ others.' In contrast, such important categories as 'patients with STIs', 'prison inmates', 'IDUs', 'contacts of individuals with HIV/AIDS', 'promiscuous individuals', 'traveling abroad', 'anonymous', 'outbreak investigation', 'males having sex with males', and 'the military' averaged for only about $10 \%$ of the tested.

From 1991 to 1996 , the case detection rate was about 1 case per 100,000 tested (Pokrovsky et al. 2000). During 1997 and 1998, the rate was about 20/100,000, and in 1999 it was $85 / 100,000$. The improvement in the case detection rate can be attributed to a slightly better targeting of screening toward groups at the highest risk for contracting HIV: since 1996, the share of IDUs among all the tested increased more than threefold (from $0.5 \%$ to $1.6 \%$ ), the share of STIs patients increased from $6.2 \%$ to $7.9 \%$, and the share of prisoners increased from $2.4 \%$ to $3.8 \%$ (Table 30 ).

Table 30. Percent distribution of HIV tests

\begin{tabular}{|c|c|c|c|c|c|c|c|c|c|}
\hline & & & & & & & & & 19 \\
\hline Others & 20.6 & 7.1 & 29.3 & 27.0 & 27.9 & 25.6 & 27.3 & 28.9 & 28.9 \\
\hline Clnleal Indlobone & 205 & 20 & 223 & 249 & 22485 & 28 & 823 & 25 & 272 \\
\hline $\begin{array}{l}\text { Blood donors and } \\
\text { recipients }\end{array}$ & 23.6 & 6.5 & 19.5 & 19.3 & 20.6 & 20.4 & 18.4 & 18.8 & 17.4 \\
\hline Muraments & 287 & at. & 20 & 18.8 & 16.6 & 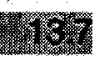 & I8: & 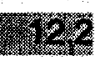 & 1118 \\
\hline STIS & 2.2 & 0.8 & 3.3 & 4.0 & 4.9 & 6.2 & 6.9 & 7.4 & 7.9 \\
\hline Prisoners & 188 & 06 & 20 & 28 & 23 & 2 & 6 & 335 & S6\% \\
\hline IDUs & 0.3 & 0.1 & 0.3 & 0.4 & 0.3 & 0.5 & 0.8 & 1.1 & 1.6 \\
\hline Promberuofrs & 0.6 & 02 & 0.6 & 068 & 07 & 0.7 & 0 & 609 & 0.7 \\
\hline HIVIAIDS contacts & 0.3 & 0.2 & 0.9 & 1.1 & 0.7 & 6.5 & 0.6 & 0.7 & 0.4 \\
\hline Traveling abrood & 0.6 & 02 & 0.6 & 0.6 & 20.7 & 008 & 05 & 0.5 & 0.3 \\
\hline Outbreak investigation & 0.0 & 0.0 & 0.0 & 0.0 & 0.0 & 0.0 & 0.0 & 0.1 & 0.3 \\
\hline MSM & 0.0 & 0.0 & 0.0 & 0.91 & 0.0 & 00 & 04 & 0.1 & o.1 \\
\hline Military & 0.4 & 0.1 & 0.3 & 0.4 & 0.2 & 0.1 & 0.0 & 0.0 & 0.1 \\
\hline Aromynons & 02 & O2: & 09 & 065 & 003 & 0 & 0.1 & 000 & 0.0 \\
\hline
\end{tabular}

Source: The authors' calculations based on data from the Federal Center for HIV/AIDS Prevention 2000.

HIV/AIDS prevention. Outreach education about the dangers of homemade drug preparation and harm-reduction messages (e.g., 'Don't share needles') have shown to be effective in reducing risky behaviors in The Russian Federation and Ukraine, including those among IDUs (Kitsenko 1998, Lutsenko 1998). However, in some areas there are few outreach activities, and overall funding is limited (Kalfin, Nozhkina 2000). Interventions such as needle exchange programs are less common and law enforcement authorities in many cases impedes this type of effort.

Educational campaigns aimed at safe sex practices and condom use have not always been favored by the authorities, who believed that they might contribute to the observed decline in the number of the Russian population and to promotion of sexual intercourse among teens. 
Responding to the spread of HIV among institutionalized populations (the military and prisons) is difficult due to lack of funds, although interest in, and need for increased HIV/AIDS prevention and training activities, is acknowledged by key officers (Litvintsev 1998).

HIV/AIDS care. In the West, a standard three-drug antiretroviral therapy starting as early as possible after detection of HIV seropositivity was shown to lead to a survival of over 14 years without development of AIDS or debilitating consequences. Trials have also demonstrated that the three-drug antiretroviral therapy is significantly more costeffective than two-drug therapy (AZT/3TC) (Gulick et al 1998, 1999).

According to the Russian Ministry of Health (MOH), the existing HIV treatment approach has been that at the early stages of HIV-infection, handling of a HIV-infected case involves only monitoring during the first four years and therapy is added later on. Also, instead of the standardized three-drug antiretroviral therapy, a two-drug therapy is used, probably due to lack of funds and drugs. These factors may negatively impact effectiveness and cost-effectiveness of antiretroviral therapy for HIV.

AZT is the only domestically produced antiretroviral drug. Most of the antiretroviral drugs used for HIV/AIDS case management are imported, but pricing at the international level makes them prohibitively expensive for both Russian patients and the health system.

HIV/AIDS costs. The impact of the HIV/AIDS epidemic in the Russian Federation has not yet been estimated. This is partly due to the relatively small number of HIV cases that were registered before 1996. Current data indicate that 577 HIV/AIDS deaths have been reported since 1987 . However, given the estimated $130,000 \mathrm{HIV}$ infected currently living in the Russian Federation, and the minimal cost of treatment per person per year (US $\$ 5,000$ as reported by the Russian Ministry of Health) for the outdated two-drug antiretroviral therapy for HIV infection, a simple calculation shows that within the near future, the Russian Federation may start paying at least US $\$ 0.65$ billion a year for treatment of all HIV cases.

Furthermore, this rough estimation does not take into account either the skyrocketing growth of the epidemic or additional treatment costs: costs of the therapy for complicated cases, costs of the standard three-drug therapy currently used in the West (US\$11,00013,000 per patient per year), and the costs of AIDS treatment (which, including costs of inpatient stay, medical exams and treatment of opportunistic infections, was estimated by the $\mathrm{MOH}$ as US $\$ 50,000$ per patient per year).

Finally, it is necessary to estimate the overwhelming economic and financial loss due to the inevitable disability or death of tens of thousands of HIV positive individuals, the majority of whom are economically productive, as well as the costs to society of foster children, orphans left by deceased AIDS patients. Though the survival period of AIDS patients in many Western industrialized countries is often 13-14 years, it is unlikely to expect such duration of survival in the Russian Federation due to financial constraints for purchasing antiretroviral drugs and the unfavorable living conditions in the country. 


\section{Potential Impact of TB Control, With Implications for HIV/AIDS}

After a gradual decline in the TB incidence rate of about $4 \%$ annually in the decades before 1990, this trend has reversed and the TB incidence rate is now increasing by approximately $10 \%$ annually, according to WHO Global TB Control 1999. The level of drug resistance, especially multi-drug resistance (MDR), is of particular concern. Prisons are often suspected to be breeding grounds for drug-resistant TB, but there may be other causes and "hotspots" of transmission as well. The reasons for this deterioration in the TB situation are not understood in detail, but some possible causes are:

- An increase in poverty and malnutrition leading to higher TB breakdown rates and perhaps higher contact rates.

- Deteriorating health services, leading in particular to lower cure rates.

- An influx of TB patients. After 1990 many ethnic Russians migrated into the Russian Federation from newly independent states. Also, many political prisoners were released. The latter group probably included many TB patients.

- Statistical changes. For example, before 1995 prisoners with TB were not included in the national figures. However, it seems unlikely that such changes can explain the sustained upward trend in case numbers.

A proposed World Bank loan is intended to help revitalize TB, HIV/AIDs and STIs control in Russia. The project should improve TB control services, including case finding, treatment outcomes, and the management of drug resistance, both in civilian and prison populations. It should reduce TB burden (incidence, prevalence and death rates) by a factor that depends on how vigorously the new program is implemented.

Mathematical modeling can help assess the potential size of the impact of improved TB control in Russia. Such a modeling study carried out prior to the planned intervention can serve two purposes:

- Modeling can help to set targets for the intervention, by specifying, for example, minimum case detection and cure rate requirements for a reduction in incidence.

- Modeling can provide projections of cases and deaths, which are a prerequisite for cost estimation and for cost-effectiveness or cost-benefit analysis.

This section presents a set of plausible scenarios for TB control in a model Russian population unit of one million. These different scenarios for a unit population can be used as building blocks to construct a wide range of more or less successful outcomes for the planned project. Taking particular notice of TB in prisons, and of the rise of multi-drug resistant disease (MDR-TB), the scenarios are:

1. No intervention, in either prison or civilian populations (p-c-).

2. Prison population encouraged to use a basic package for TB control, including short-course chemotherapy based on first-line drugs; no intervention in civilian population $(\mathrm{p}+\mathrm{c}-)$. 
3. Basic package adopted both in prison and civilian populations $(p+c+)$, with higher (h) or lower (l) cure rates for patients carrying drug-susceptible or resistant (other than MDR) strains.

4. Civilian population graduates to an enhanced package, including testing for drug susceptibility and use of second-line drugs $(p+c++)$.

5. Enhanced package adopted both in prison and civilian populations $(p++c++)$.

\section{A dynamic Compartmental Model for Tuberculosis}

Model structure. The unit of analysis is a single, 'typical' oblast of approximately $1,000,000$ (adult) inhabitants, i.e. approximately $1 \%$ of the population of the Russian Federation. Children $(<15$ years) with TB are excluded because they represent a small fraction of the disease burden and are rarely infectious, therefore contributing little to the spread of disease.

The starting point of the model was the framework devised by Dye et al. (1998), adapted to run in the ModelMaker package. For the natural history of TB, individuals are grouped in mutually exclusive compartments (Figure14).

\section{Figure 14. General model of infection and disease}

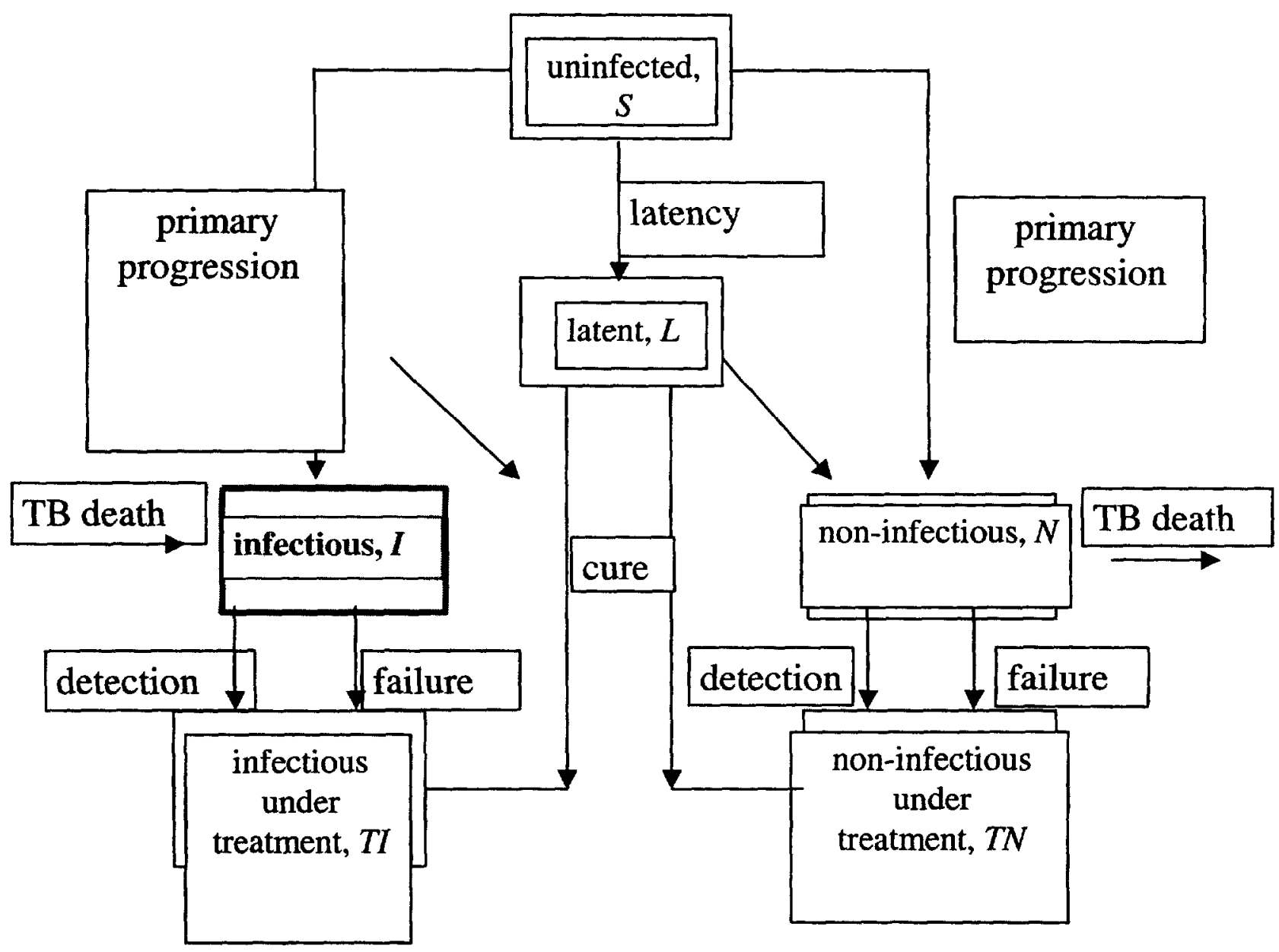


Our starting point was the framework devised by Dye et al. (1998), adapted to run in the ModelMaker package. For the natural history of TB, individuals are grouped in mutually exclusive compartments in Figure $14^{1}$. The management of drug resistance is a central element of the re-structured TB program. Balancing reality with analytical tractability, the model distinguishes between drug sensitive (DS), drug-resistant (DR, any form of resistance MDR), and MDR (resistant to at least isoniazid and rifampicin) patients (Figure 15$)^{2}$. In reality, of course, there are many more possible resistance patterns. Initial conditions were: 700,000 susceptibles $(S), 300,000$ persons latently infected $(L)$ with drug sensitive TB, and 1000 drug-sensitive infectious cases. All other boxes were initially empty. In order to fill them with plausible numbers, we allowed a run-in time of 10 years, calibrating year 11 to 1990 .

Figure 15. Treatment of drug resistance in model

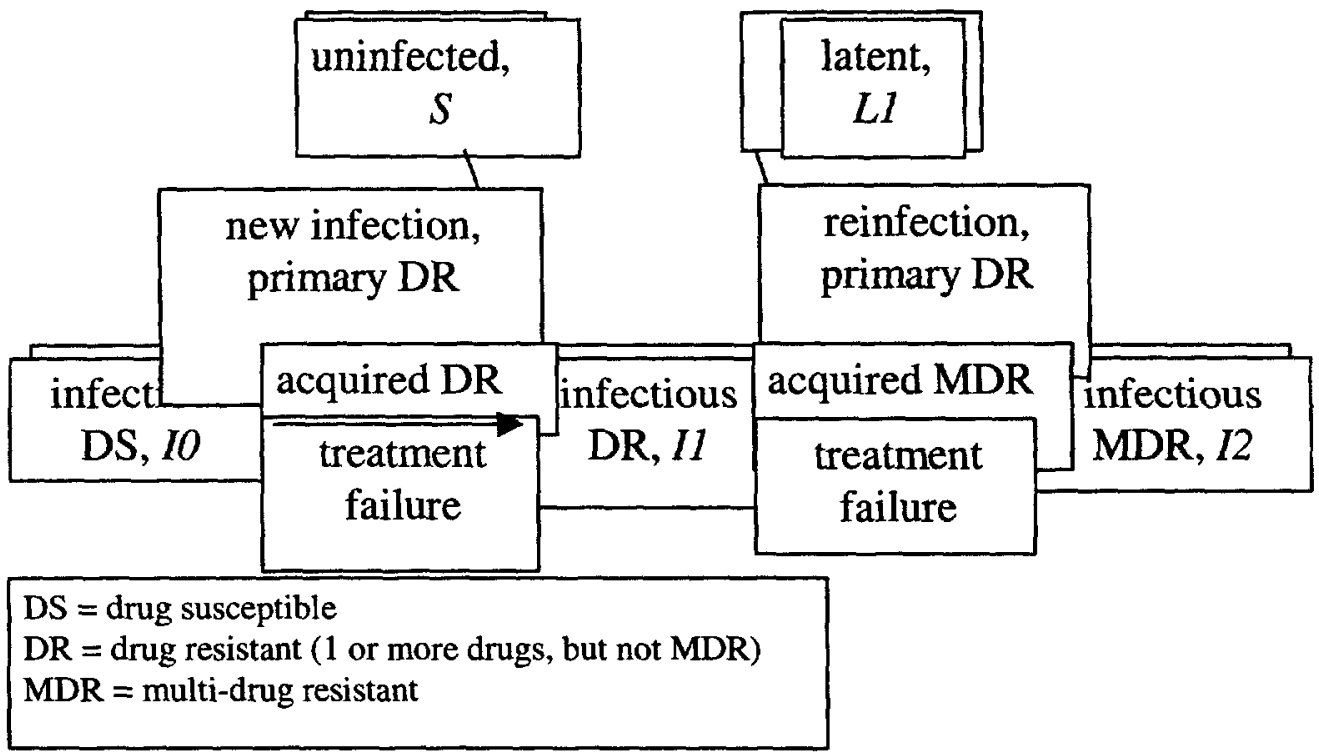

Interventions. The full intervention was assumed to have the following effects:

- Increase the cures rate of DS, DR and MDR patients to 74\%

- Increase the annual case detection rates of infectious patients by $50 \%$

- Reduce the rate by which patients under treatment develop resistance by $75 \%$

'Full intervention' means that both civilians and prisoners receive the enhanced package. Implementation of the full intervention was assumed to take five years (adjusted via a run-up parameter). If only civilians receive the enhanced package, then

\footnotetext{
${ }^{1}$ Flow chart illustrating the general model of infection and disease, based on Dye et al (1998). The same processes apply to drug-susceptible (DS), mono-resistant (DR), and multi-drug resistant (MDR) disease, and the full model therefore consists of three interlinked models as shown in Figure 17.

2 Flow chart illustrating the three interlinked models of drug-susceptible (DS), mono-resistant (DR), and multi-drug resistant disease (MDR), based on Dye, Williams 2000.
} 
the intervention has $75 \%$ of the full effect, reached linearly over five years. If both civilians and prisoners receive the basic package only, the effect is $45 \%$ of the full intervention, reached over three years (though the possibility of reaching higher cure rates for DS and DR patients is also explored). Oblasts in which only prisoners receive the basic package and civilians do not receive improved treatment reach $25 \%$ of the full intervention over three years.

To track the TB epidemic in the Russia Federation as a whole, it is necessary to combine oblasts that are making progress at different rates. To do this, the rate of decline due to any given intervention is assumed to be independent of the initial incidence, so the rate of decline for that intervention need only be calculated once. Other mathematical models of TB have shown that this assumption holds well when incidence is growing logarithmically, as is approximately true in the Russia Federation.

An exploration of selected scenarios suggests adopting, as a heuristic device, uncertainty limits of $30 \%$ below to $40 \%$ above predicted values. This makes the upper limit twice the lower limit. The projections for each scenario can also be thought of as bounding areas within which the true solution will probably lie.

Sources of data. Main sources of data for this analysis included:

- Cases reported to WHO, showing trends since 1980 (WHO 1999)

- Estimates of incidence, death and infection rates from Dye et al. (1999)

- Unpublished reports of drug resistance rates from selected oblasts (e.g. Figure 19)

- Data on epidemiological variation between oblasts, plus other background statistics presented in this volume

- Other standard texts, such as Styblo (1991)

\section{Results}

Figure 16 shows the expected total number of TB cases each year under all five scenarios. Introducing the basic package to prisons alone $(p+c-)$ is not expected to stop the rise in case number. To achieve that goal will require the basic package to be adopted in both civilian and prison populations $(p+c+)$. Assuming modest cure rates for drug susceptible and mono-resistant patients $(p+c+(1))$, incidence falls slowly from 2002 onwards, at only 1-2 percent per year. It would take about two years for the intervention to cause a downturn in cases presenting for treatment. Depending on the variability in the data, it would take longer than that to be confident of detecting the downturn. Treatment that exploits more fully the potential of first-line drugs $(p+c+(h)$, Table 31) will push incidence down more quickly in the short-term ( $<5$ years), but without having a dramatic impact on incidence in the longer term. 
Figure 16. Expected TB cases per million population (six scenarios)

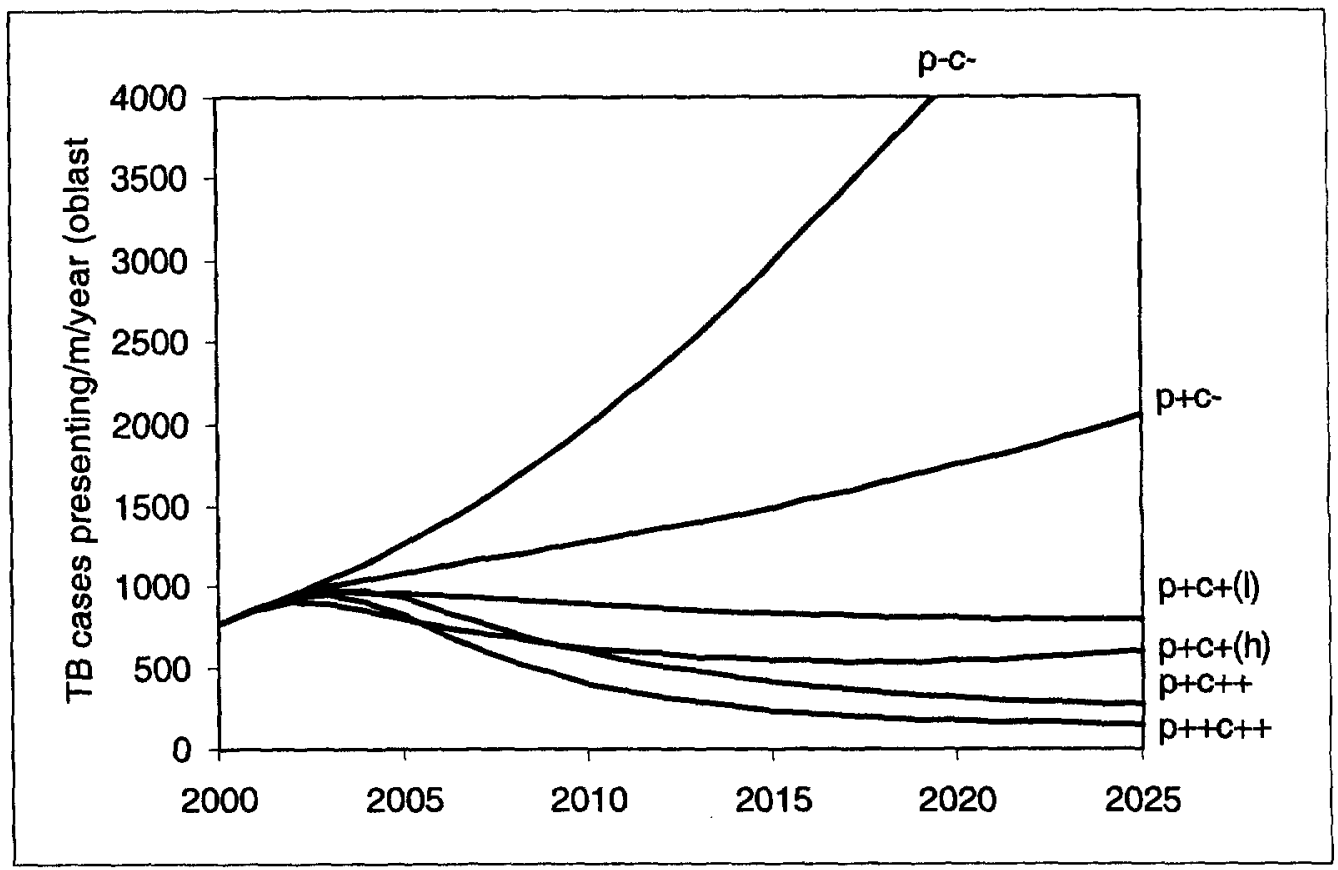

Note: Expected numbers of TB cases/million population (one oblast) presenting for treatment between 2000 and 2025 under the six different scenarios.

The enhanced package ( $\mathrm{p}+\mathrm{c}++$ or $\mathrm{p}++\mathrm{c}++)$ should, of course, achieve more. With given assumptions about the full intervention, the annual rate of decline is about 10 percent in 2010 , falling to 5 percent by 2020 . Trends in the numbers of deaths each year closely follow trends in the numbers of cases.

Introducing the basic package to prisons alone has a large impact, saving about half (47\%) the expected cases between 2000 and 2025. Adding the basic package ( $p+c+(1)$ ) to the civilian population saves an extra $20 \%$ of cases, $67 \%$ in total. The full intervention (enhanced package everywhere) saves $84 \%$ of cases by 2025 .

The time course of the MDR-TB sub-epidemic is pictured in Figure 17. With no intervention, MDR incidence would continue to increase at between 15 and 20 percent per year (doubling time 3.5-4.6 years). These calculations suggest that the basic package should be in place everywhere (prison and civilian populations) to significantly slow the rate of increase to about five percent per year (doubling time 13.8 years). The cure rate of MDR cases under SCC is unlikely to be much greater than the 58 percent ascribed in Table 31 , and the dynamics are not much affected by the cure rate of patients carrying DS or DR strains (cf $p+c+(l)$ and $p+c+(h))$. 
Table 31. Percentage of patients assumed to be cured under different interventions

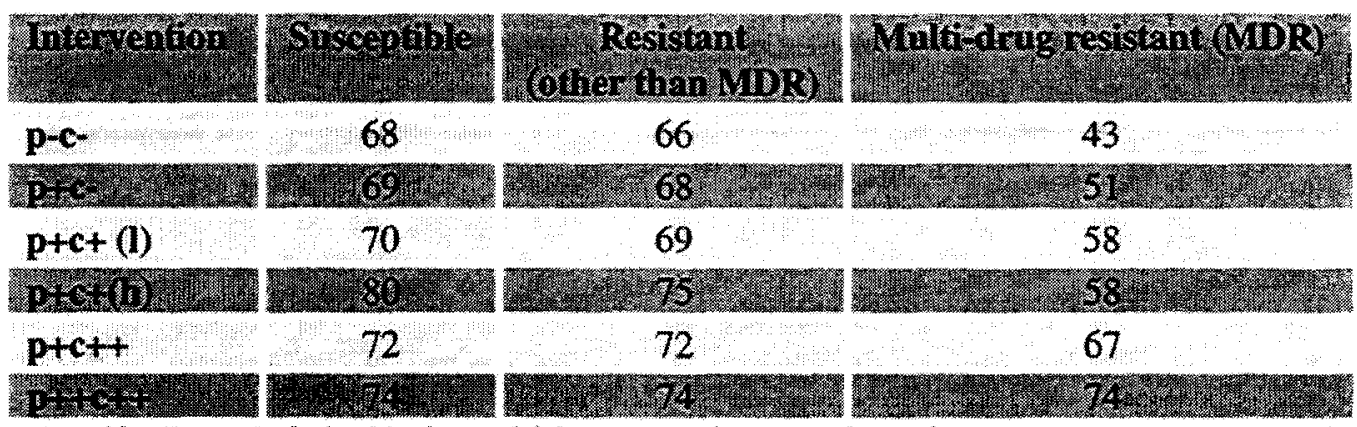

Note: Net \% cure is derived in the model from competing rates of case detection, treatment success, and death.

Figure 17. Expected numbers of MDR-TB cases/million population under six scenarios

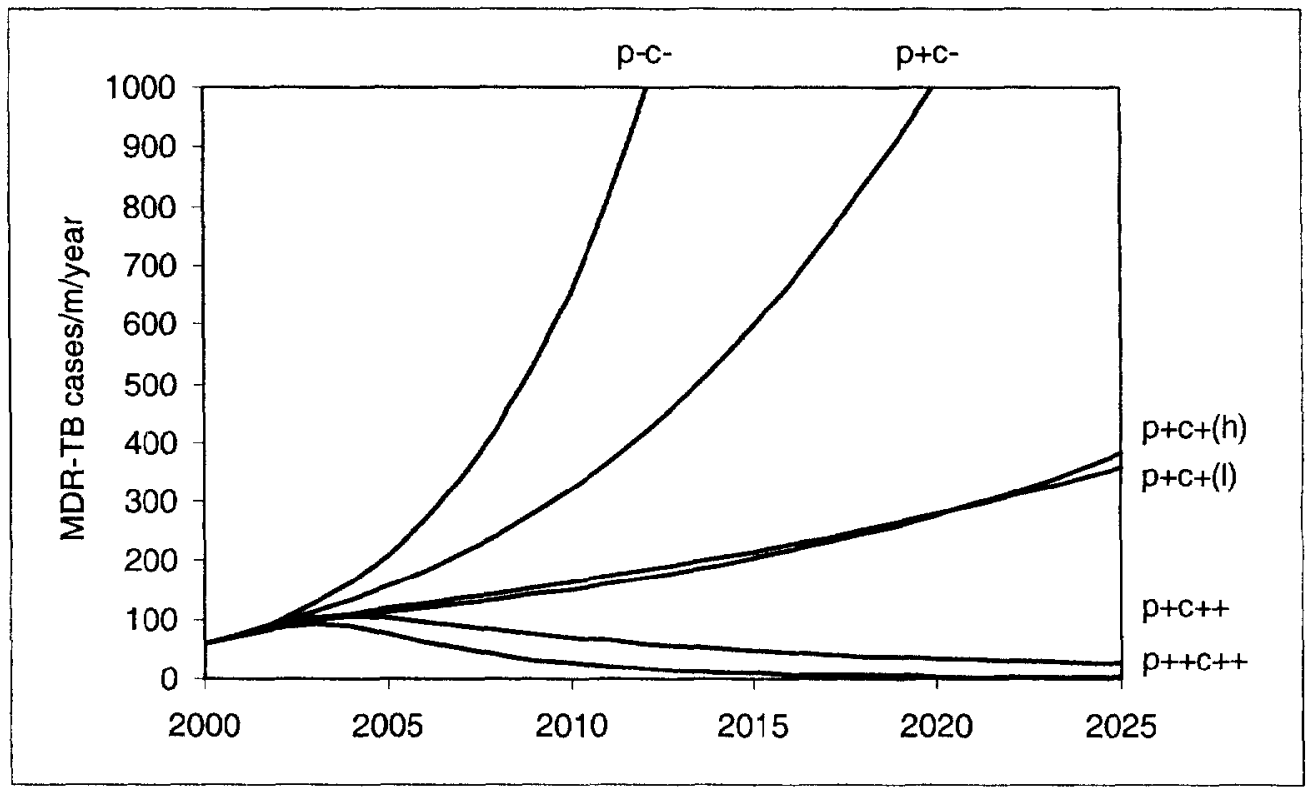

Note: Expected numbers of MDR-TB cases/million population (one oblast) presenting between 2000 and 2025 under the six different scenarios.

Up to this point, the impact of control in a typical oblast has been described. The expected number of cases and deaths in the Russian Federation as a whole depends on how many oblasts adopt the basic and enhanced packages, and how quickly. The project target (at the time of writing) is to enroll oblasts so that 30 percent of cases are covered by the basic package within three years. Those that achieve cure rates of 70 percent (all cases) would graduate to the enhanced package $(\mathrm{p}++\mathrm{c}++)$. If oblasts are enrolled so that an extra 10 percent of TB cases are covered by the basic package each year for 10 years, we expect incidence to rise until around 2010, before beginning a gentle decline. If all oblasts meet the requirements for graduation in three years, and then achieve better cure rates using the enhanced package within five years, we expect to see incidence fall before 2010; peak incidence would be lower, and the fall faster. 
Clearly, a mixed strategy - with some oblasts graduating to the enhanced package and others not - will produce a net result somewhere in between.

Throughout this analysis, HIV prevalence was assumed to remain very low in the general population. Imagine, however, that there is a much larger epidemic of HIV in which prevalence rises to two percent by 2010 and five percent by $2020(\mathrm{HIV}(\mathrm{h}))$, and that the breakdown rate to TB is three percent per year in people who are co-infected. Under these circumstances, it would be extremely difficult to stop the rise in TB incidence, using ether basic or enhanced packages. A smaller HIV epidemic in which prevalence reaches two percent by 2010 and then stabilizes (HIV(1)) would also be a significant impediment to TB control.

\section{Conclusions}

The main results are characterized in Table 32 . Without improvements in case detection and cure (p-c-), incidence is expected to continue doubling (approximately) every seven years. Although it is not fully understood how changes in transmission and susceptibility have conspired to increase TB incidence since 1991, there is no epidemiological reason why the rise could not continue. Prior to the availability of drugs, Europe suffered much higher TB incidence rates than now exist in the Russian Federation, and it is not impossible that such high rates should once again occur.

The basic package of TB control, introduced to prisons only ( $p+c-)$, could prevent a large fraction of all cases and deaths. The reason for the predicted impact is, first, that about one third of all TB cases, and half the MDR-TB cases, are thought to be in prisons. Even though the basic package contains only first-line drugs, treatment is expected markedly to improve the cure rate of MDR cases in prisons (compare 51 percent with 43 percent in Table 31 ). Second, improving the cure rate by 7 percent over 43 percent will have a bigger impact than adding a further 7 percent to 51 percent (the step from $\mathrm{p}+\mathrm{c}-$ to $\mathrm{p}+\mathrm{c}+(1)$ ). However, intervening only in prisons is unlikely to stop the overall rise in incidence. According to the projections, the minimum requirement for a downturn in cases and deaths is that the basic package be applied to both prison and civilian populations $(\mathrm{p}+\mathrm{c}+)$. Even then, the resulting fall in incidence might be slow because the Russian Federation has not generally achieved high cure rates for drug susceptible patients $(>80 \%)$, and because short-course chemotherapy with first-line drugs cannot in any event cure a very high fraction of MDR-TB cases. As the total number of TB cases gently falls, the MDR-TB sub-epidemic is expected to continue upwards. Having obtained the same result with another TB model (Dye, Williams 2000), the authors have greater confidence that it is correct. To achieve greater success with the basic package, further slowing or even stopping the rise in incidence would require faster case detection. But we cannot be confident of substantial improvements in case detection so long as case finding remains essentially passive, as intended in the basic package. 
Table 32. Summary of the potential impact of five interventions on TB epidemiology in the Russian Federation
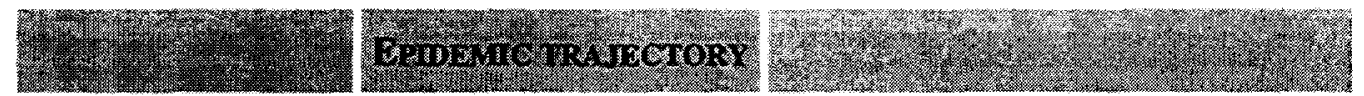

Intervention

All TB

MDR
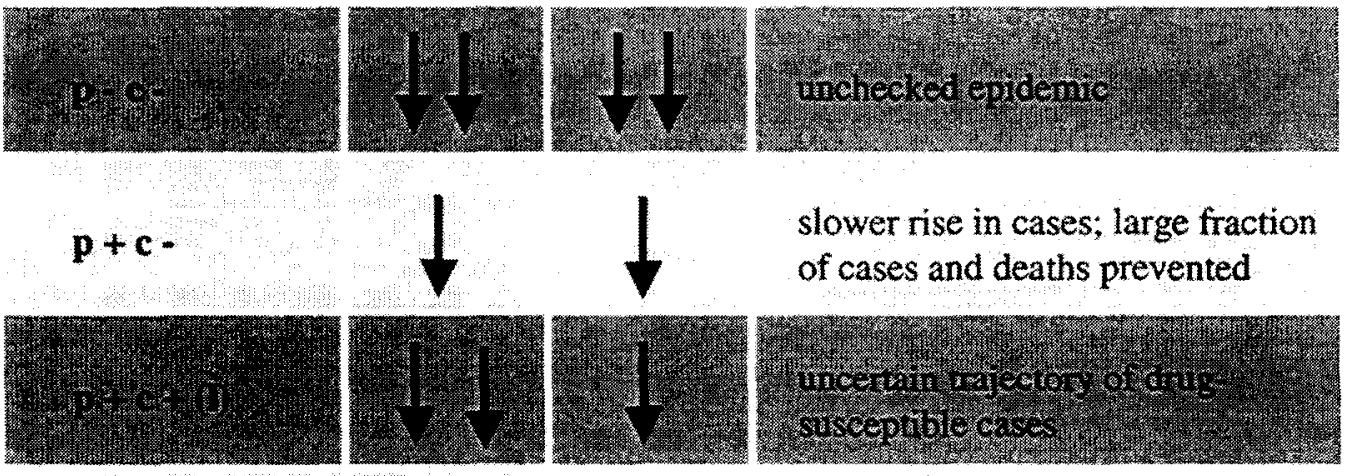

slower rise in cases; large fraction of cases and deaths prevented
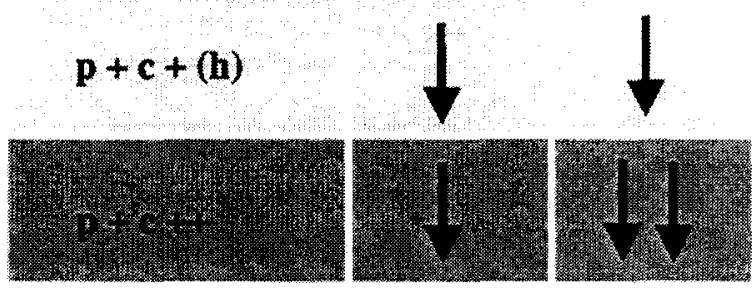

probable fall in drug-susceptible cases
$\mathbf{p}+\mathbf{c}++$
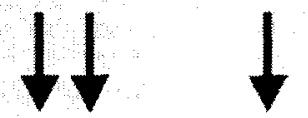
sustained fall in drug-susceptible and MDR-TB cases

Sooner or later, MDR-TB will probably have to be tackled with second-line drugs. But if the basic package is implemented well, with cure rates of about 50 percent in MDR-TB cases and over 70 percent in drug-susceptible or mono-resistant cases, the MDR-TB epidemic is expected to grow slowly (at worst). This can be viewed as a bonus under the current project design, which aims at first for the best possible results under short-course chemotherapy, and delays the introduction of second-line drugs until it is clear that their efficacy can be fully exploited. When used to full potential, second-line drugs will raise the cure rates of MDR-TB cases. When used badly, we can expect low MDR-TB cure rates in the short term, and even lower cure rates in the longer term as patients become resistant to second- as well as first-line therapy.

The speed with which TB can be controlled across the whole of Russia depends not only on success within oblasts, but also on how many oblasts adopt the basic and enhanced packages. If oblasts are recruited at the rate currently planned (covering territory occupied by 30 percent or about 20,000 smear/culture-positive cases every three years), and if they do no more than adopt the basic package, then incidence could rise until 2010 , and fall only gradually thereafter. Many would regard this as unacceptably slow progress. Ideally, oblasts would be recruited faster, and mechanisms put in place to ensure that a high fraction graduates to the enhanced package. 
All these conclusions will have to be reconsidered if HIV breaks out of high-risk groups (injection drug users, etc), and spreads widely in the general population. Our very simple model calculations in this context illustrate, qualitatively, what could happen under a moderate HIV epidemic. HIV has caused a dramatic increase in TB incidence in Africa, even in countries such as Tanzania where there have been moderately good TB control programs. The details will of course differ for the Russian Federation, for example, because $M$. tuberculosis infection rates are lower in Russia. The authors have supposed that a Russian HIV epidemic would be smaller than the southern African epidemic; nonetheless these calculations suggest that, without intense TB control, it would be difficult to stop the rise in TB incidence.

Finally, a comment on the reliability of the model and the results it has generated is as follows. The trajectory of any epidemic is hard to forecast, especially into the distant future, and especially when based on poor data. However, the authors place some extra confidence in the results, beyond the justification given here, because the model is based on other, more complex models that have been extensively tested (Dye et al 1998, Dye, Williams 2000). The present model can reproduce some of the essential results produced by these earlier models, such as the doubling time of an epidemic, the rate of decline of incidence under high rates of case detection and cure, and the failure of SCC to contain MDR-TB epidemics. More importantly, it can replicate field data, such as the rate of decline of TB seen in Western Europe since 1950. Nonetheless, the authors place much more emphasis on the qualitative and comparative conclusions that have emerged from this modeling exercise, and much less emphasis on the exact numerical results. 



\section{Annex 1. Technical Terms}

Acid-fast bacilli (AFB)

AIDS

Acquired MDR-TB

Active Case Finding (ACF)

Antiretroviral therapy

BCG

Case-detection rate

Completed treatment
Bacteria that retain a carbol-fuschin stain after the application of acid-alcohol decolorizing mixtures; the most important of these bacilli is Mycobacterium tuberculosis, the agent that causes tuberculosis.

Acquired Immunodeficiency Syndrome. Disease characterized by a loss of proper immune system function, leading to infection by infection with the human immunodeficiency virus (HIV).

Infection with a strain of $M$. tuberculosis resistant to at least isoniazid and rifampicin in a patient who has previously received at least one month of antituberculosis therapy; also called secondary MDRTB.

Case-detection strategy characterized by the systematic search for individuals with tuberculosis in a population; this contrasts with passive case finding, a case-detection strategy in which symptomatic individuals identify themselves to health services.

Treatment with medications that inhibit the replication of retroviruses. This term is most commonly used to refer to medications that inhibit HIV replication, e.g. AZT (zidovudine), ddI (didanosine), ddC (zalcitabine), protease inhibitors, nucleoside analogs etc.

Bacille Calmette-Guérin. Bacilli used to vaccinate against TB. The vaccine is believed to have moderate efficacy; it does not prevent TB infection but it is understood to reduce the risk of developing all forms of active TB. Use varies widely between countries. For developing countries with high rates of $\mathrm{TB}$, WHO supports universal BCG immunization.

Number of correctly identified cases of a disease of interest within a given time period, given the total estimated incidence.

Specific outcome category used in TB cohort analysis; defined as patients with negative sputum microscopy results at the end of the initial phase of treatment, with one or no negative sputum smear results in the continuation phase and no negative smears at the end of treatment. 
Cured

Default

DOTS

Drug resistance

Drug-susceptibility testing

Epidemic

Failure
Specific outcome category used in TB cohort analysis; this category includes patients initially smear-positive who have negative sputum smear results after treatment completion and on at least one prior occasion during therapy. However, some of these patients may be smear-negative but culture-positive upon completion of treatment, and thus not cured.

Term referred to TB patients in treatment who have failed to take their antituberculous drugs for two or more months at any time since registration as a TB patient. The term "interrupted treatment" is also used.

Directly observed therapy, short course. Refers to a specific type of tuberculosis-control program under the aegis of a country's National Tuberculosis Program, requiring the following elements: (i) government commitment to sustained TB control activities; (ii) case detection by sputum smear microscopy among symptomatic patients self-reporting to health services; (iii) standardized treatment regimens of six to eight months for at least all confirmed sputum-positive cases with directly-observed treatment (DOT) for at least the initial phase of the treatment; (iv) regular uninterrupted supply of all essential antituberculosis drugs; and (v) a standardized recording and reporting system that allows assessment of treatment results for each patient and of the TB control program overall.

Characteristic of microorganisms that are not killed or inhibited by a specific antibiotic due to the selection of naturally-occurring resistant mutants through inadequate therapy. May result from the administration of too few medications or irregular intake of drugs.

Laboratory tool for assessing susceptibility of TB bacillus to antibiotics; a key component in designing treatment regimens for patients with drug resistance.

Occurrence of a disease in a community or region above the expected. In common usage refers to a disease that is relatively new to or previously suppressed in a given population.

Specific outcome category used in TB cohort analysis. Refers to those TB patients who remain or become smear-positive at least five months after the start of treatment. 
First-line drugs

Fluoroscopy
Harm reduction

HIV

Incidence

ITR

Infection

Monoresistance
MDR-TB

Oblast
Term used to describe the most efficacious antituberculous drugs, including isoniazid ( $\mathrm{NH}$ or $\mathrm{H}$ ), rifampin ( $R I F$ or $\mathrm{R}$ ), pyrazinamide (PZA or $\mathrm{Z}$ ), ethambutol (EMB or E), and streptomycin (SM or S). Radiological screening method used to diagnose pulmonary TB; used widely in the former Soviet Union.

Or GMP. Guidelines for pharmaceutical manufacturers that provide minimum quality standards for the production of drugs.

Refers to programs providing education, condoms, bleach, needle exchange, and referral for drug treatment to injecting drug users (IDUs) to reduce transmission of the HIV epidemic to the IDUs themselves and to the rest of the population.

Human immunodeficiency virus. Human retrovirus that infects CD4 lymphocytes leading to immunosuppression and the development of opportunistic infections. In patients infected with HIV, TB is the world's most common lethal opportunistic infection.

Number of new cases of a disease in a population over a period of time. Usually expressed as a rate, i.e. number of new cases of a disease over a period of time divided by population at risk of the disease in the time period.

Individualized treatment regimens. TB treatment based on the drug-susceptibility test of an individual's patient infecting strain. The regimen includes those drugs to which a patient's infecting strain has documented in vitro susceptibility.

When used in reference to tuberculosis, the presence of $M$. tuberculosis in the body unaccompanied by signs of clinically active disease such as cough, fever, or night sweats. As regards TB, also named latency.

Resistance to only one antituberculous medication.

Multidrug-resistant tuberculosis. Strains of $M$. tuberculosis resistant to at least isoniazid and rifampin, considered the two most efficacious antituberculous drugs.

Primary administrative region within Russia, containing several rayons. 
Polyresistance

PPD-screening

Prevalence

Primary drug resistance

PPD

Reference laboratory

Second-line drugs

STIs/STDs

Short-course chemotherapy

Smear conversion
Resistance to more than one antituberculous medication, but not to both $\mathrm{NH}$ (isoniazid) and RIF (rifampicin). By convention, resistance to both $\mathrm{INH}$ and RIF defines the isolate as MDR-TB. Polyresistant strains of tuberculosis may be as difficult to treat as MDR-TB.

Method by which PPD (see below) skin testing is used to detect infection with $M$. tuberculosis.

Number of people in a population who have a certain disease at a certain point or interval divided by the population of interest (e.g. 300 cases of smear-positive TB per 100,000 population).

Drug resistance diagnosed in patients without a history of prior antituberculous therapy. Results from direct transmission of a drug-resistant strain of $M$. Tuberculosis.

Purified Protein Derivative. Substance native to the tubercle bacillus that is injected under the skin to screen for prior exposure to $M$. tuberculosis. Induration at the time of the injection site suggests prior infection with $M$. tuberculosis. See PPDscreening above.

Mycobacteriology laboratory to which samples are sent for drug-susceptibility testing. Also performs quality control for other laboratories providing TB diagnostic services.

Antituberculous medications used to treat drugresistant TB. Second-line drugs include: amikacin, capreomycin, cycloserine, ethionamide, fluoroquinolones, kanamycin, para-aminosalicylic acid (PAS), rifabutin, and thiacetazone.

Sexually-transmitted infections or sexually-transmitted diseases. Infections acquired during sexual contact, including chlamydia, HSV, HIV, and gonorrhea; strains of human papillomavirus associated with cervical cancer are also likely STIs.

Treatment of active TB using $\mathbb{N H}$ and RIF-containing regimens lasting nine months or less.

Difference in a patient's sequential smear microscopy test results (a positive result on one exam followed by a negative result on another, or vice versa). Failure to smear-convert from positive to negative after several months of directly-observed short-course 
chemotherapy may suggest that the patient is sick with MDR-TB.

Smear negative

Smear positive

Sputum smear examination

Standardized treatment regime

Surveillance data

Transferred out
Term referring to the absence of $M$. tuberculosis bacili on smear microscopy examination. Because of the low sensitivity of smear microscopy, a negative smear does not necessarily indicate the absence of TB disease. Patients who are smear-negative but who have a culture-positive result are considered by many to be less infectious than smear-positive patients, reflecting lower bacilary load.

Term used to describe the presence of $M$. tuberculosis bacili on smear microscopy.

Microscopic examination of patients' sputum that ca reveal the presence of $M$. tuberculosis.

TB treatment in which all patients enrolled are administered a single treatment regimen regardless of the susceptibility pattern of each patient's infecting strain.

Data collected to monitor the occurrence and spread of a disease.

As treatment outcome. Those patients who have been transferred to another reporting unit and for whom the treatment outcome is not known. 



\section{Bibliography}

Ahlburg, D.A. 2000. "Socioeconomic Impact of Tuberculosis". WHO/CDS/STB/2000.5.:22-24, Amsterdam, the Netherlands.

Ainsworth, M. 1998. Looming AIDS Epidemic in Transition Economies: Can it Be Avoided?

Ainsworth, M. 1998. "Setting Government Priorities in Preventing HIV/AIDS". Finance \& Development. A quarterly publication of the International Monetary Fund. Washington DC.

Ainsworth, M. Over, M. 1997. Confronting AIDS: Public Priorities in a Global Epidemic. A World Bank Policy Research Report. New York: Oxford University Press.

Antonio, P.A., Chaulet, P. 1998. Tuberculosis Handbook. World Health Organization Global Tuberculosis Program. WHO/TB/98.253. Geneva.

Arif, K. Ali, S.A., Amanullah, S., Siddiqui, I., Khan, J.A., and Nayani, P. 1997. "Physician Compliance with National Tuberculosis Treatment Guidelines: A University Hospital Study". International Journal of Tuberculosis and Lung Disease (2):225-230.

Bachman, T. 1998. "Russian Pharmaceuticals: Coming of the Dark Ages. Pharmaceuticals Report - Sector Overview". Alfa Capital Research Department, Moscow.

Carrin, G., Gray, E., Almeida, J. 1998. "Coping with Ill-Health in a Rickshaw Pullers household in Chittagong, Bangladesh". WHO Macroeconomics, Health, and Development Series Technical Paper (30). Geneva.

Cherniack, M., Chobra, T., McNabb, S., University of Connecticut Health Center and CDC, USA. 1996. "Demographic Features of Premature Mortality in the Countries of Central and Eastern Europe and the New Independent States". Current Issues in Public Health (2):78-89.

Croft, R.A., Croft, R.P. 1998. "Expenditure and Loss of Income Incurred by Tuberculosis Patients before Reaching Effective Treatment in Bangladesh". International Journal of Tuberculosis and Lung Disease (2): 252-254.

Dehne, K., Grund, J., Khodakevich, L., Kobyshcha, Y. 1999. "The HIV/AIDS Epidemic among Drug Injectors in Eastern Europe; Patterns, Trends and Determinants". Journal of Drug Users 29 (4): 729-776. 
Dye, C., Garnett, G.P., Sleeman, K., Williams, B.G. 1998. "Prospects for Worldwide Tuberculosis Control under the WHO DOTS Strategy". Lancet (352): 1886-189.

Dye, C., Williams, B.G. 2000. Strategies for the Control of Drug-Resistant Tuberculosis.

Dye, C., Williams, B.G. 2000 in press. "Population Dynamics and Control of MultidrugResistant Tuberculosis". In Portaels, F. \& Bastien, I., eds., MDR Mycobacterium Tuberculosis. Kluwer Academic Publishers. Dordrecht.

Eberstadt, N. 1999. "Russia - Too Sick to Matter?" Policy Review 9.

The Economist. 1998. Selling pharmaceuticals in Russia, December $12^{\text {th }}$.

The Economist. 1999. Health Care in Europe, Profile - the prospects for Russia's pharmaceutical industry. The Economist Intelligence Unit.

KNCV. 1999. "Surveillance of Tuberculosis in Europe (Euro TB) - Report on Tuberculosis Cases Notified in 1998". European Center for the Epidemiological Monitoring of TB (CESES), WHO Collaborating Center for the Surveillance of Tuberculosis in Europe, Royal Netherlands Tuberculosis Association.

Farmer, P.E., Becerra, M.C., Kim, J.Y. 1999. "The Global Impact of Drug Resistant Tuberculosis". Program in Infectious Disease and Social Change. Department of Social Medicine, Harvard University Medical School. Boston.

Feshbach, M. 1999. "A Sick and Shrinking Nation". The Washington Post. Sunday, October 24, 1p. B7.

Floyd, K. et. al 1997. Community-Based, Directly Observed Therapy for Tuberculosis: An Economic Analysis. Western Cape. South Africa.

Gleissberg, V,G., Maximova, Z.D., Golubchikova, V.T., Wares, D.F., and Banatvala, N. 1999. "Developing Nursing Practice as Part of the Collaborative TB Control Program, Tomsk, Siberia". International Journal of Tuberculosis and Lung Disease (3):878-885.

Goldfarb, A., Kimerling, M.E. 1999. "PHRI/Soros Russian TB Program: An Initiative of the International Center for Public Health". Submitted to the Gore-Primakov Commission Edition. Public Health Research Institute. New York.

Gordis, L. 1996. “Epidemiology”. W.B. Saunders Company.

Goskomstat, 1999. "Russian Statistical Year Book 1998". Russian State Statistical Agency, Moscow. 
Goskomstat, 2000. "Russian Statistical Year Book 1999". Russian State Statistical Agency, Moscow.

Grigorieva, N., Tchoubarova, T. 1996. "Health Status in Russia: The Need for a New Approach". Statistical Year book. Goskomstat of Russia. Moscow.

Gulick, R.M., Mellows, J.W., Havir, D. et al. 1999. "Treatment with indinavir (IDV), zidevudine (ZDV), and lamivudine (3TC); Three year follow up." Presented at the $6^{\text {th }}$ Conferrence on Retroviruses and Opportunistic Infections, Chicago.

Gulick, R.M., Mellows, J.W., Havir, D. et al. 1998. JAMA 280 (1):35-41.

Helvie, C. 1998. Homelessness in Different Countries. Sage, USA.

Illarionov, A,.L. 2000. "Myths and lessons of the August crisis". Voprosy ekonomiki/ Economic issues 3. Moscow

International Monetary Fund. 2000. International Financial Statistics, LII(6). Washington DC.

Joint IMPACT/FHI.UNAIDS. 1998. "Meeting the Behavioral Data Collection Needs of National HIV/AIDS and STD Programmes". Workshop: Report and Conclusions.

Kalfin, R., Nozhkina, N. 2000. "Prevention of HIV/AIDS amongst IDUs in Russia". The Ural State Medical Academy. Russia.

Karnolratanakul, P., Sawert, H., Kongsin, S., Lertmaharit, S., Sriwonga, J., Na-Songkhla, S., Wangmanee, S., Jittimanee, S., and Payanandana, V. 1999. "Economic Impact of Tuberculosis at the Household Level". International Journal of Tuberculosis and Lung Disease (3):1-7.

Kitsenko, N. 1998. "Harm reduction among injecting drug users in Odessa". HIV/AIDS $i$ rodstvennye problemy. 2(3): 41

Klugman, J. 1997. Poverty in Russia: Public Policy and Private Response. Washington DC: The World Bank.

Klugman, J., Braithwaite, J. February 1998. "Poverty in Russia during the Transition: An Overview". World Bank Research Observer 13(1):37-58.

Knight, L. 2000. "Tuberculosis and Sustainable Development". Report of the Stop TB Initiative 2000 (March). WHO/CDS/STB/2000.4. Amsterdam, the Netherlands.

Kononets, A. 2000. "Russian Ministry of Justice Report to the World Bank Mission". Russian Ministry of Justice. Moscow. 
Laporte, A. and Aggleton, P. 1999. "HIV/AIDS prevention in the context of new therapies. UNAIDS Best Practice Collection". UNAIDS/99.11E. UNAIDS, Geneva.

Leon, D.A., Shkolnikov, V.M. 1998. "Social Stress and the Russian Mortality Crisis". JAMA 279(10):790-791.

Litvintsev, S.V. 1998. "Drug Use in Russia and its Armed Forces". Voyenno-Meditisnsky Zhurnal. (9):21-24.

Lutsdenko, D. 1998. "Outreach work in drug user communities". HIV/AIDS i rodstvennye problemy 2(3):91-92.

Maher, D., Grzemska, M., Coninx, R., Reyes, H. 1998. "Guidelines for the control of tuberculosis in prisons". WHO/TB/98.250. WHO/International Committee of the Red Cross. Geneva.

MAP Network (Monitoring the AIDS Pandemic). 1998. "The Determinants of the HIV/AIDS Epidemics in Eastern Europe". Geneva.

MAP Network (Monitoring the AIDS Pandemic). 1998. "The Status and Trends of the HIV/AIDS Epidemics in the World". Geneva.

McNabb, S., Chobra, T., Cherniack, M., CDC and Yale University Medical School, USA. 1995. "Public Health Concerns in the Countries of Central and Eastern Europe and the New Independent States". Current Issues in Public Health 1:136-145.

Mikulenkak, M. et al. 1998. "TB at Crossroads". World Health Organization Report on the Global Tuberculosis Epidemic. WHO/TB/1998.247. Geneva.

Milanovic, B. 1998. Income, Inequality and Poverty during the Transition from Planned to Market Economy. World Bank Regional and Sectoral Studies. Washington DC.

Murray, C.J.L. 1996. "Epidemiology and Demography of Tuberculosis". In Timaeus, I.M., Chackiel, J., and Ruzieka, L. eds., Adult Mortality in Latin America, pp.199216. Clarendon Press. Oxford.

Murray, C.J.L., and Lopez. A.D. 1998. Global Burden of Disease: A Comprehensive Assessment of Mortality and Disability from Diseases, Injuries and Risk Factors in 1990 and Projected to 2020. Harvard University Press. Boston.

Murray, C.J.L., and Lopez, A.D. 1998. Global Health Statistics: A Compendium of Incidence, Prevalence and Mortality Estimates for Over 200 Conditions. Harvard University Press. Boston. 
Notzon, F.C., Komarov, Y.M., Ermakov, S.P., Sempos, C.T., Marks, J.S., Sempos, E.V. 1998. "Letter from Russia: Causes of Declining Life Expectancy in Russia". JAMA 279(10):793-800.

Oxford Analytica. 2000. "Russia: Population Plummet".

Pokrovsky, V., Ladnaya, N., Buravtsova, E. 2000. "HIV-Infection" Russia Bulletin. Russian Methodological Federal HIV/AIDS Center. Moscow.

Poloubinskaya, S. 1999. "Russian Legislation and the Prevention of HIV among IDUs". Public Health Program of the OSI (Open Society Institute). Institute of State and Law of the Russian Academy of Sciences.

PSI (Population Services International) for UNAIDS. 1998. "Social Marketing: An Effective Tool in the Global Response to HIV/AIDS". UNAIDS Best Practice Collection. UNAIDS/98.26. Geneva.

Rakhmanova, A., Chaika, N. 1999. "HIV/AIDS and other sexually transmitted Infections in St. Petersburg". St. Petersburg.

Pharmaceutical Reforms. 1999. WHO News for Newly Independent States no.5 ( September).

Rakhmanova, A., Yakovlev, A., Taitz, B., Vladimirova, B., Volkova, G., Sizova, N., Voronin, E., Chaika, N. 1999. "Some New Data on HIV/AIDS and other STD in St. Petersburg and Russia". St. Petersburg.

RECEP (Russian - European Center for Economic Policy). 2000. "The current economic situation". Obzor Rossiiskoi Ekonomiki (Russian economic review) 7.

Rutkowski, M. 1999. "Russia's Social Protection Malaise: Key Reform Priorities as a Response to the Present Crisis". World Bank Social Protection Discussion Paper. Washington DC.

Sawert, H. 1997. "The Economic Cost of Tuberculosis in Indonesia: With an Assessment of Costs and Benefits of an Improved Control Strategy". WHO. Geneva.

Sawert, H., Kongsin, S., Payanandana, V., Akarasewi, P., Nunn, P.P., and Raviglione, M.C. 1997. "Costs and Benefits of Improving Tuberculosis Control: The Case of Thailand". Social Science and Medicine (44):1805-1816.

Sheiman, I., ABT Associates. 1995. "New Methods of Financing and Managing Health Care in the Russian Federation". Health Policy (32):167-180. 
Shilova M, Perelman M, Russian Institute of Phthisiopulmonology (2000). Tuberculosis in Russia Report 1999. Moscow.

Stone, R. 2000. "Stress: The Invisible Hand in Eastern Europe's Death Rates". Science (288).

Stop TB Initiative. 2000. Amsterdam Declaration to Stop TB Workshop March 22-24. Amsterdam. The Netherlands.

Styblo, K. 1991. "Epidemiology of Tuberculosis:. Selected Papers (24). KNCV, The Hague.

TvT Associates. 1999. “The Russian Federation and HIV/AIDS". TvT Associates under the Synergy project. Washington DC.

UNAIDS. 1998. "Expanding the Global Response to HIV/AIDS through Focused Action: Reducing Risk and Vulnerability: Definitions, Rationale and Pathways". Geneva.

UNAIDS. 1998. "Pathways to Collaboration: Informal Consultation Between UNAIDS and Development Agencies". Geneva.

UNAIDS. 1998. "HIV/AIDS and the workplace: forging innovative business responses". UNAIDS Technical Update. Geneva.

UNAIDS. 1998. "Putting HIV/AIDS on the Business Agenda": UNAIDS Point of View. Geneva.

UNAIDS. 1998. "HIV-related Opportunistic Diseases". UNAIDS Technical Update. Geneva.

UNAIDS. 1999. "Gender and HIV/AIDS: Taking Stock of Research and Programmes". Geneva.

UNAIDS. 1999. "Guide to the Strategic Planning Process for a National Response to HIV/AIDS". UNAIDS Best Practice Collection. UNAIDS/98.21. Geneva.

UNAIDS. 1999. "Relationships of HIV and STD Declines in Thailand to Behavioral Change: A Synthesis of Existing Studies". UNAIDS 98.2. Geneva.

UNAIDS, and Harward University School of Public Health. 1999. "Level and Flow of National and International Resources for the Response to HIV/AIDS". UNAIDS/99.25E. Geneva.

UNAIDS. 1999. "The Response to HIV/AIDS in the Russian Federation, 1996-1998". Moscow. 
UNAIDS. 2000. "Report on the global HIV/AIDS epidemic". UNAIDS Report 2000. UNAIDS/00.13E. Geneva.

UNAIDS. 1998. "Access to Drugs". UNAIDS Best Practice Collection. WC 503.2. Technical update (October). Geneva.

UNAIDS/WHO. 1998. "Epidemiological Fact Sheet on HIV/AIDS and Sexually Transmitted Diseases: Russian Federation". Geneva.

UNAIDS/WHO. 1999. “AIDS Epidemic”. UNAIDS/99.53E/WHO/CDS/CSR/EDC/99.9. Update (December). Geneva.

UNDP. (United Nations Development Program) 1999a. "Human Development Report 1999 for the Russian Federation". Moscow.

UNDP. 1999b. "Human Development Report 1999 for Europe and the CIS". New York: Regional Bureau for Europe and CIS of the UNDP.

UNDP. 2000. Human Development Report. 2000. New York: Oxford University Press.

UNICEF (United Nations Children's Fund). 1999. “Supply Division Report” (May).

US National Research Council. 1997. "Premature Death in the New Independent States (EU, Lithuania, Latvia, Russian Federation)".

U.S. Department of Health and Human Services. 2000. "Health in the United States, 2000, with Socioeconomic Status and Health Chartbook (Statistics, Trends, Data)". (PHS) 2000-1232. Hyattsville, Maryland.

WHO. (world Health Organization). 1998. "A New Outlook for HIV/AIDS”. World Health, The Magazine of the World Health Organization(November - December). Geneva.

WHO. 1998. “Tuberculosis”. WHO Fact Sheet No.104. Geneva.

WHO. 1998. "Task Force for the Urgent Response to the Epidemics of Sexually Transmitted Diseases in Eastern Europe and Central Asia". Report on the Second Meeting of the Task Force. EUR/98/5015853. Regional Office for Europe. Copenhagen.

WHO. (2000). "Health for All Database 2000". WHO Regional Office for Europe. Copenhagen.

WHO. 2000. "Task Force for the Urgent Response to the Epidemics of Sexually Transmitted Diseases in Eastern Europe and Central Asia". Report on the Forth 
Meeting of the Task Force. EUR/00/5015853. WHO Regional Office for Europe. Copenhagen.

WHO. 2000. "Global Tuberculosis Control". Global Tuberculosis Programme. WHO Report 2000. WHO/CDS/TB/2000.275. Geneva.

World AIDS Campaign. 1999. "Listen, Learn, Live: World AIDS Campaign with Children and Young People: Facts and Figures".

World Bank. 1993. World Development Report 1993: Investing in Health. Oxford University Press. New York.

World Bank. 1993. TRANSITION (The News Letter about Reforming Economies), February, 1998. Washington DC.

WHO/UNAIDS. 1998. "Policy Statement on Preventive Therapy against Tuberculosis in People Living with HIV": Report of a Meeting held in Geneva 18 - 20 February 1998. WHO/TB/98.255 UNAIDS/98.34. Geneva.

Yesudikan, O.A.K.1994. "Behavior of the Private Sector in the Health Market of Bombay". Health Policy and Planning (9): 72-80. 


\section{Recent World Bank Technical Papers (continued)}

No. 449 Keith Oblitas and J. Raymond Peter in association with Gautam Pingle, Halla M. Qaddumi, and Jayantha Perera, Transferring Irrigation Management to Farmers in Andhra Pradesh, India

No. 450 Andrés Rigo Sureda and Waleed Haider Malik, eds., Judicial Challenges in the New Millennium: Proceedings of the Second Summit of the Ibero-American Supreme Courts

No. 451 World Bank, Privatization of the Power and Natural Gas Industries in Hungary and Kazakhstan

No. 452 Lev Freinkman, Daniel Treisman, and Stephen Titov, Subnational Budgeting in Russia: Preempting a Potential Crisis

No. 453 Bartlomiej Kaminski and Michelle Riboud, Foreign Investment and Restructuring: The Evidence from Hungary

No. 454 Gordon Hughes and Julia Bucknall, Poland: Complying with EU Environmental Legislature

No. 455 Dale F. Gray, Assessment of Corporate Sector Value and Vulnerability: Links to Exchange Rate and Financial Crises

No. 456 Salman M.A. Salman, ed., Groundwater: Legal and Policy Perspectives: Proceedings of a World Bank Seminar

No. 457 Mary Canning, Peter Moock, and Timothy Heleniak, Reforming Education in the Regions of Russia

No. 458 John Gray, Kazakhstan: A Review of Farm Restructuring

No. 459 Zvi Lerman and Csaba Csaki, Ukraine: Review of Farm Restructuring Experiences

No. 460 Gloria La Cava and Rafaella Y. Nanetti, Albania: Filling the Vulnerability Gap

No. 461 Ayse Kudat, Stan Peabody, and Caglar Keyder, eds., Social Assessment and Agricultural Reform in Central Asia and Turkey

No. 462 T. Rand, J. Haukohl, and U. Marxen, Municipal Solid Waste Incineration: Requirements for a Successful Project

No. 463 Stephen Foster, John Chilton, Marcus Moench, Franklin Cardy, and Manuel Schiffler, Groundwater in Rural Development: Facing the Challenges of Supply and Resource Sustainability

No. 465 Csaba Csaki and Zvi Lerman, eds., Structural Change in the Farming Sectors in Central and Eastern Europe: Lessons for EU Accession-Second World Bank/FAO Workshop, June 27-29, 1999

No. 466 Barbara Numberg, Ready for Europe: Public Administration Reform and European Union Accession in Central and Eastern Europe

No. 467 Quentin T. Wodon with contributions from Robert Ayres, Matias Barenstein, Norman Hicks, Kihoon Lee, William Maloney, Pia Peeters, Corinne Siaens, and Shlomo Yitzhaki, Pozerty and Policy in Latin America and the Caribbean

No. 469 Laurian Unnevehr and Nancy Hirschhorn, Food Safety Issues in the Developing World

No. 470 Alberto Valdés, ed., Agricultural Support Policies in Transition Economies

No. 471 Brian Pinto, Vladimir Drebentsov, and Alexander Morozov, Dismantling Russia's Nonpayments System: Creating Conditions for Growth

No. 472 Jit B. S. Gill, A Diagnostic Framework for Revenue Administration

No. 473 Esen Ulgenerk and Leila Zlaoui, From Transition to Accession: Developing Stable and Competitive Financial Markets in Bulgaria

No. 474 Ioannis N. Kessides, ed., Hungary: A Regulatory and Structural Review of Selected Infrastructure Sectors

No. 475 Csaba Csaki, Zvi Lerman, and Sergey Sotnikov, Farm Sector Restructuring in Belarus: Progress and Constraints

No. 476 Katherine Terrell, Czech Republic: Labor Market Report

No. 481 Csaba Csaki, John Nash, Achim Fock, and Holger Kray, Food and Agriculture in Bulgaria: The Challenge of Preparing for EU Accession

No. 482 Peter Havlik, Trade and Cost Competitiveness in the Czech Republic, Hungary, Poland, and Slovenia

No. 483 Mojmir Mrak, Communal Infrastructure in Slovenia: Survey of Investment Needs and Policies Aimed at Encouraging Private Sector Participation

No. 484 Csaba Csaki and Laura Tuck, Rural Development Strategy: Eastern Europe and Central Asia

No. 488 Nina Bubnova, Governance Impact on Private Investment

No. 489 Tim Schwarz and David Satola, Telecommunications Legislation in Transitional and Developing Economies

No. 490 Jesko Hentschel and Radha Seshagiri, The City Poverty Assessment: A Primer

No. 492 Tuntivate Voravate, Douglas F. Barnes, and V. Susan Bogach, Assessing Markets for Renewable Energy in Rural Areas of Northwestern China 
(4)

THE WORLD BAN

$1818 \mathrm{H}$ Street. V.W.

IIashington. 1).(.2.204.3 \& s.1

Telephone: 202-t7i-12it

Pacsimile: 2(12-47-6.34)

Internet: "ww.muridbank.ory

F-mail: feedhacken morddbank.org

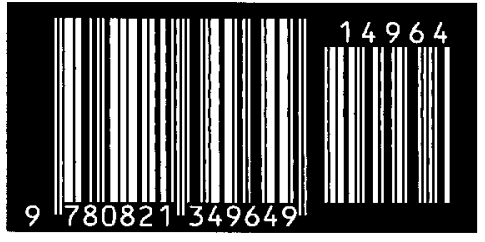

ISBN 0-8213-4964-3 